NBER WORKING PAPER SERIES

\title{
SEC REGULATION FAIR DISCLOSURE, INFORMATION, AND THE COST OF CAPITAL
}

\author{
Armando Gomes \\ Gary Gorton \\ Leonardo Madureira \\ Working Paper 10567 \\ http://www.nber.org/papers/w10567 \\ NATIONAL BUREAU OF ECONOMIC RESEARCH \\ 1050 Massachusetts Avenue \\ Cambridge, MA 02138 \\ June 2004
}

We thank Thompson Financial for providing access to the First Call database, the Rodney White Center for Financial Research for financial assistance, and Andrew Metrick for providing the Investor Responsibility Research Center governance index data. We also thank Marshall Blume, Brian Bushee, John Core, Wayne Guay, David Musto, Mitch Petersen, Michael Roberts, Catherine Schrand, Nick Souleles, Ayako Yasuda, and seminar participants at Wharton Finance, Wharton Accounting, and Moody's Investors Services for their helpful comments.The views expressed herein are those of the author(s) and not necessarily those of the National Bureau of Economic Research.

(C2004 by Armando Gomes, Gary Gorton, and Leonardo Madureira. All rights reserved. Short sections of text, not to exceed two paragraphs, may be quoted without explicit permission provided that full credit, including $(\mathrm{C}$ notice, is given to the source. 
SEC Regulation Fair Disclosure, Information, and the Cost of Capital Armando Gomes, Gary Gorton, and Leonardo Madureira

NBER Working Paper No. 10567

June 2004

JEL No. G10, G12, G14

\section{$\underline{\text { ABSTRACT }}$}

We empirically investigate the effects of the adoption of Regulation Fair Disclosure ("Reg FD") by the U.S. Securities and Exchange Commission in October 2000. This rule was intended to stop the practice of "selective disclosure," in which companies give material information only to a few analysts and institutional investors prior to disclosing it publicly. We find that the adoption of Reg FD caused a significant reallocation of information-producing resources, resulting in a welfare loss for small firms, which now face a higher cost of capital. The loss of the "selective disclosure" channel for information flows could not be compensated for via other information transmission channels. This effect was more pronounced for firms communicating complex information and, consistent with the investor recognition hypothesis, for those losing analyst coverage. Moreover, we find no significant relationship of the different responses with litigation risks and agency costs. Our results suggest that Reg FD had unintended consequences and that "information" in financial markets may be more complicated than current finance theory admits.
Armando Gomes
Gary Gorton
Leonardo Madureira
Department of Finance
Department of Finance
The Wharton School
Department of Finance
The Wharton School
University of Pennsylvania
The Wharton School
University of Pennsylvania
Philadelphia, PA 19104-6367
University of Pennsylvania
Philadelphia, PA 19104-6367
and NBER
Philadelphia, PA 19104-6367
gomes@wharton.upenn.edu
gorton@wharton.upenn.edu
madureil@wharton.upenn.edu 


\section{Introduction}

In this paper we empirically investigate the effects of the adoption of Regulation Fair Disclosure ("Reg FD") by the U.S. Securities and Exchange Commission ("SEC"). Reg FD, which took effect on October 23, 2000, was intended to stop the practice of "selective disclosure," in which companies give material information only to certain selected analysts and institutional investors prior to disclosing it publicly. ${ }^{1}$ The adoption of the rule was extremely controversial. $^{2}$ Proponents argued that selective disclosure was unfair, that it undermined the integrity of capital markets. Opponents asserted that information transfer between companies and investors would deteriorate, that there would be a "chilling effect" on communication between firms and investors. ${ }^{3}$ To provide an evaluation of Reg FD it is important to understand both how information is transmitted from firms to capital markets and how the allocation of informationproducing resources affects securities prices. We find that the adoption of Reg FD caused a significant reallocation of information-producing resources, resulting in a welfare loss for small firms, which now face a higher cost of capital. The loss of the "selective disclosure" channel for information flows could not be compensated for via other information transmission channels. This unintended consequence of Reg FD shows that "information" in financial markets is more complicated than current theory admits and has some public policy implications.

There were three reasons given by the SEC for the adoption of Reg FD. First, it was argued that selective disclosure leads to a loss of investor confidence. If small investors fear that insiders will regularly profit at their expense, they will not be nearly as willing to invest. For example, Arthur Levitt (1999) (then SEC chairman) argued that: “...the behind-the-scenes feeding of material non-public information from companies to analysts is a stain on our markets. This selectiveness is a disservice to investors and it undermines the fundamental principle of

\footnotetext{
1 "Selective disclosure" is not the same as insider trading. "Selective disclosure" means revealing material nonpublic information by a corporate insider to an analyst, information which could be used profitably. "Insider trading" refers to trading on the basis of material nonpublic information by a company's own officers and directors in the absence of disclosure to the SEC. Other investors could engage in illegal insider trading by trading based on nonpublic information received from a corporate insider. Rule 10b-5 of the Securities Exchange Act of 1934 sets out that trading on the basis of material nonpublic information is prohibited.

${ }^{2}$ The SEC received nearly 6,000 comment letters. See SEC Final Rule: Selective Disclosure and Insider Trading (2000). Arthur Levitt, the then SEC chairman, describes the intense political environment in which Reg FD was finally adopted. See Levitt (2002).

${ }^{3}$ Laura Unger, the only commissioner to vote against FD, was at least partially sympathetic to the arguments of both Wall Street and public companies. She previously voiced concern that FD would compromise the integrity of American public markets by decreasing the level and quality of communication between companies and investors, a point Wall Street has pressed since even before its enactment. A survey of analysts administered by the Association of Investment Management and Research
} 
fairness." The reason, according to the SEC, is that "...those who were privy to the information beforehand were able to make a profit or avoid a loss at the expense of those kept in the dark" (SEC (2000, p.2)). This has been a long-standing concern, at the root of mandatory disclosure in general. $^{4}$

A second rationale concerned the link between corporate governance and the incentives to engage in selective disclosure. This problem was the use of information by management to essentially bribe analysts, perhaps in exchange for a quid pro quo, i.e., “...the potential for corporate management to treat material information as a commodity to be used to gain or maintain favor with particular analysts or investors" (SEC (2000, p. 3)). In other words, a CEO could essentially "spin" or "frame" information about his company by trading it in exchange for favorable analyst reports or kickbacks, e.g., allocations in initial public offerings. In fact, the SEC also noted the problem that (prior to Reg FD) "analysts may feel pressured to report favorably about a company or otherwise slant their analysis in order to have continued access to selectively disclosed information" (see SEC (2000)). ${ }^{5}$

Finally, the SEC stated the view that selective disclosure is not required for market efficiency because of technological change: “...technological limitations no longer provide an excuse for abiding the threats to market integrity that selective disclosure represents" (Release, 65 Fed. Reg. at 51716). As one SEC commissioner put it: "The mechanisms by which our markets become efficient are changing...Institutions and analysts' brokerage firms are no longer the primary means by which our markets achieve efficiency" (Hunt (2000)). The basic idea seems to be that companies can now use websites and/or "webcast" conference calls via the internet, making the channel of information flow from firm managements to analysts less important.

The intention of Reg FD was not to change the informativeness of prices, that is, market efficiency. According to Laura Unger, the acting SEC Chairman after Arthur Levitt's term ended, "the impetus for Regulation FD was to prevent analysts from passing material nonpublic information on to others so that those individuals could trade" (SEC (2000)). The way in which communication occurred was to change, but not the information content of what is transmitted from firms to markets. Under the Reg FD regime instead of a firm's management selectively

(AIMR) found that 57 percent believe the volume of substantive information decreased in the six months after FD was enacted.

${ }^{4}$ Government-mandated disclosure of information by corporations dates from the New Deal era and has always been controversial. See Loss (1983).

${ }^{5}$ The canonical example of this quid pro quo is the twenty-one of the hottest IPOs that were allocated in part to Bernie Ebbers of Worldcom by Jack Grubman and Salomon Smith Barney apparently in exchange for the selective disclosure of information by Ebbers to Grubman. See Lowenstein (2004). 
communicating with one or a few analysts, firm management would say the same thing publicly. The same information would be released, but without privately benefiting particular analysts and managers.

Is Reg FD a desirable public policy? Clearly, it is difficult to assess notions of "fairness," even if that is interpreted to mean social welfare. Our view is that some assessment is warranted in order to understand public policies with regard to disclosure in securities markets, in particular, Reg FD. ${ }^{6}$ We focus on assessing the effects of Reg FD on information production and transmission in capital markets; we ask whether the same information is transmitted to capital markets since the passage of Reg FD, just via a different channel now (albeit in a possibly "fairer" way), or whether, for some reason, there is less information transmitted to capital markets. We view this issue as of independent interest. Little is known about whether the sources of information or the costs of producing the information have any impact on firm values and security prices. Ultimately, we care about the effects on security prices and the resulting allocation of resources. We use the natural experiment of the adoption of Reg FD to investigate these issues.

Information can be transmitted from firms to markets via four channels: (1) firms, in addition to mandatory disclosures, can disclose information to the public voluntarily (e.g., earnings pre-announcements); (2) firms can selectively disclose information, e.g., phone calls, or one-on-one meetings; (3) "sell side" analysts can produce research which is released to the public, e.g., analysts reports; (4) private information can be produced by outsiders, "informed traders," who then trade on the basis of their information. ${ }^{7}$ Reg FD sought to eliminate the second channel of information flow, under the implicit assumption that the same information would still flow into markets but by the other channels, particularly channel (1). But, Reg FD also affects channel (3) because the biggest impact of Reg FD is on analysts. Reg FD "has made most analysts stock-guessers rather than [stock-] pickers because they do not receive that wink and nod from company management" (Syre and Stein (2001, p. F1)). Consequently, some have predicted that Reg FD will either lead to a diminished role for analysts since the information will now be available for everyone or a large-scale reduction in analysts' jobs since many simply cannot perform an adequate analysis without the aid of selective disclosure (Coffee (2000)). If analysts' previous role is subsumed by the other channels of information flow, then market efficiency is not changed. This is the logic of Reg FD that is our focus.

\footnotetext{
${ }^{6}$ It is not, however, our intention to assess the idea of mandatory disclosure generally. There is a large literature on that topic. Recent examples include Glaeser, Johnson, and Shleifer (2001) and Greenstone, Oyer, and Vissing-Jorgensen (2003).
} 
Our main empirical strategy is to explore various cross-sectional differences among firms pre- and post-Reg FD. In this regard, our prior belief is that there are important cross sectional differences with regard to firm size. There are two reasons to believe that Reg FD had different impacts on firms of different size. First, there is survey evidence. A survey of members of the securities bar by the American Bar Association (2001) found that 67 percent of respondents believed that Reg FD had a greater impact on small and mid-cap companies than on large-cap companies. A survey by the National Investor Relations Institute (2001) found that the fraction of firms that responded that less information was being provided post-FD was higher for low-cap firms when compared to the group of mid- and high-cap firms. The same survey found that the fraction of firms that perceived a decrease in analyst following post-FD was higher for the group of low-cap firms, while the fraction of firms that perceived an increase in analyst following was higher for the group of big firms

Secondly, there are theoretical reasons to believe that there is a link between firm size and the amount of information produced. King, Pownall and Waymire (1990) argue that large firms have better disclosure policies because the incentives for private information acquisition are greater in their case. Lang and Lundholm (1993) argue that production of information entails fixed costs and thus disclosure costs per unit of size are more likely to decrease with size. Moreover, Goshen and Parshomovsky (2001) argue that small firms may need selective disclosure of information to maintain and/or attract analyst following, because for small firm liquidity may be so low that the costs of obtaining private information may be higher than the gains from selling or trading on private information.

Our main finding is that there was a reallocation of information-producing resources and that this reallocation had asset pricing effects. We document that small firms on average lost 17 percent of their analyst following, and big firms increased theirs by seven percent, on average. Moreover, while big firms are almost twice as likely to make voluntary earnings announcements (pre-announcements), small firms did not increase their pre-announcements significantly. We find consistent effects of this reallocation on earnings forecast errors and market responses to earnings announcements: small firms experience higher forecast errors (Agrawal and Chadha (2002) find similar results) and volatility, consistent with a higher information gap; no significant increases occur for big firms. These results suggest that big firms were able to replace the loss of channel (2) with channels (1) and (3), but that small firms were not able to do so.

\footnotetext{
${ }^{7}$ This could include illegal trading based on inside information (by the legal definition); see Loss (1983).
} 
We demonstrate that this reallocation resulted in a higher cost of capital for small firms (and no significant change for big firms). Grossman and Stiglitz (1987) were the first to recognize that the costs of producing information have asset pricing effects; several other papers that followed focused on the link between disclosure of information and the cost of capital (recently Easley and O'Hara (2003); see also the survey by Verrecchia (2001)). Our empirical results suggest that increases in the costs of producing information had a measurable impact on the asset prices of small firms. We also find evidence in support of the investor recognition hypothesis of Merton (1987). The stocks of small firms that completely lost analyst coverage after Reg FD experienced significant increases in the cost of capital, while small stocks with no previous analyst coverage-which presumably did not have any analysts benefiting from selective disclosure pre-FD — experienced no significant change in the cost of capital.

Information disclosed by firms differs in its complexity and in its litigation risk (risk of shareholder lawsuits), and these factors could explain why different firms responded to the regulation differently. We find that more complex firms (using intangible assets as a proxy for complexity) overall are being more adversely affected by the policy change than less complex firms. After controlling for size, we find that the subgroups of firms with high intangibles tend to suffer a significantly bigger loss of analyst following than the subgroup of firm with low intangibles, and larger increases in the cost of capital. The changes in public voluntary disclosure are consistent with the view that the public channel is an imperfect substitute for private communications, especially with respect to complex information, and this effect is reflected in variables such as the cost of capital. Aumann and Hart (2003) provide a theoretical demonstration that more is "achieved by a long conversation than by a single message - even when one side is strictly better informed than the other" (p. 1619). ${ }^{8}$ Also, we find no evidence of a chilling effect of Reg FD on high litigation risk firms, a concern expressed by some critics in their comments on initial drafts of the regulation. This finding is consistent with high litigation risk firms making less use of selective disclosure pre-FD or with the final draft of the regulation properly mitigating criticism regarding legal liability concerns (SEC (2000)).

\footnotetext{
${ }^{8}$ The idea that one-on-one communication, where there are long conversations, might be valuable is one of the reasons that courts did not interpret the existing laws to prohibit selective disclosure. In general, courts have been sympathetic to the difficulties of legally overseeing communication between managers and analysts, describing such discussions as "a fencing match conducted on a tightrope," in which the managers are "compelled to parry often incisive questioning while teetering on the fine line between data properly conveyed and material inside information that may not be publicly revealed" (SEC v. Bausch \& Lomb, Inc. F. 2d 8, p.9 (2d Cir. 1977' quoted in Tishbi (2002)). To protect such communication the U.S. Supreme Court decided a series of cases, most notably Dirks v. SEC (463 U.S. 646 (1983)), in which managers and analysts were shielded from liability (see Tishbi (2002)).
} 
We test for a link between agency problems and incentives to make selective disclosures. To proxy for the degree of agency costs we use the corporate governance provisions in firms' charters and by-laws and state takeover laws (see Gompers et al. (2003)) to break-up the sample into groups of firms with "good" and "bad" governance. We show that analyst following exhibits a significantly higher increase in the good governance sample, but there is no significant difference between the two groups based on all other measures that we follow, such as preannouncements, forecast errors, volatility, and the cost of capital. This result is consistent with the view that bad governance firms became less attractive to analysts relative to the good governance firms, because perhaps now they cannot be "spoon fed" information anymore, but this reallocation has had no significant asset pricing effects.

Several papers examine the impact of Reg FD in the information environment. There is a consensus in the literature that the quantity of voluntary public disclosures increased as reported in, for example, Heflin et al. (2003), Bailey et al. (2003), and Straser (2002). However, the evidence is mixed on other relevant aspects such as the dispersion and accuracy of analyst forecasts, volatility around earnings announcement, and the degree of information asymmetry and informed trading. For example, with respect to the accuracy or dispersion of analyst forecasts, Shane, et al. (2001) and Heflin, et al. (2003) find no significant change in either, and Bailey et al. (2003) find no increase in the accuracy but significant increases in dispersion. However, Agrawal and Chadha (2002) and Mohanram and Sunder (2001) find increases in both, and Irani and Karamanou (2002) find increases in dispersion. On measures of the information gap, like return volatility around earnings announcement, Heflin, et al. (2003), Shane, et al. (2001), and Eleswarapu, et al. (2002) find decreases, but Bailey et al. (2003) find no increase after controlling for important factors. Similarly, with respect to the level of information asymmetry reflected in trading costs, Eleswarapu, et al. (2002) find that it decreases, consistent with SEC goals to level the playing field, but Straser (2002) finds opposite results. Other studies that explored interesting aspects of Reg FD include Bushee et al. (2003), who analyzed how firms previously using closed or open conference calls responded to the rule change, and Jorion et al. (2003), who investigated whether credit rating agencies -- exempted from the application of Reg FD -- gained an informational advantage.

The paper proceeds as follows. Section 2 contains a discussion of the data sets and broad methodology. In Section 3 we investigate the reallocation of information-producing resources following the enactment of Reg FD. In Section 4 we look at the effects of this reallocation, in terms of the effects on earnings forecast errors, market responses to earnings announcements, and the cost of capital. In Section 5 we investigate whether characteristics aside from size help 
explain the results. Some robustness results are discussed in Section 6. The implications for inferences about information and public policy are in the final section, Section 7.

\section{Data and Methodology}

We collect NYSE and NASDAQ firm-quarter observations from CSRP for the period 1997:2002 and merge them with information from First Call (actual earnings announcements, analysts forecasts and pre-announcements), COMPUSTAT (accounting data) and IRRC (corporate governance index). The Appendix describes details on the construction of our sample.

Motivated by the previous discussion, many tests are based on a break-up of the sample according to firm size. Each firm is allocated to one of three groups based on its average size during the entire sample period, 1997-2002. The group of small firms is formed by taking firms with average size below the $50^{\text {th }}$ percentile of the distribution; the group of mid-size firms is formed by firms with average size between the $50^{\text {th }}$ and the $80^{\text {th }}$ percentiles and the group of big firms is formed by firms in the upper quintile of the distribution (see Appendix for details).

We analyze the effects of Reg FD on market variables (analyst following, use of preannouncements, forecast error and volatility at earnings announcements) by running panel data (cross-sectional time series) fixed-effects regressions on the variables of interest. For each such variable, we run panel data regressions with the aggregated data from the pre-FD and post-FD subsamples, using as explanatory variables one or more variables related to the Reg FD period and other variables that control for factors other than Reg FD. Panel data regression is particularly interesting in that it allows for a better treatment of the omitted variables problem (in fact, in many setups, the primary motivation for using panel data is to solve this omitted variables problem). ${ }^{9}$ Using fixed effects panel data is equivalent to running a regression with a dummy for each firm in the sample. These dummies control for each firm's fixed effects, i.e. for crosssectional differences that are due to firms' fixed characteristics. Adding these firms' dummies also simplifies the data collection, since any control variable that can be deemed a firm characteristic (i.e., one that that does not change through time) does not need to be included in the

\footnotetext{
${ }^{9}$ In general, if in a regression specification the set of explanatory variables does not include a variable (the omitted one!) which itself is correlated with at least one of the explanatory variables, then typical -in this case, pooled - OLS results are biased and inconsistent. In a panel data setup, the inclusion of a $c_{i}$ intercept specific to each cross-sectional unit allows the regression to capture this omitted variable as long as it is (roughly) constant through time.
} 
regression, because its effects will be absorbed by the firm's dummy in the panel data specification. $^{10}$

Panel data allows us also to maximize the use of the data in the time series dimension. First, by including all available data in just one regression, we avoid the difficulties of identifying effects that occur gradually through time. If firms gradually adapt to the new regulation, using shorter periods (e.g., regressing data for one period post-FD and one corresponding period preFD) may fail to identify Reg FD effects even if they do happen. Moreover, by using longer period data we reduce the likelihood of spuriously interpreting circumstantial patterns over shorter periods as effects of the regulation. On the other hand, increasing the time span of our examination increases the risk that some market effects being examined here might be driven by some contemporaneous economic factors not related to Reg FD; ${ }^{11}$ this risk can be attenuated by using proper control variables in the multivariate regressions.

\section{The Post-Reg FD Reallocation of Information-Producing Resources}

In this section we first investigate whether there is a change in information production by analysts (channel (3)), and then we look at whether firms have changed the use of voluntary disclosures (pre-announcements) - channel (1).

\section{A. The Reallocation of Analysts}

Analyst following is an important part of a firm's information environment. ${ }^{12,13}$ In order to proxy for the activity of production of public information by market professionals, we track

\footnotetext{
${ }^{10}$ In a panel data setup, one always faces the issue of whether to adopt the fixed or random effects model. A basic requirement for using random effects is that the effect $c_{i}$ must be uncorrelated with the other explanatory variables. This requirement seems very stringent when referring to firm's characteristics. Fortunately, the requirement is dropped for the fixed effects model. The drawback of using fixed effects that there is no way to distinguish the effects of time-constant observable characteristics from the timeconstant fixed effects term $c_{i}$ - is not an issue here since we are mainly interested in the effect of Reg FD, which is not a time-constant characteristic. The other important requirement for the estimation of (both fixed and random effects) panel data is strict exogeneity, which implies that explanatory variables in each time period be uncorrelated with the idiosyncratic error in each time period; it does not seem to present a concern in our specification.

${ }^{11}$ In this regard, we decided to end the post-FD period in the $3^{\text {rd }}$ quarter of 2002 even though data beyond that quarter is already available. The increasing scrutiny of the analysts' industry by the media and regulators (e.g. the Global Settlement of May 2003) is an example of another exogenous shock that could affect the allocation of analysts; thus, it would be difficult to isolate effects from Reg FD from this shock if data from more recent periods were used.

${ }^{12}$ There is a long list of papers that examine the activity of security analysts as a component of the firm's information environment. Some examples are: Bhushan (1989a), Brennan and Hughes (1990), Shores (1990), Skinner (1990) and Brennan and Subrahmanyam (1995).

${ }^{13} \mathrm{We}$ are abstracting from what motivates the analysts to produce earnings forecasts for the firm. Brennan and Hughes (1991), for example, argue that the analysts are rewarded by brokerage commissions, in that
} 
analyst following of firms by sell-side financial analysts. ${ }^{14}$ Sell-side analysts release different kinds of information, from forecasts about upcoming financial releases to more complex text reports analyzing the firm's status, future prospects, state of the industry, etc. These text reports are subjective, qualitative in nature and not broadly tracked by financial databases, making it very difficult to statistically analyze them. None of these shortcomings are present for data on financial analysts' forecasts of upcoming earnings releases. Moreover, earnings forecasts are closely tracked, and they can be compared with the subsequent actual earnings releases, so we can extract a simple measure of the quality of the analyst's research. Thus, we adopt the release of sell-side earnings forecasts as our proxy for information production by market research professionals (hereafter referred to as "analyst following").

Our first measure of analyst following is $N_{O F O R}$ : the number of outstanding analyst forecasts for firm $i$ 's upcoming earnings release for quarter $q$, released up to 2 days before the quarter $q$ 's actual earnings release. However, since we are trying to examine the determinants of this variable along a time series dimension, we have to worry about possible time trends in the market for financial analysts. To tackle this issue, we define a measure of standardized analysts following, NOFOR_STD ${ }_{i, q}$, which is computed by dividing $N O F O R_{i, q}$ by the total amount of analyst forecasts available for all firms in quarter $q$. Roughly speaking, NOFOR_STD ${ }_{i, q}$ is firm $i$ 's share of the market for financial analysts in quarter $q$, measured in percentage terms. ${ }^{15}$

Table 1 presents univariate statistics on analyst following before and after Reg FD. Panel A reports results based on all the sample data. They indicate that, after Reg FD is adopted, there is a significant increase in the average number of forecasts accompanied by a decrease in the median number of forecasts, which might suggest a shift in the distribution of the number of forecasts, with the mass being more concentrated on the right side of the distribution. ${ }^{16}$ The results in Panel B, which repeat the univariate statistics for each group of firms based on size,

investors will trade only on stocks they "know about", that is, stocks for which earnings forecasts have been produced by analysts.

${ }^{14}$ Analyst following involves both buy-side and sell-side professionals. Buy-side analysts generally produce information to trade on. Their research output is generally not available to the public. Sell-side analysts produce information that is sold to a broader class of clients, so their research does become public. Data availability limits us to sell-side analysts but, more importantly, sell-side analysts provide information that is more publicly available than information produced by buy-side analysts, and thus is a better proxy for the production of public information by market professionals.

${ }^{15}$ Notice that our measures of a firm's analyst following are more informative than simply counting the analysts that are assigned to that firm. This is because being assigned to do research on a firm does not imply necessarily that any information will actually be produced; in other words, releasing a forecast is a signal that an analyst is actively tracking a firm.

${ }^{16}$ The difference in the mean standardized number of forecasts is driven by the fact that the two samples have different sizes. If the two samples had the same size then the mean values would be exactly the same. 
allow us to better assess the shift in the distribution of the number of forecasts. The average number of forecasts significantly increases for the big firms and decreases for small firms, and the results are robust to using the standardized measure of analyst following. For the portfolio of mid-size firms, the results are not clear cut: the average number of forecasts seems to increase, but one cannot reject the hypotheses that the median number of forecasts and the standardized measures of analyst following are the same for the periods pre- and post-FD.

Overall, the univariate show a reallocation of analyst coverage after Reg FD was adopted, with big firms enjoying an increase in analyst following at the expense of a decrease in analyst following of small firms. However, a multivariate analysis is necessary in order to control for other factors that might influence analyst following as well as to avoid biases from the portfolio formation procedure. In the multivariate setup, we estimate a panel data (cross-sectional time series) fixed effects regression of number of forecasts. Let the subscript $q$ indicate the quarter of the year, and $i$ indicate firm $i$. Then the basic regression model is:

$$
N_{i, q}=a_{0 i} \text { FIRM }_{i}+a_{1} \text { POSTFD }_{i, q}+a_{2} \operatorname{SIZE}_{i, q}+a_{3} \operatorname{LOSS}_{i, q}+a_{4} \text { ABSCAR }_{i, q}+a_{5} \operatorname{SIGNCAR}_{i, q}+\varepsilon_{i, q}
$$

where

$$
\begin{aligned}
& N_{i, q} \quad=\text { Dependent variable, either } N O F O R_{i, q} \text { or NOFOR_STD } D_{i, q} \\
& \text { FIRM }_{i}=\text { Dummy set to } 1 \text { for the } i^{\text {th }} \text { firm } \\
& \text { POSTFD }_{i, q}=\text { Dummy set to } 1 \text { when the data point is observed after Reg FD } \\
& \text { was adopted } \\
& S I Z E_{i, q} \quad=\quad \text { Log of market value of the firm } i \text { at the end of the quarter } q \\
& \text { divided by the market index } \\
& \operatorname{LOSS}_{i, q} \quad=\quad \text { Dummy set to } 1 \text { when the actual earnings for firm } i \text { in quarter } \\
& q \text { are negative } \\
& A B S C A R_{i, q}=\text { The absolute value of the cumulative abnormal return for firm } \\
& i \text { in quarter } q \\
& \operatorname{SIGNCAR}_{i, q}=\text { Dummy set to } 1 \text { when the cumulative abnormal return for firm } \\
& i \text { in quarter } q \text { is negative }
\end{aligned}
$$

To assess the importance of Reg FD, we include dummies that identify whether the data point is from the period after Reg FD was adopted. These dummies should then capture any effect of Reg FD on analyst following. The control variables are motivated by the extant literature on analyst following. First, there is overwhelming evidence that SIZE can explain analyst 
following. ${ }^{17}$ The three other explanatory variables - whether the firm is about to release a negative earnings report and the recent path of abnormal returns for the firm - are different dimensions of firm performance, which might influence an analyst's decision to track a firm. ${ }^{18}$

By having one intercept $a_{0 i}$ for each company in the sample (estimates for these intercepts are not shown), we can abstract from company characteristics that explain analyst following and rather focus on determinants of changes in analyst following associated with the adoption of Reg FD. The only exception to this rule is the use of SIZE as an explanatory variable; we opt to keep SIZE in the regression because in the period over which the panel data is applied - 20 quarters, composed of eight quarters pre-FD, four quarters in which Reg FD was put into discussion, passed and put into effect, and eight quarters post-FD - a firm might have changed its size to such an extent that it would influence analyst following. The other explanatory variables are firm characteristics that are clearly dependent on the time-period in which they are measured, and thus are not likely to be absorbed by the company fixed effects' intercept.

According to the literature on the determinants of analyst following, there are other characteristics that might be necessary to control for when studying analyst following, such as the firm's industry, the firm's riskiness, variability of earnings, past performance, institutional ownership etc. However, these results are mostly based on cross-sectional regression; here the use of a panel data is likely to diminish the problems of not including them. If the variables are firm characteristics that do not change much over time, then the firm fixed effect will absorb this. This is the case for variables related to industry such as industry membership, whether the industry is regulated, etc. Others variables could indeed change over time, but not enough to be captured over our sample period. For example, since a proxy for past performance or variability of earnings needs a considerable time series (say five or ten years), we do not expect much variation on the measure from 1998 to 2002, and therefore its effects will also be embedded in the company fixed effects' intercept. ${ }^{19}$

The results for the panel data fixed effects of analyst following are reported in Table 2. When all the data are examined together, in specifications I and V in panel A of Table 2, the

\footnotetext{
${ }^{17}$ The literature is extensive; examples are Bhushan (1989b), Brennan and Hughes (1991), Lang and Lundholm (1993, 1996) and Chung and Jo (1996).

${ }^{18}$ See Bhushan and O'Brien (1990).

${ }^{19}$ The results regarding Reg FD reported here are robust to the inclusion of institutional ownership holdings as an explanatory variable in regression (1). However, causality inferences are particularly problematic when using institutional holdings as a control variable (see Bhushan and O'Brien (1990)). Coupled with the fact that the inclusion of such explanatory variable forces the sample size to be reduced due to missing data on institutional holdings, we opt not to include it in our specification. Results are also robust to the inclusion of volume (turnover) as an explanatory variable.
} 
coefficient on the post-FD dummy is positive and statistically significant, indicating an overall increase in the number of quarterly forecasts available after Reg FD is adopted. However, a more distinctive picture is available when we examine differential effects on groups of firms based on size. For this, we break down the post-FD dummy in specifications II and VI into different dummies according to the size group each firm belongs to. The results indicate that while big firms have increased their analyst following post-FD, mid and small firms suffered the opposite effect, having their analyst following decreased. The models in panel A of Table 2 have significant explanatory power: the $\mathrm{R}^{2}$ is around 15 percent even after accounting for firms' fixed effects characteristics. ${ }^{20,21}$

All the results discussed above are from an unbalanced panel, so there is the question of whether survival issues could be playing a role in driving these results. It could be the case, for example, that small firms would be dying post-FD more often than big firms, forcing a decrease in analyst following over time. We argue that such issues are not likely to explain the differential effects we observe on firms grouped by size. First, the inclusion of size and performance proxies as control variables can account for a decrease in the analyst following due to a decrease over time in firm's size and performance. Also, we repeat the same regression for a balanced panel in which only companies that have observations available for all 16 quarters under examination are included and the results are qualitatively the same.

Another concern regarding the results reported in panel A of Table 2 is that the models impose the same regression coefficients independently of the size group that the firm belongs to. Since specifications II and VI allow for different patterns of an explanatory variable - the postFD dummy - depending on the firm's group, one might argue that we should allow for other

\footnotetext{
${ }^{20}$ All the $\mathrm{R}^{2}$ s reported for OLS panel data are within-groups $\mathrm{R}^{2}$ s. The within $\mathrm{R}^{2}$ is obtained from a regression using demeaned variables. Since we are mostly interested in the effect of the post-FD dummy, we avoid using the between or overall $\mathrm{R}^{2}$ 's because they are driven more by the explanatory power coming from the cross-sectional variation between firms. For example, the between $\mathrm{R}^{2}$ for specification VI in Table 2 is 0.60 , but this is largely due to the high correlation between size and analyst following. Therefore, we use a more conservative measure of how the time-series variation in the control variables - including whether the observation is from the period before or after Reg FD is adopted - helps explain variation in analyst following.

${ }^{21}$ Notice that we report simple OLS results. There is, though, a concern regarding the characteristics of the dependent variables that proxy for analyst following: NOFOR can be considered a count variable and NOFOR_STD can be considered a censored variable. Alternatively, we ran panel data Poisson regressions when using NOFOR and the results are qualitatively similar to the ones reported in Table 2 (although there is also a concern that analyst following does not conform to all the requirement of a count variable in a Poisson context). For the censored nature of NOFOR_STD, first notice that this is a minor issue for the groups of big and mid-size firms, given that almost all observations have at least one analyst, and so in practice are not censored. Anyway, running a Tobit regression with panel data fixed effects does not affect the results reported here.
} 
explanatory variables' responses to vary as well with the firm's group. To address this concern, we repeat the panel data fixed effects regression (1) separately for each group. The results reported in panel $\mathrm{B}$ indicate that the coefficients on the control variables indeed vary among the groups. However, the results regarding the effects of Reg FD on analyst following do not change qualitatively: each model keeps its high explanatory power and big firms experience an increase in analyst following at the expense of mid-sized and small firms, which have their following decreased post-FD.

To give a sense of the magnitude of the changes in analyst following post-FD, we can compare the coefficients on the post-FD dummy to the pre-FD mean analyst following. The comparison using the coefficients in specification VI of panel A of Table 2 and the pre-FD averages from Table 1 indicates that big firms on average experience an increase of about 7 percent in quarterly analyst following; mid-size firms have an average decrease of 5 percent and small firms face an average decrease of 17 percent in the their analyst following.

\section{B. Response of Firms' Pre-Announcements to Reg FD}

In this section we examine whether firms changed the way they employ voluntary public disclosures after Reg FD. We focus on the firm's use of public pre-announcements that refer to future annual earnings, quarterly earnings, or both, as our proxy for firms' voluntary disclosures. $^{22}$ It is common that more than one pre-announcement is issued on a specific date (e.g., one for the upcoming quarterly earnings and another for the next annual earnings announcement). Firms make pre-announcements all during the quarter, sometimes together with earnings announcements. Finally, there are different types of pre-announcements, either of a quantitative (e.g. point or range estimate) or qualitative nature. These different characteristics have to be considered when defining the specific measure of the use of pre-announcements to adopt.

In adopting a definition of a measure of a firm's propensity to voluntarily disclose information we want to discriminate among pre-announcements in terms of their relevance as instruments of information dissemination, and also based on the firm's motivation for using preannouncements. This leads us to treat pre-announcements differently according to the date they are issued. For example, a pre-announcement issued on the last day of a quarter is likely to be more relevant (in terms of incremental information) than a pre-announcement issued

\footnotetext{
${ }^{22}$ We collected data on pre-announcements from the CIG (Company Issued Guidelines) file in the First Call Historic Database. First Call emphasizes in the description of this file that "companies make earnings forecasts in press releases and interviews before they report the actual earnings".
} 
concomitantly with the release of the previous quarter's earnings announcement. During an earnings announcement event, the volume of information produced - by the firm as part of a mandatory release, by security professionals, by the media etc. - is already high and is likely to contain, to some extent, information of a forward-looking nature, even when the firm does not mention it explicitly, for example, the next quarterly earnings number. And if the firm does include some specific information that can be classified as a pre-announcement in the First Call database, it is likely it will be at most of marginal importance given the volume of information that already comes with the mandatory release. Moreover, it is natural to think that at the end of the current quarter the firm has a much better picture regarding the upcoming earnings release than it does on the day of the previous quarter's earnings announcement. Thus, we assume that the closer a pre-announcement is to the actual earnings announcement that it refers to, the more relevant it is likely to be.

The approach we pursue is to examine the likelihood that a company, as of date $\tau$, will voluntarily disclose information of a forward-looking nature - by means of using one or more pre-announcements - given the conditions holding at this date. For example set $\tau$ to 15 days before the end of the calendar quarter. Since we are trying to examine the use of preannouncements that can convey useful information, it is important not to have $\tau$ much before the end of the quarter. Around this period we can assume that managers have a good picture of what the upcoming earnings will be, so that a voluntary disclosure will be viewed with confidence by the market. On the other hand, having $\tau$ ahead of the end of the quarter will result in a loss of data points, since as we go further ahead we will have firms already issuing their mandatory earnings announcements.

We include all pre-announcements, whether they refer to quarterly or annual earnings. Our examination focuses on the dissemination of information regarding the next earnings announcement release; since this information is a subset of the information that can be released regarding other future earnings announcements - for example, the next annual earnings number -, we interpret the release of a pre-announcement for a future annual number as containing information for the upcoming quarterly release. ${ }^{23}$ For the same reason, we do not try to distinguish whether a pre-announcement is for the upcoming earnings release or for a future one.

\footnotetext{
${ }^{23}$ Moreover, this choice turns out not to be restrictive based on how annual pre-announcements are used. In our sample, 55 percent of annual pre-announcements were released together with actual earnings announcements. An extra 14.9 percent of the pre-announcements described as referring to annual numbers were actually for the upcoming release that includes both annual and quarterly numbers, and therefore can be considered as well to be quarterly pre-announcements. Another 16.3 percent were issued concomitant
} 
Given that we do not try to explore the information content of pre-announcements, we also do not distinguish pre-announcements according to their nature, whether qualitative or quantitative. We are trying to identify if and when firms disclose information voluntarily to the market, without a precise characterization - from both theoretical and empirical standpoints - of the relative merits of qualitative or quantitative pre-announcements; the approach is to treat them equally. Therefore, we examine the propensity of a firm to voluntarily disclose information; we do not ask at this point about the quality of the information released when the firm does so.

Table 3 presents some descriptive statistics on the issuance of pre-announcement before and after Reg FD. Panel A includes the results for the complete sample. Overall, we observe a steep increase in the use of pre-announcements, from 5,582 before Reg FD to 12,162 after the regulation was adopted, and the fraction of firm-quarters with at least one pre-announcement doubled, from 14.9 percent to 30.6 percent. ${ }^{24}$ Moreover, the increase after Reg FD in the number of pre-announcements issued and in the number of firms that used at least one pre-announcement is significant for all the subperiods of the analysis. If we consider only pre-announcements in the period that comprises the end of previous quarter up to date $\tau$, the fraction of firms that voluntary discloses goes from 3.5 percent to 5.6 percent; for the pre-announcements released from $\tau$ up to 2 days before the current quarter's actual earnings release, the fraction of quarters in which firms voluntarily disclose jumps from 8.8 percent to 12.7 percent; finally, when we consider only preannouncements issued together with mandatory earnings release, this percentage increases even more, from 4.3 percent to 20.3 percent. Therefore, although the biggest increase in the issuance of voluntary disclosures occur for pre-announcements released together with mandatory earnings releases, the general pattern of increase is observed no matter how we define the relevance of a pre-announcement. In particular, the increase for the period between $\tau$ and the mandatory earnings announcement, which will be the focus of our multivariate analysis, is very significant.

A more interesting picture is presented in Panel B, where the summary statistics are broken down according to groups of firms based on size. Focusing on the pre-announcements not released with actual earnings announcements we observe that the increase in the use of pre-

with another quarterly pre-announcement. From the remaining, sample, 3.8 percent were doubled preannouncements. Therefore, if we choose to analyze pre-announcements that are not doubled and are not issued with mandatory earnings announcement, the decision to drop from our sample the annual earnings announcement would amount to a removal of, in fact, only 10 percent of the initial sample of annual preannouncements.

${ }^{24}$ We also report in Table 3 the number of 'doubled' pre-announcements, i.e. pre-announcements that were issued in a day where another pre-announcement is also issued. Given that our focus is on instances where a firm voluntarily discloses, no matter whether it refers to one or more future earnings releases, we do not use the information whether a pre-announcement is doubled or not in any further analysis. 
announcements after FD is confined to the big and mid-size firms. Regarding pre-announcements released between $\tau$ and the actual earnings releases, for big (mid-size) firms voluntary disclosure is present in 10.1 percent (9.6 percent) of firm-quarters pre-FD and in 18.1 percent (14.6 percent) of the firm-quarters post-FD, while if we restrict the analysis to pre-announcements before date $\tau$, for big (mid-size) firms we observe voluntary disclosures in 6.4 percent (3.5 percent) of firmquarters pre-FD and in 12 percent (5 percent) of the firm-quarters post-FD. However, for small firms, the univariate analysis indicates a small, albeit not significant, decrease in the use of voluntary disclosures after Reg FD for either period in which pre-announcements are issued. If we consider all pre-announcements in the sample, independently of when they are issued along the quarter, the fraction of small firms voluntarily disclosing indeed increases significantly after Reg FD, but we can see that this result is misleading in that it is driven by an increase in the preannouncements that are issued together with mandatory earnings releases.

Figure 1 plots the quarterly fraction of companies (inside each group based on size) that issue pre-announcements. The picture reinforces the consistency of the different patterns, according to firm size, on how use of pre-announcements changes in relation to Reg FD. Before Reg FD, bigger firms indeed pre-announce more, but the differences in the average use of preannouncements among the size groups is not striking. After Reg FD we observe a steep increase in the fraction of big and mid-size firms that issue pre-announcements, while small firms keep their average use of pre-announcement similar to the pre-FD numbers.

We now turn to multivariate analysis, with the objective of examining the determinants of the firm's decision to issue pre-announcements. Our dependent variable is a dummy that, for each firm-quarter, is set to one whenever the firm issues one or more pre-announcements in the period from date $\tau$ until two days before the actual earnings release. ${ }^{25}$ Our first step is to check the validity of the control variables to be used later when examining whether and how the use of preannouncements change with the adoption of Reg FD. For this purpose, we run the following quarterly cross-sectional logistic regressions:

\footnotetext{
${ }^{25}$ This defines a binary variable. We could instead use a model of multiple choices, e.g. measuring whether the firm issues only one or more than one pre-announcement during a certain period. However, the summary statistics on Table 3 indicate that (e.g., for pre-announcement issued between date $\tau$ and the actual earnings announcement) the fraction of firms with more than one pre-announcement is very small compared with the fraction of firms with at least one pre-announcement, and the evolution post-FD of these two fractions is very similar. This suggests that it would be very difficult to capture the effect on a decision to issue more than one pre-announcement when compared with the decision to issue only one. Based on this and on the fact that the econometric treatment of the panel data fixed effects logistic regression is much simpler when dealing solely with a binary dependent variable, we opt to use the binary decision only.
} 


$$
\begin{aligned}
& \operatorname{Prob}\left[P R E A N N_{i, q}=1\right]=f\left(a_{0}+a_{1} \operatorname{SIZE}_{i, q}+a_{2} N A S D A Q_{i, q}+a_{3} S_{S U R R I S E_{i, q}}+a_{4} N E G_{-} S U R P R I S E_{i, q}+\right. \\
& \left.a_{5} \text { ABSCAR }_{i, q}+a_{6} \operatorname{SIGNCAR}_{i, q}+a_{7} \text { PA_INDUSTRY } Y_{i, q}+\Sigma a_{8, n} \operatorname{INDUSTR}_{i, q, n}+\varepsilon_{i, q}\right)
\end{aligned}
$$

and

$$
\begin{gathered}
\operatorname{Prob}\left[\operatorname{PREANN}_{i, q}=1\right]=f\left(a_{0}+a_{1} \operatorname{SIZE}_{i, q}+a_{2} \operatorname{NASDA}_{i, q}+a_{3} \operatorname{LOSS}_{i, q}+\right. \\
\left.+a_{4} \operatorname{ABSCAR}_{i, q}+a_{5} \operatorname{SIGNCAR}_{i, q}+a_{6} \operatorname{PA}_{-} \operatorname{INDUSTRY}_{i, q}+\Sigma a_{7, n} \operatorname{INDUSTRY}_{i, q, n}+\varepsilon_{i, q}\right)
\end{gathered}
$$

where

$$
\begin{aligned}
& \operatorname{PREANN}_{i, q}=\text { Dummy set to } 1 \text { when there is at least one pre-announcement } \\
& S I Z E_{i, q}=\log \text { of market value of the firm } i \text { at the end of the quarter } q \\
& \text { divided by the market index } \\
& N A S D A Q_{i, q}=\text { Dummy set to } 1 \text { when firm } i \text { is traded on NASDAQ } \\
& \operatorname{LOSS}_{i, q}=\text { Dummy set to } 1 \text { when the actual earnings are negative } \\
& \text { SURPRISE }_{i, q}=\text { Absolute value of the difference between the actual earnings and } \\
& \text { the consensus mean forecast at date } \tau \text {, scaled by the end of the } \\
& \text { quarter book equity per share } \\
& \text { NEG_SURPRISE } E_{i, q}=\text { Dummy set to } 1 \text { when the actual earnings is below the consensus } \\
& \text { forecast available at date } \tau \\
& A B S C A R_{i, q}=\text { The absolute value of the cumulative abnormal return for firm } i \\
& \text { along quarter, up to date } \tau \\
& \operatorname{SIGNCAR}_{i, q}=\text { Dummy set to } 1 \text { when the cumulative abnormal return for firm } i \\
& \text { along quarter } q \text { (up to date } \tau \text { ) is negative } \\
& \text { PA_INDUSTRY } Y_{i, q}=\log \text { of the number of the pre-announcements issued by firms in } \\
& \operatorname{INDUSTR} Y_{i, q, n}=\text { Industry dummy set to } 1 \text { if firm } i \text { belongs to industry } n
\end{aligned}
$$

The explanatory variables are motivated by extant literature on the firm's decision to disclose information. First, firm size seems to be an important determinant of a firm's disclosure policy. King, Pownall and Waymire (1990) hypothesize that big firms have better disclosure policies because the incentives for private information acquisition are greater for them when 
compared to small firms. Diamond and Verrecchia (1991) present a model in which firms use disclosure to reduce information asymmetry and thus to decrease the cost of capital, and big firms disclose more information because they are the ones that benefit most from the mechanism. From the point of view of costs, Lang and Lundholm (1993) argue that disclosure costs are more likely to decrease with size, so that, other things equal, the amount of disclosure should increase with firm size. Skinner $(1994,1997)$ suggests that litigation costs, which increase with firm size, would be especially important for bigger firms when deciding whether and when to disclose information. ${ }^{26}$ From an empirical perspective, Lang and Lundholm (1993) provide evidence that size is positively correlated with analysts' evaluations of the firm's voluntary disclosure practices. More recently, a survey conducted by the National Investor Relations Institute (NIRI (2001)) found responses that differ, based on size of the firm, as to whether firms are releasing more or less information after Reg FD: the fraction of firms that responded that less information is being provided post-FD is higher for the group of low-cap firms when compared to the group of midand high-cap firms.

The inclusion of SURPRISE and NEG_SURPRISE is motivated by research that posits voluntary disclosures as instruments used to align market expectations with the manager's private information. ${ }^{27}$ Skinner (1994) argues that firms tend to be more forceful in disclosing bad news than good news, first because of fear of lawsuits if a big negative surprise at the earnings announcement provokes a large decline in stock price, but also to maintain a good reputation with security professionals; to account for this possibility we include the LOSS control variable. PA_INDUSTRY allows for the possibility of an idiosyncratic effect taking place among firms in the same industry around the time the firm issues a pre-announcement. For example, some turmoil in an industry that leads some of firms to issue pre-announcements to correct market expectations might cause another firm in the same industry to pre-announce even when it does not have any news per se; it pre-announces simply to calm down the market. Finally, we include dummies for membership in the 48 industries defined in Fama and French (1997). ${ }^{29}$

\footnotetext{
${ }^{26}$ The fact that small firms have fewer mandatory disclosure requirements mandated by FASB and SEC can be taken as indirect evidence that smaller firms face a bigger cost per unit of size to disclose. Empirical evidence on the differential marginal disclosure costs by firms of different sizes can be found in Bushee and Leuz (2003): they document that the regulatory change mandating firms on the OTC Bulletin Board to comply with disclosure requirements under the Securities Exchange Act of 1934 had a negative effect specially for small firms, which could not cope with the significant disclosure costs and were essentially forced off the OTC Bulletin Board. These arguments relate to costs of mandatory disclosures, but a similar relation can be expected between size and costs of voluntary disclosures.

${ }^{27}$ See, for example, Ajinkya and Gift (1984) and Matsumoto (2002).

${ }^{28}$ Notice that some of the variables defined in the regression model above have a forward-looking nature. SURPRISE, NEG_SURPRISE and LOSS use in their definition the actual value of the earnings to be
} 
The first regression specification uses only a subset of the data available on preannouncements. For a data point to be included in the regression it is necessary that a proxy for market expectations regarding future earnings releases can be obtained; using the analysts' consensus forecast as a proxy for this expectation, our sample selection requires that at date $\tau$ there must be at least one valid earnings forecast available. In order to avoid the data restriction on market expectations, the second specification drops the explanatory variables based on market expectations and instead use only a dummy based on the actual earnings value to be released. Thus, all data points can be used in the second regression specification.

Results of regressions (2) and (3) are reported in Table 4 (results on dummies for industry membership are omitted). The coefficient on SURPRISE is significantly positive throughout the quarters, suggesting that managers use pre-announcements to correct market expectations and increase their use when the consensus forecast prevailing in the market is far away from the actual earnings to be released in the future. The coefficient on NEG_SURPRISE is also consistently positive and significant, indicating that managers' motivation for use of preannouncements to correct expectations is amplified when the prevailing consensus is below the actual earnings. That firms like to avoid bad news is also suggested by the positive (although not always significant) coefficient on LOSS in Panel A: in the face of upcoming negative earnings numbers firms are more willing to release pre-announcements, thus bringing the consensus forecast closer to the actual earnings and reducing an expectations gap more likely to be negative.

There is limited evidence that firms trading on NASDAQ make less use of preannouncements: the coefficient on NASDAQ is negative for most of the quarters in panels A and $\mathrm{B}$, but most of the times not significant. Regarding industry clustering, we observe that, except for the first quarter of the sample, the coefficient on PA_INDUSTRY is significantly positive in

announced in the future days. This definition is not troublesome if we assume that at date $\tau$ the manager already has this knowledge (that's why it is crucial to establish $\tau$ at a point in time not much before the end of the quarter, when decisions about what and when to announce might be already done), because we are trying to model exactly the manager's decision on whether to pre-announce.

${ }^{29}$ Other control variables could be included. As an example, Lang and Lundholm (1993) try to explain "better" disclosure firms (as proxied by analyst ratings of corporate disclosures) using performance variables (returns and forecast errors), structural variables (size, return variability and correlation between annual returns and earnings) and an offer variable (whether the firm is active in issuing securities). In our setup, we are not using performance variables (other than size) and the offer variable. However, our panel data specification mitigates the problems of not including these extra variables, because their effects can be considered firm fixed effects. According to Lang and Lundholm (1993), "structural variables measure firm characteristics that are widely known and likely to remain stable over time", more so over the relatively short period of this study and in a similar way we can assume the classification of a firm as of an offer class is unlikely to change over this period. 
both specifications. Finally, we observe that SIZE is very positively correlated with the use of pre-announcements, corroborating the univariate results seen in Table 3.

Both models have a good explanatory power. Panel A has quarterly pseudo $\mathrm{R}^{2}$ on average around 17 percent and panel $B$ has an average pseudo $R^{2}$ around 22 percent. The pseudo $\mathrm{R}^{2}$ for the specification using surprise measures are consistently higher than the specification using all sample data, suggesting that using explanatory variables based on market consensus forecast prevailing prior to the issuance of pre-announcement adds a good deal in explaining the use of pre-announcements.

We now turn to the examination of the use of pre-announcements over time, in relation to the period Reg FD is adopted. Our univariate analysis indicated an overall increase in the use of pre-announcements by firms, but this increase seems to be confined to the big and mid-size firms. This pattern is also suggested by the estimates of SIZE coefficient in the cross-sectional regressions in Table 4. The estimated coefficient gets bigger and more significant as we go from the pre-FD to post-FD quarters, suggesting that firm's size plays a more important role in explaining whether a firm issues pre-announcements during the period in which Reg FD is in place.

However, a more thorough investigation of the effects of Reg FD on the use of preannouncements requires a multivariate cross-sectional approach that also takes the time-series dimension into consideration. For this, we run a cross-sectional time-series (fixed effects) logistic regression. Similarly to the traditional panel data regression, the fixed effects logistic regression is equivalent to having one intercept for each firm. ${ }^{30}$ The fixed effects logistic models are presented below. They are similar to the cross-sectional regression models, with the differences that we now include a dummy for post-FD quarters and we remove the dummies for NASDAQ and industry membership because these dummies do not change for each firm over time, so that their effects are incorporated into the firms' fixed effect dummies. ${ }^{31}$

\footnotetext{
${ }^{30}$ Although in this case these intercepts are not estimated because, given the formulation of the logistic function, the conditional likelihood does not include the firms' dummies. This is also important in that, by avoiding the inclusion of the firms' dummies, the estimation procedure does not face the incidental parameters problem. For details on the fixed effects logistic regression, see Chamberlain (1980) and Greene (1997).

${ }^{31}$ Another way to explore this question is to collect all pre-announcements and include a control sample such that each pre-announcement has a corresponding control observation, e.g. matching the day of the preannouncement for a firm in a similar industry or with similar size etc. This is the approach taken by Soffer, Thiagarajan and Walther (1998). This alternative approach does not control directly for fixed effects, but rather through the inclusion of the control sample.
} 


$$
\begin{aligned}
& \operatorname{Prob}\left[\operatorname{PREANN}_{i, q}=1\right]=f\left(a_{o i} \text { FIRM }_{i}+a_{1} \text { POSTFD }_{i, q}+a_{2} \operatorname{SIZE}_{i, q}+a_{3} \text { SURPRISE }_{i, q}+\right. \\
& \left.a_{4} N E G \_S U R P R I S E_{i, q}+a_{5} \text { ABSCAR }_{i, q}+a_{6} \operatorname{SIGNCAR}_{i, q}+a_{7} \text { PA_INDUSTRY }_{i, q}+\varepsilon_{i, q}\right)
\end{aligned}
$$

and

$$
\begin{gathered}
\operatorname{Prob}\left[\operatorname{PREANN}_{i, q}=1\right]=f\left(a_{o i} \text { FIRM }_{i}+a_{1} \operatorname{POSTFD~}_{i, q}+\right. \\
\left.a_{2} \operatorname{SIZE}_{i, q}+a_{3} \operatorname{LOSS}_{i, q}+a_{4} \text { ABSCAR }_{i, q}+a_{5} \operatorname{SIGNCAR}_{i, q}+a_{6} \text { PA_INDUSTRY }_{i, q}+\varepsilon_{i, q}\right)
\end{gathered}
$$

The results of the fixed effects logistic regressions are reported in Table 5. ${ }^{32}$ In general, the sign and significance of the control variables in the fixed effects logistic regressions strengthen the results obtained in the cross-sectional regressions presented in Table 4. Even after controlling for companies' fixed effects, pre-announcements are more frequently used by big firms, when there is a gap between market expectations and the manager's private information, with upcoming bad news or when more firms in the same industry are also issuing more preannouncements.

Regarding the effects of Reg FD, we observe that in specifications I and IV of Table 5, that investigate post-FD effects for all companies as just one group, the coefficient on the post-FD dummy is significantly positive, confirming the univariate results we saw above of an overall increase in the use of pre-announcement by all the firms. A more detailed and interesting picture emerges from specifications II and V, though. When breaking up the post-FD dummy according to the size group the firm belongs to, only the coefficients identifying post-FD observations of big and mid-size firms are significantly positive: in other words, the increase in the use of preannouncements occurs for big and mid-size firms, but not for small firms. ${ }^{33}$

In panel B of Table 5, we repeat the fixed effects logistic regression separately for each group, thus addressing the concern that the models reported in panel A impose the same regression coefficients for the control variables independently of the group the firm belongs to, even when we allow the post-FD dummy to vary among groups. The results reported in panel B indicate that the coefficients on the control variables indeed vary among the groups, but are

\footnotetext{
${ }^{32}$ Notice that the number of observations of the fixed effects model is substantially reduced. This occurs because firms which have pre-announcements in all quarters in which they appear in the sample, or that do not have pre-announcements in any of these quarters, are dropped from the sample, since they do not contribute to the maximum likelihood estimation procedure.

${ }^{33}$ Specifications III and VI of Table 5 provide for an even higher pseudo $\mathrm{R}^{2}$. However, we view these results with caution. The improvement of $\mathrm{R}^{2}$ is obtained after the inclusion of PA_INDUSTRY, but since PA_INDUSTRY is likely to be affected by Reg FD effects, we prefer to focus on specifications II and V when analyzing Reg FD effects on the use of pre-announcements.
} 
qualitatively similar to the results from the regressions using aggregated data. Most importantly, the results regarding the effects of Reg FD on the use of pre-announcements do not change.

To give a sense of the magnitude of the changes in the use of the voluntary disclosure we examine the odds ratio associated with the post-FD dummies in panel A of Table 5. For big firms, the odds ratio of the post-FD dummy is 1.97 , that is, controlling for the explanatory variables discussed above, the big firms are twice as likely to voluntarily disclose information after Reg FD compared to the period before Reg FD; for mid-size firms, the effects are also substantial, with an odds ratio of 1.65; finally, the odds ratio of small firms is indistinguishable from 1, indicating no change in the likelihood of occurrence of voluntary disclosure associated with the adoption of the regulation.

In terms of an assessment of the overall use of pre-announcements by the market, our results indicating an increase in the use of pre-announcements by firms after Reg FD confirm the current literature by using a more stringent definition of the use of pre-announcements, more data both in the dimension of the number of firms and the time period, and a robust logistic regression that takes care of company fixed effects. ${ }^{34}$ More importantly, though, is that our analysis makes clear the cross-sectional differences in the behavior of firms regarding the use of preannouncements according to firm's size.

\section{Effects of the Reallocation}

\section{A. Forecast Errors}

News shocks at earnings announcement dates are a result of a gap between the information contained in the (mandatory) earnings announcement and the amount of information available about the firm prior to the earnings announcement. That information could be privately produced or voluntarily released by the firm. ${ }^{35}$ In this section we examine whether earnings announcement date surprises change in relation to Reg FD.

\footnotetext{
${ }^{34}$ Straser (2002), Heflin et al. (2003) and Bailey et al. (2003), using different definitions of preannouncement and different statistical tests, all report increases in the use of pre-announcements after Reg FD. Bailey et al. (2003) and Heflin et al (2003), for example, use as a measure of voluntary disclosures the total number of pre-announcements issued by the firm between two consecutive quarterly earnings announcement. Bailey et al. then make use of a univariate analysis based on matched pairs of pre-FD and post-FD quarters. Heflin et al. (2003) also uses logistic regression to explain the use of pre-announcements, although in their case, by summing up pre-announcements during the entire quarter, they are not able to use the current market consensus inside the quarter as an explanatory power, which as we see from Table 5 adds much explanatory power to the regression.

${ }^{35}$ In a survey released by the Association of Information Management and Research in March 2001 (AIMR (2001)), 71 percent of the respondents reported that Reg FD had contributed to an increase in market
} 
We first examine forecast errors at earnings announcement dates. We define the "unscaled forecast error" as the absolute value of the difference between the actual earnings per share for firm $i$ at quarter $q$ and the consensus (mean) forecast as of two days before the actual earnings announcement day for firm $i$ 's quarter $q .{ }^{36}$ In order to get a comparable measure across firms, we define the "scaled forecast error" (henceforth simply "forecast error") as the unscaled measure described above divided by firm $i$ book equity per share computed at the end of quarter $q$.

To examine the effects of Reg FD, we run the following panel data regression:

$$
\begin{gathered}
\text { EA_SURPRISE } E_{i, q}=a_{0 i} \text { FIRM }_{i}+a_{1} \text { POSTFD }_{i, q}+a_{2} \text { SIZE }_{i, q}+ \\
a_{3} \text { LOSS }_{i, q}+a_{4} \text { ABSCAR }_{i, q}+a_{5} \operatorname{SIGNCAR}_{i, q}+\varepsilon_{i, q}
\end{gathered}
$$

where

$$
\begin{aligned}
& \text { EA_SURPRISE } E_{i, q}=\text { Absolute value of the difference between actual earnings } \\
& \text { per share for firm } i \text { at quarter } q \text { and the consensus (mean) } \\
& \text { forecast as of } 2 \text { days before the actual earnings } \\
& \text { announcement day for firm } i \text { 's quarter } q \text {, divided by firm } i \\
& \text { book equity per share computed at the end of quarter } q \\
& \text { FIRM } \quad=\text { Dummy set to } 1 \text { for the } i^{\text {th }} \text { firm } \\
& \operatorname{POSTFD}_{i, q} \quad=\text { Dummy set to } 1 \text { when the data point is observed after Reg } \\
& \text { FD was adopted } \\
& S_{I Z E_{i, q}} \quad=\quad \log \text { of market value of the firm } i \text { at the end of the quarter } q \\
& \text { divided by the market index } \\
& \operatorname{LOSS}_{i, q} \quad=\text { Dummy set to } 1 \text { when the actual earnings for firm } i \text { at } \\
& \text { quarter } q \text { are negative } \\
& \operatorname{ABSCAR}_{i, q} \quad=\text { Absolute value of the cumulative abnormal return for firm } \\
& i \text { along quarter } q \\
& \operatorname{SIGNCAR}_{i, q}=\text { Dummy set to } 1 \text { when the cumulative abnormal return for } \\
& \text { firm } i \text { along quarter } q \text { is negative }
\end{aligned}
$$

volatility, with many blaming it on a reduction of earnings guidance (from firms), that is, on an increase in forecast errors at the earnings announcement.

${ }^{36} \mathrm{We}$ repeat the tests described subsequently using an alternative definition of forecast error that takes the median forecast instead of the mean forecast as the consensus measure, and the results do not change qualitatively. 
Besides the dummies that isolate effects of Reg FD, we include control variables. Given that firm size seems to be an important determinant of the quality of the firm's information environment, the ability of analysts to forecast earnings could be related to SIZE. LOSS is included because there is evidence that forecast errors at earnings announcements differ between profits and losses (see Brown (2001)). Finally, we include ABSCAR and SIGNCAR to analyze possible effects from contemporaneous firm's return on the ability of analysts to predict upcoming earnings.

Table 6 presents results of the panel data regressions to explain scaled forecast error. If we scale forecast error by share price, the results indicate an overall increase in forecast error post-FD: the post-FD coefficients for the sample as a whole (specification I) as well as for each group of firms (specification II) is positive and highly significant. In fact, these results are distorted by the fact that the post-FD period is a period of market decline. The market decline induces a downward trend in the deflator measure used as the denominator in the definition of the scaled forecast error; therefore, even if the forecast error had not decreased post-FD, the scaled forecast error could still have increased due solely to the declining share price. ${ }^{37}$

Our main interest is in assessing possible changes in the forecast error scaled by book equity per share. ${ }^{38}$ These results are reported in specifications III and IV of panel A of Table 6. When all firms are examined together as just one group in specification III, the coefficient on the post-FD dummy is insignificant, i.e. there is no evidence of change in scaled forecast error measure after Reg FD is adopted. However, the break-up of the post-FD dummy - according to the size group each firm belongs to - provides evidence of movements in scaled forecast error that are negatively correlated with size: forecast error increases for small firms, decreases for big firms and reveals no significant change for mid-size firms. The result is robust to whether we also allow the coefficients on the other explanatory variables to vary according to the firm's group, as evidenced by the results in panel B of Table 6 .

Given the definition of forecast error, all the inferences seen so far apply to the sample of firm-quarters having at least one earnings forecast issued for the quarter. However, taking the presence of forecasts as a proxy for the knowledge of the market regarding the upcoming numbers, it is reasonable to think that, for a firm-quarter with no forecasts available, the surprise - as a measure of how much news was really incorporated in the released number - at the

\footnotetext{
${ }^{37}$ To examine further this issue, we simulate a distribution of each company's unscaled forecast errors for the post-FD period based on the actual distribution of unscaled forecast errors pre-FD for that same company (i.e., by construction forecast errors do not change post-FD). Regressions on forecast error scaled by share price indicate an increase in forecast error post-FD (results not reported).

${ }^{38} \mathrm{We}$ also examine effects of scaling forecast error by assets per share. The results do not change qualitatively.
} 
earnings announcement can be even more substantial than that for a firm-quarter with some earnings forecasts available. Therefore, the results above support the view that for small firms, forecast error at earnings announcement increases after FD, but that does not necessarily implies that the average surprise at earnings announcement also increases.

In order to get more robust inferences regarding the information environment of firms before earnings announcements, we have to examine whether Reg FD is associated with any patterns based on the sample of firm-quarters without forecasts. For a firm-quarter with no earnings forecast available, we do not have a comparable measure of surprise at earnings announcements, and, therefore, we can not compare amongst firm-quarters without an available forecast. A simple examination can be done, though, by looking at whether the sample of firmquarters without forecasts changed after Reg FD. For this, Figure 2 plots, for each group of firms, the quarterly fraction of firm-quarters that have analyst following (i.e. at least one forecast available about upcoming quarterly earnings).

The graph indicates that the groups of big and mid-size firms have a very large and constant fraction of observations with analyst following. However, for the group of small firms, the fraction of firms-quarters with analyst following seems to follow two different regimes in relation to Reg FD: before Reg FD around 65 percent of the quarterly observations have forecasts available, while after Reg FD this number runs close to 50 percent, and the difference on these averages is both significant and substantial. Given that the average number of forecasts increases with size, small firms are more likely to have their status, regarding whether there is at least some analyst following, changed as result of a change in the number of forecasts. This is reflected in the figure: the deterioration in analyst following for small firms diagnosed in Section 3 materializes also as a reduction in the number of firm-quarters being researched at least by one analyst, while the increase (decrease) in analyst following for big (mid-size) firms does not lead to a substantial change in the fraction of observations with at least one analyst following

Figure 2 corroborates inferences from the panel data regressions. For big and mid-size firms, regression results indicate no degradation in forecast error in relation to Reg FD (in fact, forecast errors decrease for the sample of big firms), while the figure suggests no change in the (small) fraction of observations with no forecast available after Reg FD was adopted; taken together, they suggest that the surprise component of earnings announcements does not change after Reg FD. But, after Reg FD small firms face both an increase in forecast error for the sample with analyst following and an increase in the number of observations with no forecast at all, leading to increases in the surprise news component at quarterly earnings announcements. 
In conclusion, the multivariate analysis indicates no reliable evidence of an overall increase in forecast errors at quarterly earnings announcements, corroborating some results from other papers in the literature. ${ }^{39}$ However, our panel data adds to the picture by revealing strong evidence of size as a cross-sectional determinant of the effect of Reg FD on surprises at earnings announcements. While no deterioration is observed for big and mid-size firms, small firms were indeed affected by Reg FD. Small firms lost analyst following after Reg FD was adopted, and for those still covered by analysts there are larger forecast errors.

\section{B. Market Response to Earnings Announcements}

The market response to news shocks at earnings announcements is another dimension likely to be affected by changes in the way information about the firm is produced and released. In fact, one main argument of critics of Reg FD is that the regulation would cause an increase in volatility because information would not be released smoothly as when there is constant contact between the company and the analysts, but rather in lumps, e.g. if information is held up until the next mandatory earnings announcement. In this section we investigate this possibility by examining whether volatility at earning announcements changes in relation to Reg FD.

Volatility at earnings announcement dates is computed as the cumulative absolute abnormal return over the window $[-1,+1]$ around the earnings announcement day, where the abnormal return is obtained as the residual of a market model based on the value-weighted market index returns. $^{40}$

Figure 3 depicts the univariate behavior of volatility at earnings announcement, by plotting the quarterly average volatility for each group of firms. In the cross-sectional dimension, we observe that volatility is correlated across groups. Since this volatility measure is idiosyncratic (by the definition of market model residuals), the pattern seen in the figure suggests the existence of a common factor in volatility across size (that is not part of the market model). When we compare volatility levels across groups, the small (mid-size) firms consistently have higher average volatility than the mid-size (big) firms do, which corroborates evidence in the literature that volatility is negatively correlated with size. ${ }^{41}$

When we look at the time-series evolution of average volatility before and after Reg FD, there is a discernable pattern of decreasing volatility for three consecutive quarters right after Reg

\footnotetext{
${ }^{39}$ Heflin et al. (2003) investigate pairs of pre-FD and post-FD quarter and also find evidence of no change in forecast error for the sample of firm-quarters that indeed have some analyst following.

${ }^{40} \mathrm{We}$ use as an alternative simple excess returns, i.e. the residuals from a constant-mean-return model, and all the results are qualitatively the same.
} 
FD was adopted (Q3:2000, represented by the horizontal line to the right of the figure, is the last quarter before Reg FD is adopted). In addition, decreasing volatility can also be observed if one takes pairs of quarters separated by one year right around the adoption of the regulation (more specifically, Q1:2000 against Q1:2001, Q2:2000 against Q2:2002 or Q3:2000 against Q3:2001). ${ }^{42}$ However, when we extend the analysis to other quarters, post-FD, and to the quarters before Reg FD was proposed, the pattern of decreasing volatility after Reg FD is missing. For example, in the last quarter before Reg FD was proposed, the average volatility for each group is higher than in the first quarter after Reg FD was adopted. To take into account seasonality in quarterly results, we can compare the volatility in Q2:1999 - two quarters before Reg FD was proposed - with Q2:2001 (or, for that matter, with all the three consecutive quarters right after Reg FD was adopted), and we see an increase in the volatility post-FD for all groups of firms.

To summarize, univariate analysis of average volatility across size and through time does not suggest any specific effect related to the adoption of Reg FD. Of course, univariate pictures do not control for changes in firms' characteristics that are determinants of market responses to earnings announcements. Regarding market wide conditions, the use of residuals from a market model theoretically controls for possible changes in non-idiosyncratic determinants of volatility, although the correlation among groups' average volatility through time suggests the presence of a systematic component of volatility not captured by firm size. To tackle these issues, we use multivariate panel data (cross-sectional time series) regressions to explain the market response at the time of earnings announcement as follows:

$$
\begin{gathered}
\operatorname{VOLAT}_{i, q}=a_{0 i} \operatorname{FIRM}_{i}+a_{1} \operatorname{POSTFD}_{i, q}+a_{2} \operatorname{SIZE}_{i, q}+a_{3} \operatorname{LOSS}_{i, q}+ \\
a_{4} \operatorname{NEG}_{-} S U R P R I S E_{i, q}+a_{5} \operatorname{SURPRISE}_{i, q}+a_{6} \operatorname{ABSCAR}_{i, q}+a_{7} \operatorname{SIGNCAR}_{i, q}+a_{8} \operatorname{VIX}_{i, q}+\varepsilon_{i, q}
\end{gathered}
$$

where

$$
\begin{aligned}
\operatorname{VOLAT}_{i, q}= & \text { Cumulative absolute abnormal return during the } 3 \text { days } \\
& \text { (window }[-1,+1] \text { ) around the earnings announcement day, } \\
& \text { where the abnormal return is obtained as the residual from } \\
& \text { the market model } \\
\text { FIRM }_{i}= & \text { Dummy set to } 1 \text { for the } i^{\text {th }} \text { firm } \\
\operatorname{POSTFD~}_{i, q}= & \text { Dummy set to } 1 \text { when the data point is observed after Reg }
\end{aligned}
$$

\footnotetext{
${ }^{41}$ For example, see Atiase $(1980,1985)$ and Freeman (1987).

${ }^{42}$ Bailey et al (2003) report results on these matched pairs without taking into consideration the separation of firms in groups based on size. Eleswarapu et al. (2003) analyzes effects of Reg FD based on comparison of Q4:1999 (pre-FD) and Q4:2000 (post-FD) quarters.
} 


$$
\begin{aligned}
& \text { FD was adopted } \\
& S I Z E_{i, q}=\log \text { of market value of the firm } i \text { at the end of the quarter } q \\
& \text { divided by the market index } \\
& \operatorname{LOSS}_{i, q}=\text { Dummy set to } 1 \text { when the actual earnings for firm } i \text { at } \\
& \text { quarter } q \text { are negative } \\
& N E G_{-} S U R P R I S E_{i, q} \text { Dummy set to } 1 \text { when the actual earnings is below the } \\
& \text { consensus forecast available two days before the earnings } \\
& \text { announcement } \\
& \text { SURPRISE } E_{i, q}=\text { Absolute value of the difference between the actual earnings } \\
& \text { and the consensus mean forecast } 2 \text { days before the earnings } \\
& \text { announcement, scaled by the end of the quarter book equity } \\
& \text { per share } \\
& A B S C A R_{i, q}=\text { Absolute value of the cumulative abnormal return for firm } i \\
& \text { along quarter } q \\
& \operatorname{SIGNCAR}_{i, q}=\text { Dummy set to } 1 \text { when the cumulative abnormal return for } \\
& \text { firm } i \text { along quarter } q \text { is negative } \\
& V I X_{i, q}=\text { Value of the VIX index at the earnings announcement day }
\end{aligned}
$$

In the regression specification above, the dummy variable POSTFD allows for the examination of whether changes in volatility are related to Reg FD. The other control variables are motivated by an extensive literature related to volatility and returns at earnings announcement dates. As mentioned before, there is evidence in the literature that SIZE is correlated with volatility; besides, firm size can account for differences in risk that are not captured by the market model. ${ }^{43}$ LOSS is included to allow for possible differences in market responses to negative earnings. ${ }^{44}$ SURPRISE accounts for effects of news content of released earnings that goes beyond the consensus forecast, and NEG_SURPRISE tries to capture the asymmetric responses of returns to good and bad shocks. ${ }^{45}$ ABSCAR tries to control for patterns of volatility that are contemporaneous to the earnings announcement period. SIGNCAR is included due to evidence that volatility tends to be higher in down markets. ${ }^{46}$

\footnotetext{
${ }^{43}$ See Fama and French $(1992,1993)$.

${ }^{44}$ Hayn (1995) hypothesizes that, because shareholders have a liquidation option, losses are not expected to be perpetual. Therefore, losses are less informative that profits about firm's prospects. Hayn (1995) and Lipe, Bryant and Widener (1998) provide empirical evidence supporting this conjecture.

${ }^{45}$ For a review of the literature on the subject see Kothari (2001).

${ }^{46}$ See for example Christie (1982) and $\mathrm{Wu}(2001)$.
} 
Despite using an 'idiosyncratic' measure of volatility at earnings announcement dates (market model residuals), the correlation of the measure of volatility among groups of firms suggests that there might still be some general component of volatility that we are not capturing. This motivates incorporating the VIX index on the earnings announcement day as an explanatory variable in the regressions. VIX is an expected volatility index traded on the Chicago Board Options Exchange; it is calculated by taking a weighted average of the implied volatilities from eight calls and puts on the S\&P 100 index. ${ }^{47}$ By including it, we are investigating whether the market reaction to earnings news somehow relates to a proxy for the market expectations about future market volatility.

The results of running the panel data regressions to explain volatility at earnings announcements are presented in Table 7. First take a look at panel A. Overall, controlling for firms' fixed effects, the coefficients on the explanatory variables are in the predicted direction and, in general, are significant. Volatility decreases with firm size. In terms of information contained in the released earnings numbers, volatility increases with the surprise that comes with the earnings announcement and increases even more when the surprise is negative. The coefficient on LOSS is significantly negative, supporting the hypothesis in Hayn (1995) that losses are less informative than positive profits. The positive coefficient on ABSCAR confirms the contemporaneous relation between the market return and the pattern of cumulated returns along the quarter, and the positive coefficient on SIGNCAR supports the idea that volatility is higher in down markets.

The effects of Reg FD on volatility at earnings announcements are captured by the dummies for post-FD periods. In specifications I and III, in which all firms are treated as a single group, the coefficients on the post-FD dummy are significantly positive, indicating that there is an increase in the volatility at earnings announcements after Reg FD is adopted.

The VIX index does have explanatory power with respect to the market reaction to earnings announcements: the inclusion of the VIX index as a control is responsible for an increase in the $\mathrm{R}^{2}$ of the regression from 3.5 percent to 5.4 percent. Moreover, after the inclusion of VIX, the effect of Reg FD as measured by the post-FD dummy is reduced by 75 percent,

\footnotetext{
${ }^{47}$ There could be a concern, of course, as to whether the left-hand side variable, volatility, is used to define VIX (so that we would be ultimately regressing a variable on itself!). However, according to the CBOE, VIX is supposed to be a measure of "investors' expectations about future stock market volatility", not of the current market volatility. Moreover, even if the expected future volatility is related to the current market volatility (e.g. if market volatility has a persistent component), the left-hand side is a measure of idiosyncratic volatility that is independent of market volatility. Thus, we interpret the VIX index as an appropriate control variable in regression (7).
} 
suggesting that a big part of what might be interpreted as an effect of the regulation is in fact related to an increase in expectations about future volatility of the market.

Differential effects of Reg FD on firm groups based on size are analyzed by breaking up the post-FD dummy in specifications II and IV. Without the inclusion of the VIX index, the coefficients on all post-FD dummies are positive, indicating that market reaction to earnings announcement consistently increases across all the groups. However, after controlling for VIX in specification IV, only mid-size and small firms have significant post-FD dummies. Moreover, in panel B of Table 7 we report results from running regressions separately for each group, and they indicate that only the group of small firms has a significant coefficient on the post-FD dummy. ${ }^{48}$

\section{The Cost of Capital}

The results presented in Section 3 suggest that the adoption of Reg FD caused changes in the way information is produced for groups of firms based on size. Small firms did not increase their use of voluntary disclosures after Reg FD - in stark contrast to mid-sized and big firms, which substantially increased the use of these disclosures- and they also face a decrease in analyst following in the post-FD period. Taking the use of pre-announcements as a proxy for the quality and quantity of public release of information by firms, public release of information (channel (1)) by small firms has not improved after Reg FD. Taking sell-side analyst activity as a proxy for information production by analysts, these results indicate that activity in channel (3) above has also worsened for small firms after Reg FD. If Reg FD shut down channel (2), and if informed trading (channel (4)) for small firms has not increased enough to compensate for the lower level of information production in other channels, then there would be an overall deterioration in the information environment for the group of small firms.

For mid-size firms, results regarding their information environment are ambiguous. They increase the use of voluntary disclosures (channel (1)), but still face a decrease in analyst following after Reg FD (channel (3)). Finally, the information environment for big firms seems to unambiguously improve: big firms make more use of voluntary disclosures and face an increase in analyst following after Reg FD.

\footnotetext{
${ }^{48}$ The evidence of an increase in the market response to earnings announcements - at least for small firms contrasts with some other results in the Reg FD literature. Shane, Soderstrom and Yoon (2001), Heflin, Subramanyan and Zhang (2001), Eleswarapu, Thompson and Venkataraman (2002), Bailey, Li, Mao and Zhong (2003), find no significant evidence of increase, and sometimes evidence of a significance decrease, in market reactions to earnings announcements. However, none of these references investigate the possibility of cross-sectional differences on market reactions to earnings announcements based on firm size.
} 
Evidence of changes in the information environment of groups of firms is reinforced by the results in this section that some market variables behave as if less information is being produced about small firms. Forecast errors about earnings announcements, a proxy for overall market lack of knowledge about firms' future prospects, seem to increase after Reg FD is adopted, and this is also reflected in a larger market response to earnings announcement news. On the other hand, forecast errors seem to decrease for big firms post-FD, and there is no significant change in the market response to earnings announcements. For mid-size firms, the ambiguity of what happens in the information environment is also translated in terms of market variable effects: while forecast error significant decreases post-FD, market response at earnings announcement seems to increase, although not significantly.

We now turn to the question of whether the changes in the information environment of small firms materialize as a risk factor, that is, whether they are priced in the cost of capital of those firms. The motivation for linking the quality of information environment to cost of capital comes from an extensive literature. In an asset pricing model developed in Easley and O'Hara (2003), linkage between a firm's information environment and its cost of capital is caused by investors demanding a higher return to hold stocks with more private than public information (and, in general, demand lower returns when more public and private information is produced). In particular, the authors argue that, as a recipe to reduce its cost of capital, firms can adapt their corporate disclosure policies, e.g. releasing more public information or attracting an active analyst following.

In another stream of this literature, improved disclosure might play a role in reducing information asymmetries among informed and uninformed investors, so that investors are more confident that the stock will be traded at a 'fair price', thus reducing liquidity risk (see, e.g., Diamond and Verrecchia (1991) and Kim and Verrecchia (1994)). Assuming liquidity risk as a sizable component of the firm's cost of capital, improved disclosure can lead to a lower cost of capital. More directly, Diamond (1985) argues that firms have incentives to make information available to shareholders in order to reduce the costs of private information acquisition, and Barry and Brown (1984) propose the existence of an "information risk" in that securities with less information available will be deemed riskier because investors will face more uncertainty regarding their future payoffs.

From an empirical standpoint, there are many studies that investigate the relationship between disclosure of information and the firm's cost of capital. Leuz and Verrecchia (2000) find evidence that increased levels of disclosure lowers the information asymmetry's component of the cost of capital. Likewise, Botosan (1997) and Botosan and Plumlee (2000) find evidence that 
increased disclosure is associated with a lower cost of capital, and Sengupta (1998) provides evidence that firms with high disclosure quality ratings from financial analysts are rewarded with a lower cost of issuing debt.

To investigate whether and how the cost of capital of small firms relates to the adoption of Reg FD, we adopt the Fama-French three-factor framework. Given that the evaluation of the cost of capital for individual firms can lead to very imprecise measures (see Fama and French (1997)), we opt to analyze the cost of capital for each portfolio based on firm size.

Table 8 presents the results of estimating Fama-French three-factor regressions for monthly returns on the value-weighted size-based portfolios during the period 1997:2002. Specification I reproduces the basic Fama-French regressions, while specifications II through IV include some additional variables in order to examine potential effects of Reg FD. A POSTFD dummy allows us to investigate shifts in the cost of capital unrelated to the three risk factors in the Fama-French model. Given that the portfolios are constructed based on the size characteristic, we also interact POSTFD with the SMB factor to investigate whether there are changes in cost of capital related specifically to the loading on SMB - the factor intended to capture firm size differences. $^{49}$

The results indicate no evidence of changes in cost of capital that are unrelated to the Fama-French risk factors: the coefficients on POSTFD are insignificant in all specifications. However, the coefficient on the interacted variable POSTFD_SMB shows changes in the cost of capital formation in the period post-FD. This coefficient is significantly positive for the portfolios of mid-sized and small firms, whether it is modeled together with POSTFD or not, while it is negative for the portfolio of big firms (although not significantly so).

The results suggest a significant increase in the loading of the SMB risk factor for the period in which Reg FD is operating: for the group of small (mid-size) firms the coefficients indicate that the SMB loading pre-FD is $0.46(0.47)$, while the same loading post-FD is 1.18 (0.96). Taking the three-factor model as a valid specification model for the riskiness of a portfolio and assuming the same pattern of the risk factors before and after Reg FD, the results here indicate a significant increase in the unconditional cost of capital for the portfolio of small and mid-size firms after Reg FD is adopted. SMB is the difference between average return on

\footnotetext{
${ }^{49}$ Fama and French (1993) showed that, beyond the CAPM market risk factor, two other factors are important in explaining the cross-sectional variation in equity returns: one is related to book-to-market (HML) and another is related to size (SMB). SMB ("Small Minus Big") is the monthly difference between returns on small- and big-stock portfolios, thus is "meant to mimic the risk factor in returns related to size"
} 
portfolios of small stocks and average return on portfolios on big stocks. Our POSTFD_SMB for small stocks is 0.71 . Thus, the effect is $0.71 *$ (expected SMB). The average SMB over the sample is 0.16 (sixteen basis points), meaning that the effect would be 11 basis points per months, or 138 basis points per year.

A caveat to this inference is that these results might be driven by the way the portfolio of small firms is formed. In particular, in the Appendix we show that this portfolio has a small decrease in average market value through time, so it is reasonable to expect that the loadings on the size risk might change as well through time - although the magnitude of changes in risk loading does not seem to conform to the small changes in average market value of the portfolio. Instead of trying to correct the Fama-French regression for this change in size, we take a different approach to check the robustness of the results in Table 8. For this analysis, we repeat the FamaFrench three-factor regressions with the addition of the POSTFD_SMB variable for the 25 portfolios formed on size and book-to-market from Fama and French (1993). Since these portfolios are also formed based on the size dimension, we are able to investigate the effects of Reg FD period on portfolios of small firms without depending on the details on how our portfolios were constructed. The results are reported in Table 9.

As a check on how well our size-based portfolios in reality proxy for Fama-French portfolios' returns, we present in Panel C of Table 9 the correlation between monthly returns of our portfolios and monthly returns of Fama-French portfolios. The correlation between our portfolio of small firms and Fama-French small portfolios reaches 0.93 and decreases as FamaFrench portfolios increase in size. The results suggest that our portfolios represent well the FamaFrench portfolios across size. Similarly, the correlation between our portfolio of mid-size firms and the Fama-French portfolios peaks at the second and third quintile, and our portfolio of big firms indeed mirrors the Fama-French big portfolios. ${ }^{50}$

Panel A of Table 9 reports the Fama-French regressions for the period between 1997 and 2002 , in which our portfolio of small firms is defined. We observe that the t-statistics for the POSTFD_SMB are positive for all portfolios in the first three size quintiles, above one for 14 out of 15 portfolios, significantly positive at the 5 percent level in eight out of 15 portfolios, and significantly positive at the 5 percent for all portfolios in the second quintile. As a final

(Fama and French (1993, p. 9)). See Fama and French (1993) for a detailed description of these factors as well as how to construct them.

${ }^{50}$ Our portfolio of small firms very closely matches Fama-French portfolios at the fifth quintile. The average size of our portfolio through time is 0.66 million while the average size of the Fama-French fifth quintile is 0.69 million (although, as discussed in the Appendix, the Fama-French portfolio formation procedure allows firms to switch portfolios every month). 
robustness check, we run the Fama-French regressions extending the pre-FD period to July 1963. Results reported in Panel B of Table 9 indicate that, even with this long specification, we still observe the POSTFD_SMB as significantly increasing post-FD for all portfolios in the second quintile.

\section{Understanding the Factors behind Reg FD Effects}

The cross-sectional differences reported so far are based on the size dimension. The relationship is expected given that, as we argued before, size is an important determinant of a firm's information environment. In this section, we explore other firm characteristics besides firm size that might contribute to cross-sectional variation in the information environment preand post-Reg FD. This analysis allows us to better understand how information is transmitted and incorporated into asset prices, and also serves as additional robustness test of the empirical methodology used throughout the paper.

We first test whether our small-firm effect is related to the investor recognition hypothesis. There was a reallocation of analysts from small to large stocks and as a consequence many small stocks completely lost analyst coverage. We analyze whether the loss of investor recognition is the factor behind the increase in the cost of capital for small stocks. Second, we predict that the "complexity" of the information communicated by the firm leads to changes in outcomes before and after the rule change. The rationale for this prediction is that more complex information can be better communicated in private one-on-one meetings. Third, we test whether firms with more severe management-shareholder agency problems are more affected by the policy change. Possibly managers of firms with more severe agency problems are more likely to treat information as a commodity and selectively disclose it in exchange for private benefits. Finally, we investigate whether firms in "high litigation" industries experience the most deterioration in the information environment and, in particular, whether the small-firm effect is related to this litigation risk.

\section{A. Investor Recognition Hypothesis}

Our results so far show that the rule change had a particularly adverse effect on small firms. The analysis indicates that the loss of channel (2) - selective disclosure - was associated with a loss of analyst coverage (channel (3)), no significant increases in the amount of public voluntary disclosures (channel (1)), and a resulting increase in the cost of capital for small firms.

In this subsection we explore whether the investor recognition hypothesis can explain our small-firm effect. Merton (1987) developed an asset pricing model in which investors are not 
aware of the existence of some assets, and he showed that firms with a smaller investor base have lower values (and higher costs of capital). The investor recognition hypothesis has received substantial empirical support and has been extended in many directions. ${ }^{51}$

The passage of Reg FD was an exogenous shock that provoked a change in analyst coverage leading to a reallocation of analyst following from small to large stocks. Goshen and Parshomovsky (2001) argue that small firms may need selective disclosure of information to maintain and/or attract analyst following because the "cost of gathering and processing information to the market does not guarantee any individual analyst a sufficient return to justify the coverage...For small companies whose shares are traded with low liquidity the exclusivity generated by selective disclosure is analogous to that created by patent or copyright protection. In all cases, the loss associated with the grant of temporary exclusivity is presumably outweighed by the ensuing long-term benefits" (p. 1268). In this view, while large firms may respond well to the loss of selective disclosure, because the private gains to produce information are sufficient to compensate the costs, it may be difficult for small firms, without being able to enhance private gains by means of selective disclosure, to attract analyst coverage. ${ }^{52}$

As result of this reallocation, many small stocks lost analyst coverage, and thus are likely to also have lost recognition among investors. We test whether changes in the cost of capital of firms losing all analyst coverage are consistent with the predictions of the investor recognition hypothesis. Moreover, we hypothesize that the group of small firms with no analyst following pre-Reg FD should not be affected by the adoption of Reg FD because they did not have any analysts benefiting from selective disclosure to start with. Thus, the subgroup of firms with no coverage is a control group against which to make comparisons. This control group is also useful because it helps to separate the effect of the regulation from other concomitant and unrelated changes over the sample period.

Thus, to empirically evaluate the hypothesis we divide our sample of small firms into further groups: those that had no analyst following before Reg FD and those that had at least one analyst covering before. This division only makes sense for the group of small firms because a large majority of mid-size and big firms have analyst coverage (see Figure 2). The results are reported in Table 10. The results in the table show that there is no increase in the cost of capital

\footnotetext{
${ }^{51}$ Empirical papers are numerous, including Kadlec and McConnell (1994), Foerster and Karolyi (1999), and more recently Kaniel et al. (2003). Theoretical developments include Basak and Cuoco (1998) and Shapiro (2002).
} 
for the group with no analyst coverage before Reg FD (the POSTFD_SMB dummy is not significantly different from zero). The cost of capital increases significantly only when we look at the groups of small firms with some analyst coverage before the rule change. Notice that we break the sample of firms with some analyst covering before between those who completely lost coverage and those who lost coverage but not completely. This allows us to isolate a subgroup that had some coverage before and with very comparable sizes pre- and post-FD. The results indicate that the loading on the size factor increases for both subgroups (the POSTFD_SMB dummy is 0.58 and 0.77 , both significant at 5 percent). ${ }^{53}$

\section{B. Information Complexity}

Another firm characteristic that may exhibit differences in outcomes before and after the policy change is the "complexity" of the information communicated to the market by the firm. Other things equal, a more complex information environment surrounding a firm (e.g. firms with high intangibles, complex business models, or opaque growth opportunities) would lead to more information asymmetry between informed and uninformed investors and, in general, to more uncertainty about the firm's value.

There are both empirical and theoretical reasons to believe that more complex information can be better communicated in private one-on-one meetings than publicly before a large audience. Bushee et al. (2003) empirically find that firms with more complex information (as proxied for by the level of intangible assets) were more likely in the pre-FD period to use closed conference calls to disseminate information (i.e., calls that restrict access to invited professionals, typically buy- and sell-side analysts). And, as mentioned in the Introduction, Aumann and Hart (2003) provide a theoretical demonstration that information can be better communicated by a long conversation than by a single message. These results lead us to predict that firms with more complex information to transmit are more likely to be affected by the Reg FD policy change.

\footnotetext{
${ }^{52}$ A related point is raised by King et al. (1990) who predict that disclosure increases with firm size because incentives for private information acquisition are greater as a result of higher profits to trading on private information.

53 The way the subgroups are defined precludes us from analyzing effects on forecast error and volatility for some of the subgroups. For the first (second) subgroup, forecast error is not defined in any of the preFD (post-FD) observations, therefore precluding us of running a panel data on forecast error and volatility (given that we need the consensus forecast as an important explanatory variable). In results not reported, the regressions results on forecast error and volatility for the third group, "all other small firms", are similar to the results of running the regressions for all small firms.
} 
We hypothesize the following changes in the outcome variables before and after the policy change for groups of firms with different complexity. First, the change in analyst coverage is expected to be negatively related to measures of complexity. This is so because without selective disclosure analysts will face additional burdens in gathering and interpreting complex information without as much ability to engage in valuable one-on-one communication with managers. ${ }^{54}$ Second, the direction of the change in firms' voluntary public disclosures is less clear. On the one hand, the firm might want to disclose more information in order to resolve the asymmetries and uncertainty coming from its complex information environment--if this was happening pre-FD by direct contact between the firm and analysts, in order to compensate for the shut-down of this channel the firm would have to release more information publicly. But on the other hand, public communication may be an imperfect substitute for private communication of complex information as both theory indicates (e.g., Aumann and Hart (2003)) and also empirical evidence. E.g., Bushee et al. (2003) argue that firms with complex information are likely to “...prefer closed calls to ensure that information is filtered through more sophisticated sources, such as financial analysts, reducing the potential for misinterpretation and excess volatility" ( $p$. 155); they have evidence indicating that volatility increases when firms open access to conference calls to the public. Finally, changes in the other outcome variables are predicted to be positively related to complexity, to the extent that the substitution of private and public channels is imperfect. That is, we predict higher forecast errors, volatility, and cost of capital for firms with more complex information that were unable to substitute the private for the public channel.

Having argued that a firm's complexity works as a determinant of the change in firm's behavior around Reg FD, we now empirically explore this possibility by taking complexity as another dimension, subordinate to firm's size, when defining groups of firms. Firms are first sorted and divided into groups based on size; then each firm is classified into low or high complexity, relative to the median complexity inside the firm's size group. ${ }^{55}$ The six resulting groups (big, mid-size and small firms combined with low and high complexity) are then examined using the same multivariate regression setups from Table 2 through Table 7.

Table 11 presents the results of the estimation taking the presence of intangible assets (as a fraction of the firm's assets) as a proxy for complexity. ${ }^{56}$ To save space, the estimates of the

\footnotetext{
${ }^{54}$ Alternatively, though, private research could exploit that complexity increases information asymmetries and thus coverage could be more profitable and positively related to complexity.

${ }_{56}^{55}$ More details in the formation of the groups are in the Appendix.

${ }^{56} \mathrm{We}$ also used low versus high book-to-market as a proxy for complexity. The results are qualitatively the same. However, we decide to focus the results on intangibles as a proxy for complexity because book-tomarket is highly correlated with our first determinant of the partitioning of group, size.
} 
other explanatory variables are omitted from the table. First note that the results indicate that firms of the same size behave qualitatively as before, regardless of their complexity level: for example, big firms in both complexity subgroups enjoy an increase in analyst coverage and increase the use of pre-announcements; both subgroups of mid-size firms have analyst coverage decreased post-FD but increase the use of pre-announcements; and both subgroups of small firms have analyst coverage decreased post-FD and do not increase significantly the use of preannouncements.

However, within size groups, the differences in output variables among complexity groups are largely as predicted. First, changes in analyst following are as predicted: the subgroups of firms with high intangibles tend to suffer a significantly larger loss of analyst following than the subgroup of firm with low intangibles and similar size (the difference is significant for mid-size and small firms, but not significant for big firms). This difference is also economically significant (high-intangible and low-intangible small firms lost 21 percent and 11 percent of analyst coverage, and high-intangible and low-intangible mid-size firms lost 9 percent and 5 percent, respectively). Second, the changes in public voluntary disclosure are consistent with the view that the public channel is an imperfect substitute for private communications: there is no significant difference at the 5 percent level between the subgroups of high and low intangibles of same size with respect to the propensity to release pre-announcements. Finally, the differences in changes in forecast error, volatility and cost of capital among high- and lowintangibles are only significant for small firms: volatility increases significantly more for highintangibles than low-intangibles for small firms ( $p$-value $<.0001$ ), and the cost of capital for highintangibles small firms seem to have increased by more than low-intangibles firms (POSTFD_SMB coefficients are respectively 0.75 (p-value 0.02) and 0.65 (p-value 0.05)). Overall the results are consistent with the view that more complex small firms were more adversely affected by the policy change than less complex firms.

\section{Governance}

One of the goals of the SEC when adopting Reg FD was to curb managers from treating material information as a commodity by selectively disclosing it to analysts in exchange for private gains (e.g., allocations in hot IPOs) or slanted analysis (SEC (2000), Lowenstein (2004)). We investigate in this section whether firms with more severe management-shareholder agency problems were particularly affected by Reg FD--because perhaps managers of these firms were using more selective disclosure in order to extract private benefits. The hypothesis we test is whether firms with more significant agency problems experienced bigger changes in their information environment and asset prices after Reg FD. 
A widely held view in corporate finance is that agency problems are particularly severe when managers are entrenched and can resist hostile takeovers (Jensen and Ruback (1983), Shleifer and Vishny (1989)). Corporate governance provisions such as antitakeover charter and bylaw clauses are commonly used mechanisms to entrench management, ${ }^{57}$ and extensive empirical evidence links the use of these provisions with agency problems. For example, Borokhovich et al. (1997) and Bertrand and Mullainathan (1999) find that firms adopting antitakeover provisions and firms newly covered by state takeover laws increase CEO compensation. Garvey and Hanka (1999) found that the adoption of such state antitakeover laws led to reductions in leverage, and several event studies (e.g., Jarrell and Poulsen (1987) and Karpoff and Malatesta (1989)) indicate that antitakeover provisions reduce firm value.

To evaluate the cross-sectional variation in agency costs, we use the corporate governance provisions in firms' charters and bylaws and state takeover laws, as proxies for the degree of agency costs. The data on the corporate governance provisions for each individual firms is from the Investor Responsibility Research Center (IRRC), and we follow the approach used in Gompers et al. (2003) to compute for each firm a governance index ( $\mathrm{G}$ index). We use all IRRC observations from 1993 to 2000 to compute the average $G$ for each firm, and then use this average $\mathrm{G}$ to partition the sample of big firms according to their governance structures. Firms with good governance (democracies) are defined as the ones with average $\mathrm{G}$ in the lower quintile of the distribution, while firms with bad governance (dictatorships) are the ones in the upper quintile of the distribution. Unfortunately, the partition based on $\mathrm{G}$ cannot be carried out for the group of mid-size and small firms, as $\mathrm{G}$ is defined primarily for big firms: while the fraction of big firms without $\mathrm{G}$ is only 15 percent, for mid-size and small firms this fraction jumps up to 65 percent and 90 percent, respectively.

Table 12 reports the results based on breaking up the sample into high and low G (again we only report the post-FD dummies for both groups). Analyst following exhibits a significantly higher increase in the good vs. the bad governance group. This result is consistent with the view that bad governance firms became less attractive to analysts relative to the good governance firms, because perhaps now they cannot be spoon fed anymore to the same extent. However, we find that there is no significant difference between the two groups in all other measures that we follow such as pre-announcement, forecast error, volatility, and cost of capital. In summary, the

\footnotetext{
${ }^{57}$ Examples of antitakeover provisions are the prohibition of shareholder voting by written consent or calling of special meetings, classified board, supermajority requirements to approve mergers, and adoption of poison pills (see Daines and Klausner (2001) and Gompers et al. (2003)).
} 
analysis suggests that overall the flow of information and asset prices did not change in any significantly different way between firms with good and bad governance.

\section{Litigation Risk}

The risk of shareholders lawsuits is an important factor that firms take into account when deciding whether or not to disclose information and, if they choose to disclose, which channel to use. The relationship between disclosure decisions and litigation risks is illustrated by Johnson et al. (2001) who find that after congress revised the federal securities law, enacting the Private Securities Litigation Reform Act of 1995 (this legislation was intended to reduce abusive class action securities lawsuits), firms increased the frequency of earnings and sales forecasts. There is, however, no consensus in the literature as to whether disclosure deters or triggers litigation (see, e.g., Kasznik and Lev (1995)). Voluntary disclosure of information, especially of material bad news, can potentially reduce expected litigation cost as shown by Skinner (1994). On the other hand, voluntary disclosure of information can also increase expected litigation costs by imposing a duty to update the information and increasing the risk of making selective disclosures of material information. For example, Francis et al. (1994) find that firms that issued earnings warnings were actually more likely to be sued by shareholders.

Our goal in this section is to investigate whether Reg FD has had any differential impact on the level of information produced by firms with ex-ante different exposures to litigation risk. In particular, we also want to understand whether the adverse impact on small firms is associated with litigation risks. In light of the complex relationship between litigation costs and disclosure of information, there is no clear prediction about how the imposition of Reg FD affected firms facing different litigation risks. Public announcements may create higher legal liability costs than private communication because the latter is off-the-record, and it may be harder for shareholders to file lawsuits on the basis of a duty to update information. This view would suggest that less information would be produced by high litigation firms after Reg FD. The concern that legal liability could create a chilling effect under Reg FD influenced the SEC in the original drafting of the regulation. ${ }^{58}$ But Frankel et al. (2003) find that after Reg FD there was a substantial increase in the number of firms adopting a "quiet period" in order to reduce the legal risks associated with selective disclosures, and this increase was particularly pronounced among firms with high

\footnotetext{
${ }^{58}$ The SEC attempted to mitigate legal liability concerns by drafting the rule so that failure to make a public disclosure required by Reg FD: (1) is not a breach of the anti-fraud provision of Rule 10b-5 (so there is no private right of action for violations of Reg FD); (2) has no effect on a company's eligibility to use short-from registration under the Securities Act; (3) has no effect on whether a company is in compliance with the current public information requirements of Rule 144; and (4) does not result in a loss of the
} 
litigation risks. ${ }^{59}$ This evidence suggests that it is possible that high litigation risk firms were exante already more concerned about the risks of disseminating information privately--selective disclosure of material information can provide an additional motive for shareholders facing trading losses to file lawsuits. This counterintuitive reasoning implies that high litigation firms were actually less impacted in terms of the amount of information that is produced than low litigation risk firms.

Francis et al. (1994) find that biotechnology, computers, electronics, and retailing are the industries with a higher incidence of litigation. Therefore, similarly to Frankel et al. (2003), we consider firms in these industries as having ex-ante higher litigation risk. Table 13 reports the results of the estimation taking litigation risk into account (again we just report variables related to the change post Reg FD). The first key finding of the analysis is that litigation risk does not seem to explain why small firms were adversely impacted by the rule change; small firms in both high and low litigation risk categories seem to have been equally negatively affected. Interestingly, mid-size and big firms in the high litigation risk category seem to have increased their analyst following and increased the use of pre-announcements by more than firms of the same size and but in the low litigation risk category. This evidence is not consistent with the view that Reg FD had a chilling effect on high litigation risk firms. The evidence seems more consistent with the view that high litigation firms were less exposed to the change in legislation, presumably because they made less use of selective disclosure beforehand. This puzzling finding is an interesting issue for future research to explore.

\section{Robustness Checks and Other Issues}

In this section we briefly report on some results that take into account the onset of recession. Also, we summarize results on the use of conference calls by firms, another way to publicly disclose information. Finally, we report on the effects of Reg FD on American Depository Receipts (ADRs) and foreign common stock.

availability of the "safe harbor" protections under the Private Litigation Reform Act of 1995. The SEC enforces Reg FD through administrative actions.

${ }^{59}$ The term "quiet period" refers to the period that begins when a company files a registration statement with the SEC and lasts until the SEC's staff has declared the registration statement "effective." During this period, the federal securities laws limit what information a company and related parties can release to the public. There is no required quiet period before a company announces its quarterly or year-end financial results, but firms may voluntarily adopt such quiet periods. 


\section{A. The 2001 Recession}

The post- Reg FD period coincides with the business cycle downturn in early 2001. The business cycle downturn might play a role in the analyst coverage scenario. If a general recession also means recession in the sell-side industry, then the downturn in early 2001 could have caused the reduction in the supply of analysts. This could mean an overall reduction in the coverage of firms in the market. ${ }^{60}$ However, what we see in the post-FD period is that only mid-size and small firms suffer this reduction in coverage, while big firms actually enjoy an increase in coverage. Even this pattern could be related to the business cycle if a reduced supply of analysts is consistently linked to a reshuffling of coverage between firms of different sizes. ${ }^{61}$ To control for this we reran the multivariate regressions on analyst following including a recession dummy ${ }^{62}$ - for the quarters classified by NBER as recessions (2001:2 through 2001:4) - interacted with the post-FD dummies for each group (i.e. allowing for the computation of two post-FD coefficients for each group, one related to the recession quarters and another related to the non-recession quarters) and the results presented before do not change qualitatively.

\section{B. Conference Calls}

Conference calls are another important method used by firms to voluntarily disclose information (alongside earnings pre-announcements which we analyzed before). Former SEC Chairman Arthur Levitt explicitly noted that closed conference calls (those where only invited investors have access) put the general public at a competitive disadvantage. However, advances in information technology now allow firms to "webcast" conference calls via the internet at low cost, disseminating the information promptly to all investors. Curbing the widespread use of

\footnotetext{
${ }^{60}$ If this is the case, the recession effect is likely to be captured in a panel data design because the recession would also affect the explanatory variables.

${ }^{61}$ This hypothesis is tested by Gorton and Madureira (2004).

${ }^{62}$ The period in which Reg FD operates also coincides with some other important exogenous shocks that might, as well, have influenced the market variables we examine in this paper, namely, the emergence of accounting scandals (starting with the Enron debacle in late 2001) and the attempts to regulate the security analysts (such as the National Association of Security Dealers and New York Stock Exchange new regulations on the security industry put into effect starting in the Summer of 2002 and the Global Settlement in May 2003). Regarding accounting scandals, the oversight of corporate governance issues by the media and regulators is likely to affect the way information is disseminated about a firm, both from the sell-side industry and from the firm standpoints, although it is not quite clear how the effects would be felt. Anyway, assuming that these effects would be felt starting in late 2001, the patterns of reshuffle in analyst coverage and changes in the use of pre-announcements would be robust to the presence (and effects) of the accounting scandals. The increasing oversight of the securities industry and the resulting legislation specifically aimed at it are also likely to be strong determinants of changes in the way the industry operates. However, if these changes were not anticipated well ahead in time, this does not seem to pose a problem to our research given that only our last two quarters coincides with the NASD and NYSE changes - and the results are robust to eliminating these two quarters.
} 
closed conference calls and enhancing the use open-access conference calls were an important motivation behind the adoption of Reg FD.

In order to have a more complete picture of how the information environment changed around Reg FD, it is also important to examine changes regarding the use of conference calls (see Bushee et al. (2003) for an in-depth analysis of this issue). Figure 4 shows a plot of the quarterly fraction of firms within each size group that use conference calls around earnings announcements. The figure displays a pattern of sharp increase in the use of conference calls, but there are no cross-sectional differences between groups based on size: big, mid-size and small firms all present a pattern of increasing the use of conference calls. More importantly, the increase seems to have no relation to the timing of the adoption of Reg FD; it starts well before the beginning of the discussion on Reg FD - actually, starting in the beginning of our sample - and continues steadily through time. By the time Reg FD was proposed, around 70 percent of big firms were already using quarterly conference calls. While a multivariate regression would indicate a significant post-FD dummy for the use of conference calls, the pattern in Figure 4 does not lend much credibility to the view that this increase is related solely to the adoption of the regulation.

\section{American Depository Receipts (ADRs) and Foreign Common Stocks}

U.S. listed ADRs and foreign common stock (foreign private issuers) are exempted from Reg FD. These exempted firms have no compelling legal reason to change their behavior due to the new regulation, and thus might provide a natural control sample. However, as suggested in the SEC comments about Reg FD, foreign issuers were also expected to follow the practices of U.S. companies subject to the legislation because the SEC is seriously investigating extending the regulation to foreign issuers or simply because of herd behavior. ${ }^{63}$ Moreover, companies incorporated outside US are also subject to their own home country legislation, and some countries already have regulations that mirror, to some extent, the goals of Reg FD - e.g. United Kingdom and Canada - making it difficult to isolate a sample of firms that are really free from the requirements of Reg FD. These considerations cast doubt on the idea that foreign private issuers constitute a good control sample.

\footnotetext{
${ }^{63}$ Celanese AG, a company incorporated in Germany and trading at NYSE, illustrates the case. Although exempted from Reg FD, it professes on its web page that: "Fair Disclosure: The Board of Management and the Company's employees, as a matter of Company policy, are required to comply with all legal requirements concerning disclosure of information. This not only includes compliance with applicable German law, but also with various SEC and NYSE rules and regulations such as those concerning selective disclosure and insider trading." (see http:/www.celanese.com/ print/index/about_index/governance/governance_guideline/governance_guidelinedisclosure.htm). Herd behavior may be rational if the markets penalize companies not acting according to Reg FD requirements.
} 
To evaluate the impact of Reg FD on U.S. listed ADRs and foreign common stocks, we repeat the regressions in Table 2 through Table 7 after adding two new groups: one for ADRs and another for foreign common stocks. The results (not reported here; available upon request) do not contribute to disentangling Reg FD effects from other possible intervening events. Overall, foreign firms and ADRs behave according to their size: foreign firms, which on average are big firms, increase analyst following and increase their use of pre-announcements post-FD, like big US firms. ADRs, which on average are smaller in size, resemble the behavior of small U.S. firms; they do not increase analyst following and the use of pre-announcements marginally decreases.

\section{Discussion}

Efficient securities markets depend on the flow of information. There are different channels through which information can be transmitted from firms to market participants. Regulation Fair Disclosure closed one of these channels (labeled channel (2) above): firms are no longer permitted to selectively disclose information to some market participants, but not others. For the information previously transmitted via this channel to still be transmitted in the post-Reg FD period, it must be transmitted by some other channel: by public disclosure (channel (1)); through information production and public release by sell-side analysts (channel (3)); or by private information production (channel (4)). Our analysis has focused on whether the remaining three channels are sufficient to provide the same information post-Reg FD as pre-Reg FD.

We found that small firms were adversely affected by Reg FD; their cost of capital rose. This finding is reminiscent of the "small-firm effect," which was first documented by Banz (1981) and Reinganum (1981). They found that risk-adjusted returns to stocks with relatively low equity capitalization were significantly positive, on average. This was viewed as an anomaly. But, subsequent to its discovery it has been reported to have largely disappeared; that is, the differential risk premium for small firms has been much smaller since 1982 than it was during the period 1926-1982. See Schwert (2003) for a review. Our finding of the return of a small firm effect suggests a reason for the original finding, namely, there was a lack of information, perhaps a certain kind of information about small firms. Schwert (2003) suggests that this information was subsequently forthcoming because investors responded to the academic studies. But that was prior to Reg FD.

Our investigation allows us to say more about the information at the root of the "small firm effect." We can draw inferences about how the forms of communication outlined above differ by their costs, and hence by the complexity of the information that can be communicated. If there is no difference between what is communicated via channels (1) and (2), other than who is 
told first, then under Reg FD firms would simply announce everything publicly that previously was communicated via selective disclosure. Otherwise, channels (3) and (4) could take over. But, for small firms, this is not what happened. Some small firms just completely stopped being followed by analysts, and consistent with the investor recognition hypothesis, the cost of capital increased for those firms. Moreover, public communication does not seem to be a good substitute for private one-on-one communication, where there is a free give and take, especially for firm communicating complex information, consistent with ideas in Aumann and Hart (2003) - the increase in cost of capital was more pronounced for firms communicating complex information. Overall, our results suggest that Reg FD had unintended consequences and that "information" in financial markets may be more complicated than current finance theory admits. 


\section{Appendix: Data Description}

\section{Data Sources and Data Requirements}

We use the First Call Historic Database to collect data on analyst following and forecasts, actual earnings announcements and pre-announcements. Data on prices, returns and shares outstanding come from the CRSP database and are complemented with some additional information on firm characteristics from COMPUSTAT.

We study firm-quarter data points. Our sample consists of all firms on the NYSE and NASDAQ (common stocks; share code 10 or 11), ADRs (share code 30, 31 or 32) and foreign stocks (share code 12) that are in the CRSP database at any point between 1997 and 2003. For each of these firms, we collect all quarterly earnings announcement data from Q4:1997 to Q3:2002 that are in the pre-FD and post-FD subsamples as defined below. ${ }^{64} \mathrm{We}$ then complement our data with security returns and prices from CRSP and additional firm characteristics from COMPUSTAT.

Reg FD was formally proposed by SEC on December 20, 1999, was approved on August 10, 2000 and became effective on October 23, 2000. These are the relevant dates we use to establish our pre- and post-FD subsamples. A firm-quarter data point is considered post-FD when the observation refers to a quarter equal to or after Q4:2000 and whose earnings announcement day is after October 23,2000 , i.e. after the adoption of the rule. ${ }^{65}$

The definition of the pre-FD period is a more contentious one. Some studies have used the date of the adoption of the regulation as the milestone to define both post- and pre-FD periods. We opt instead to view the period between the date Reg FD was proposed and the date it was adopted as a transition period, in which it is especially difficult to predict the behavior of firms and markets in regard to the regulation. If the firms indeed changed their behavior as a result of the regulation, was it a sudden change that took place only after the final rule was in place, or was it a gradual one? Reg FD has attracted a lot of attention since it was proposed, and it is possible that firms would somehow prepare themselves for when the new rules would take

\footnotetext{
${ }^{64} \mathrm{We}$ use only the original reported earnings number, thus ignoring the presence of restated numbers.

${ }^{65}$ It is possible that for some of the observations classified as post-FD, the period in which the effects of Reg FD could be felt would in fact fall before the adoption of the rule. For example, if there is an observation with fiscal quarter at October 2000 and that releases its earnings on Nov 1, 2000, most of the period in which the production of information for that quarter would occur would fall before the limit date of October 23, 2000, but the observation would still be deemed as post-FD according to the classification procedure above. However, this does not seem to be a concern given that 87 percent of the firms in the Q4:2000 sample has fiscal calendar in December and that the median earnings announcement day for that quarter is January $31,2001$.
} 
place. In other words, given that the adoption of the rule was a completely anticipated event, treating observations during the transition period as functioning under pre-FD status can be misleading. On the other hand, we can not assume that the effects of Reg FD can be observed in the transition period: firms could as well simply keep on functioning under pre-FD rules (e.g., providing selective disclosure) up to the effective date of the regulation. Thus, we decide to drop the transition period and instead define the pre-FD period as the one before the date Reg FD was proposed: a firm-quarter data point is considered pre-FD when the observation refers to a quarter equal or before Q3:1999 and whose earnings announcement day is before December 20, 1999.

The post-FD sample contains data from 8 quarters, from Q4:2000 to Q3:2002. In order to use a pre-FD sample of comparable size, we define our pre-FD sample also with 8 quarters, from Q4:1997 to Q3:1999. Notice that by using 8-quarters subsamples, we guarantee that both subsamples have 2 of each calendar quarter (i.e. 2 first quarters, 2 second quarters etc). This can ameliorate effects of potential seasonal differences in measured variables across calendar and/or fiscal quarters. ${ }^{66}$

For a firm-quarter to be included in the sample, some conditions must hold. The usual availability restrictions apply regarding First Call, CRSP and COMPUSTAT databases. For example, when examining data on market returns we require that price and return data from CRSP be available for that firm-quarter. In particular, in order to use the market model to compute abnormal returns, we require that returns over the window [-200,-11] must also be available in CRSP.

The measurement of some variables can be conditioned on the contents of available data. For example, forecast error at earnings announcement can be properly defined only when we have data available for (besides the actual earnings number) at least one analyst's forecast for that quarter. Therefore, a legitimate firm-quarter observation - in terms of availability of data from CRSP, COMPUSTAT and First Call - can be deemed invalid to examine forecast error if the number of analysts posting forecasts for that quarter is zero. This firm-quarter observation will also be dropped from the sample if we use forecast error as a control variable to explain market response at earnings announcement. For this reason, sample sizes of different statistical tests will differ according to which specific variables these tests require.

Regarding earnings announcements, besides data on the current quarter being analyzed, we require that data on earnings announcements for the previous quarter must also be available in First Call. Moreover, since we try to measure conditions holding at the interval between

\footnotetext{
${ }^{66}$ For example, Mendenhall and Nichols (1988) report differences in market responses to bad news at earnings announcements when they are released in earlier quarters versus the firm's fiscal fourth quarter.
} 
consecutive earnings announcements, we drop from the sample observations in which this interval is smaller than 20 days. We also drop from the sample firm-quarters whose share price at the end of the quarter is below $\$ 1$.

Finally, to reduce the impact of outliers, all statistical tests that involve a variable that is subject to the presence of big outliers are preceded by a procedure to winsorize the variable. We winsorize data on earnings surprises and volatility.

\section{Subgroups Based on Firm Size}

As was discussed in the Introduction, in order to allow for the identification of crosssectional differences in the way Reg FD affected firms we analyze the effects of the regulation on groups that are defined based on firm's size. Each firm is allocated to one of three groups based on its average size through the complete sample 1997-2002. The group of small firms is formed by firms with average size below the 50th percentile of the distribution; the group of mid-size firms is formed by firms with average size between the 50th and the 80th percentiles and the group of big firms is formed by firms in the upper quintile of the distribution. Then the statistical tests can be run taking into consideration these groups; for example, regressions can be run separately for each group, allowing the relationship between the variables we ought to explain and Reg FD to take a piecewise linear form. ${ }^{67,68}$

Table 14 presents summary statistics on size for these 3 groups. Bigger firms are also older and more likely to belong to NYSE instead of NASDAQ, and Panel B indicates no clear industry clustering in the groups' samples. One concern is that this method can lead to patterns in the evolution of average size of each group through time. Certainly each firm's size fluctuates through time, but a general pattern of change in the size of firms can cause the average size of groups also to evolve through time; thus, some changes in market variables that are known to be correlated with size would be nothing more than adjustments to the changes through time in the average size of the components of each group. For example, if it is the case that small (big) firms are decreasing (increasing) in size in the post-FD period, due to the market crash of 2000, then

\footnotetext{
${ }^{67}$ Notice that we do not reallocate a firm to a different group each quarter; instead, a firm is classified as belonging to one and only one group throughout the whole sample. This is essential for our research design based on panel data, since we will use group membership as a company characteristic and thus as criteria to break up the sample: if a firm were allowed to change groups through time, we would not be able to use the fixed effects control in the regression specification, given that the same firm would show up in two different groups.

${ }^{68}$ As a robustness check, we repeat the univariate tests in Section 2 with a time-varying definition of group membership, by which a firm is allocated to a (possibly) different group each quarter, according to the
} 
the average size in the group of small (big) firms will be decreasing (increasing) through time, and a finding that analyst following for the group of big firms increase through time at the expense of the analyst following for the group of small firms would be a direct result of the way we partitioned our groups. Fortunately, the results in Table 14 suggest that the problem might not be severe: the average size of the components of each group seems stable through time, and the range of one standard deviation of size around the average measure suggests that the methodology does provide for good break points in firm size. More important, though, is that we still use firm size as a control variable when analyzing the evolution of market variables through time, therefore controlling for any size pattern that might take place inside each group in the time series dimension. ${ }^{69}$

percentile of that firm's size compared to the distribution of size among all firms on that quarter. The results (not reported) do not change qualitatively.

${ }^{69}$ That average size in the group of small (big) firms decreases (increases) through time can result simply from the sorting of the firms based on average size over the whole period: for example, a firm classified as small is more likely to have their size decreased -- than increased -- through time. As an alternative definition, we classify firms based on their average size pre-FD (except for firms entering the sample after Reg FD was adopted), and the results reported in this study to not change qualitatively. 


\section{References}

Agrawal, Anup and Sahiba Chadha (2002), "Who is Afraid of Reg. FD? The Behavior and Performance of Sell-Side Analysts Following the SEC's Fair Disclosure Rules," working paper.

Ajinkya, B. and M. Gift (1984), “Corporate Managers' Earnings Forecast and Symmetrical Adjustments of Market Expectations. Journal of Accounting Research 22, 425-444.

American Bar Association (2001), "FD Task Force Survey," retrieved from www.abanet.org/buslaw/fedsec.

Association for Investment Management and Research (2001), "Analysts, Portfolio Managers say Volume, Quality of information have fallen under Regulation FD AIMR member survey shows," http://www.aimr.org/pressroom/01 releases/regFD_survey.html.

Atiase, R. (1980), "Predisclosure Informational Asymmetries, Firm Capitalization, Financial Reports, and Security Price Behavior," PhD dissertation, University of California.

Atiase, R. (1985), "Predisclosure Information, Firm Capitalization, and Security Price Behavior around Earnings Announcements," Journal of Accounting Research, 21, 36.

Aumann, Robert and Sergiu Hart (2003), “Long Cheap Talk,” Econometrica 71, 1619-1660.

Bailey, Warren, Haitao Li, Connie X. Mao and Rui Zhong (2003), "Regulation FD and Market Behavior around Earnings Announcements: Is the Cure Worse than the Disease?," Journal of Finance, 2487-2514.

Banz, R.W. (1981), "The Relationship between Return and Market Value of Common Stocks," Journal of Financial Economics 9, 3-18.

Barry, C. and Stephen Brown (1984), "Differential Information and the Small Firm Effect," Journal of Financial Economics 13, 283-294.

Basak, Suleyman and D. Cuoco (1998), "An Equilibrium Model with Restricted Stock Market Participation", Review of Financial Studies 11, 309-341.

Bertrand, Marianne, and S. Mullainathan (1999), "Corporate Governance and Executive Pay: Evidence from Takeover Legislation," MIT Working Paper.

Bhushan, R. (1989a), "Collection of Information about Publicly Traded Firms: Theory and Evidence," Journal of Accounting and Economics 11, 183-206.

Bhushan, R. (1989b), "Firm Characteristics and Analyst Following," Journal of Accounting and Economics 11, 255-274.

Bhushan, R. (1989b), "Firm Characteristics and Analyst Following," Journal of Accounting and Economics 11, 255-274.

Bhushan, R. and P. O'Brien, P., R. (1990). "Analyst Following and Institutional Ownership," Journal of Accounting Research 28 (Supplement), 55-76. 
Borokhovich, Kenneth, K. Brunarski, and R. Parrino (1997), "CEO Contracting and Antitakeover Amendments," Journal of Finance 52, 1495-1518.

Botosan, C.A. (1997), "Disclosure Level and the Cost of Equity Capital," The Accounting Review 72, 323-349.

Botosan, C.A. and M.A. Plumlee (2000), “A Re-examination of Disclosure Level and Expected Cost of Capital. Working Paper, University of Utah.

Brennan, M and P. Hughes (1991), "Stock Prices and the Supply of Information," Journal of Finance 46, 1665-1691.

Brennan, M and A. Subrahmanyam. (1995), "Investment Analysts and Price Formation in Securities Markets," Journal of Financial Economics 38, 361-381.

Bricker, R., J. Grant, T. Fogarty and G. Previts (1999), "Determinants of Analyst Following," Journal of Corporate Communications 1 (1999), 1-29.

Brown, L. (2001), "A Temporal Analysis of Earnings Surprises: Profits versus Losses," Journal of Accounting Research 39 (2), 221-241.

Bushee, Brian L., D. Matsumoto, and G. Miller (2003), "Managerial and Investor Responses to Disclosure Regulation: The Case of Reg FD and Conference Calls," University of Pennsylvania, working paper.

Bushee, Brian L. and Christian Leuz (2003), "Economic Consequences of SEC Disclosure Regulation," University of Pennsylvania, working paper.

Chamberlain, G. (1980), “Analysis of Covariance with Qualitative Data," $\underline{\text { Studies }} 47,225-238$.

Christie, A. (1982), "The Stochastic Behavior of Common Stock Variances - Value, Leverage and Interest Rate Effects," Journal of Financial Economics 10, 407-432.

Chung, K. H. and H. Jo. (1996), “The Impact of Security Analysts' Monitoring and Marketing Functions on the Market Value of Firms," Journal of Financial and Quantitative Analysis 31, 493-512.

Coffee, John (2000), “Tackling New Regulation FD,” National Law Journal, September 18, 2000, p. B6.

Daines, Robert, and M. Klausner (2001), "Do IPO Charters Maximize Firm Value? Antitakeover Protection in IPOs," Journal of Law, Economics, and Organization 17, 83-120.

Diamond, D. (1985), "Optimal Release of Information by Firms," Journal of Finance 40, 10711094.

Diamond, D and R. Verrecchia (1991), "Disclosure, Liquidity, and the Cost of Capital," The Journal of Finance 66, 1325-1355. 
Easley, David and Maureen O'Hara (2004), “Information and cost of capital," Journal of Finance, forthcoming.

Eleswarapu, Venkat R, Rex Thompson, Rex and Kumar Venkataramn (2002), "Measuring the Fairness of Regulation Fair Disclosure through its Impact on Trading Costs and Information Asymmetry," Journal of Financial and Quantitative Analysis, forthcoming.

Fama, E. and K. French (1992), "The Cross Section of Expected Returns," Journal of Finance 47, no.2, 427-465.

Fama, E. and K. French (1993), "Common Risk Factors in the Returns of Stocks and Bonds," Journal of Financial Economics 33, 3-56.

Fama, E. and K. French (1997), "Industry Costs of Equity," Journal of Financial Economics 43, 153-193.

Foerster, Stephen and A. Karolyi (1999), "The Effect of Market Segmentation and Investor Recognition on Asset Prices: Evidence from Foreign Stock Listing in the U.S.," Journal of Finance 54, 981-1013.

Francis, J., D. Philbrick, and K. Schipper (1994), "Shareholder Litigation and Corporate Disclosures," Journal of Accounting Research 32, 137-164.

Frankel, Richard, Peter Joos, and Joseph Weber (2003), "Litigation Risk and Voluntary Disclosure: The Case of Pre-Earnings Announcement Quiet Periods," MIT, working paper.

Freeman, R. (1987), “The Association Between Accounting Earnings and Security Returns for Large and Small Firms," Journal of Accounting and Economics 9, no. 2 195-228.

Garvey, Gerald and G. Hanka (1999), "Capital Structure and Corporate Control: The Effect of Antitakeover Statutes on Firm Leverage,” Journal of Finance 54, 519-546.

Glaeser, Edward, Simon Johnson, and Andrei Shleifer (2001), "Coase versus the Coasians," Quarterly Journal of Economics 116, 401-425.

Gompers, Paul, J. Ishii, and A. Metrick (2003), "Corporate Governance and Equity Prices," Quarterly Journal of Economics 118, 107-155.

Goshen, Zohar and G. Parchomovsky (2001), "On Insider Trading, Markets, and "Negative Property Rights in Information,” Virginia Law Review 87, 1229-1277.

Greene, W. H. Econometric Analysis. 3d ed. 1997. Prentice Hall.

Greenstone, Michael, Paul Oyer, and Annette Vissing-Jorgensen (2003), "Mandated Disclosure, Stock Returns, and the 1964 Securities Acts Amendments," Kellogg School, Northwestern University, working paper.

Grossman, Sanford and Stiglitz, J. (1987), "On the Impossibility of Informationally Efficient Markets,” American Economic Review 70, 393-408 
Hayn, C. (1995), “The Information Content of Losses,” Journal of Accounting and Economics 20, 125-153.

Heflin, Frank; Subramanyam, K. R.; Zhang, Yuan (2001), "Stock Return Volatility Before and After Regulation FD," working paper,

Heflin, Frank, K. R. Subramanyam, K. R. and Yuan Zhang (2003), "Regulation FD and the Financial Information Environment," The Accounting Review 78, 1-37.

Hunt, Isaac (2000), Remarks given at the $26^{\text {th }}$ Annual Cleveland Securities Law Institute on Securities Regulation, Cleveland, Ohio (February 28, 2000); http//www.sec.gov/news/speeches/spch349.htm.

Irani, Afshad and Karamanou, I. (2002), "Regulation Fair Disclosure, Analyst Following and Analyst Forecast Dispersion," forthcoming Accounting Horizons.

Jarrell, Gregg and A. Poulsen (1987), "Shark Repellents and Stock Prices: The Effects of Antitakeover Amendments since 1980," Journal of Financial Economics 19, 127-168.

Jensen, Michael, and R. Ruback (1983), "The Market for Corporate Control: The Scientific Evidence," Journal of Financial Economics 11, 5-50.

Johnson, Marilyn, R. Kasznik, and K. Nelson (2001), "The Impact of Securities Litigation Reform on the Disclosure of Forward-Looking Information by High Technology Firms," Journal of Accounting Research 39, 297-327.

Jorion, Philippe, and Z. Liu and C. Shi (2003), "Informational Effects of Regulation FD: Evidence from Rating Agencies," working paper Univ. of California at Irvine.

Kadlec, Gregory and J. McConnell (1994), "The effect of market segmentation and illiquidity on asset prices: Evidence from exchange listings," Journal of Finance 49, 611-636.

Kaniel, Ron, D. Li and L. Starks (2003), "The investor Recognition Hypothesis: International Evidence and Determinants," working paper Duke University.

Karpoff, Jonathan and P. Malatesta (1989), "The Wealth Effects of Second-Generation State Takeover Legislation," Journal of Financial Economics 25, 291-322.

Kasznik, R. and B. Lev (1995), "To Warn or Not to Warn: Management Disclosures in the Face of Earnings Surprise," The Accounting Review 70, 113-134.

Kothari, S.P., T. Lys, C. Smith, and R. Watts (1988), "Auditor Liability and Information Disclosure," Journal of Accounting, Auditing, and Finance 3, 307-339.

Kim, O. and R. Verrecchia (1994), "Market Liquidity and Volume around Earnings Announcements," Journal of Accounting and Economics 17, 41-68.

King, R., G. Pownall and G. Waymire (1990), "Expectations Adjustments via Timely Management Forecasts: Review, Synthesis and Suggestions for Future Research," Journal of Accounting Literature 9, 113-144. 
Kothari, S. (2001), "Capital Markets Research in Accounting," Journal of Accounting and Economics, 105-231.

Lang, M and Russell Lundholm (1996), "Corporate Disclosure Policy and Analyst Behavior," The Accounting Review 71, no. 4, 467-492.

Lang, M and Russell Lundholm (1993), "Cross-sectional Determinants of Analyst Ratings of Corporate Disclosures," Journal of Accounting Research 31, no. 2, 246-271.

Leuz, C. and R. Verrecchia (2000), "The Economic Consequences of Increased Disclosure," Journal of Accounting Research 38, Supplement, 91-124.

Levitt, Arthur (1999), speech October 18, 1999, to the Economic Club of New York, "Quality Information: The Lifeblood of Our Markets," www.sec.gov/news/speech/speecharchive/1999/spch304.htm.

Levitt, Arthur (2002), Take on the Street (Pantheon Boos; New York).

Lipe, R., L. Bryant and S. Widener (1998), "Do Nonlinearity, Firm-specific Coefficients, and Losses Represent Distinct Factors in the Relation between Stock Returns and Accounting Earnings?," Journal of Accounting and Economics 25, 195-214.

Loss, Louis (1983), Fundamentals of Securities Regulation (Little Brown and Company; Boston).

Lowenstein, Roger (2004), Origins of the Crash (Penguin Press; New York).

Matsumoto, D. (2002), "Management's Incentives to Avoid Negative Earnings Surprises," Accounting Review 77, no. 3, 483-514.

Mendenhall, R. and W. Nichols (1988), "Bad News and Differential Market Reactions to Announcements of Earlier versus Fourth Quarter Earnings," Journal of Accounting Research 26 Supplement, 63-86.

Merton, Robert (1987), "A simple model of capital market equilibrium with incomplete information", Journal of Finance 42, 483-510.

Mohanram, Partha S. and Shyam Sunder (2001), "Has Regulation Fair Disclosure Affected Financial Analysts' Ability to Forecast Earnings?," New York University, working paper.

National Investor Relations Institute (2001), “Corporate Disclosure Practices Survey 2001," www.niri.org.

Reinganum, Mark (1981), "Misspecification of Capital Asset Pricing: Empirical Anomalies based on Earnings' Yields and Market Values," Journal of Financial Economics 9, 19-46.

Schwert, William (2003), "Anomalies and Market Efficiency," chapter 15 of Handbook of the Economics of Finance, edited by George Constantinides, Milton Harris, and Rene Stulz (North Holland; Amsterdam), 937-972.

Sengupta, Partha (1998), "Corporate Disclosure Quality and the Cost of Debt," The Accounting Review 73, 459-474. 
Shane, P, N. Soderstrom and S. Yoon (2001), "Earnings and Price Discovery in the post-Reg FD Information Environment: A Preliminary Analysis," University of Colorado, working paper.

Shapiro, Alexander (2002), "The investor recognition hypothesis in a dynamic general equilibrium: Theory and evidence," Review of Financial Studies 15, 97-147.

Shleifer, Andrei, and R. Vishny (1989), "Management Entrenchment: The Case of ManagerSpecific Investments," Journal of Financial Economics 25, 123-140.

Shores, D. (1980), "The Association between Interim Information and Security Returns Surrounding Earnings Announcements," Journal of Accounting Research 28, 164-181.

Skinner, D. (1994), "Why Firms Voluntarily Disclose Bad News", Journal of Accounting Research 32, no. 1, 38-60.

Skinner, D. (1997), "Earnings Disclosures and Stockholders Lawsuits," Journal of Accounting and Economics 23, 249-282.

Syre, Steven and Charles Stein (2001), "Boston Capital: After One Year, All's Fair in Disclosure," Boston Globe, October 21, 2001, p. F1.

Soffer, L., S. Ramu Thiagarajan and Beverly R. Walther (1998), "Earnings Preannouncements," Northwestern University, working paper.

Soffer, L., S. Ramu Thiagarajan and Beverly R. Walther (2000), "Earnings Preannouncement Strategies," Review of Accounting Studies 5, 5-26.

Straser, Verna (2002), "Regulation Fair Disclosure and Information Asymmetry," University of Notre Dame, working paper.

Tishbi, John (2002), "Regulation FD: The Year that Passed and the Years Ahead," Loyola of Los Angeles Law Review 35, 1131-1156.

Verrecchia, Robert (2001), "Essays on disclosure," Journal of Accounting and Economics 32, 97180.

United States Securities and Exchange Commission (2000), Final Rule: Selective Disclosure and Insider Trading, Exchange Act Release No. 33-7881 (Oct. 23, 2000), htt://www.sec.gov/rules/final/33-7881.htm.

Wu, G. (2001), “The Determinants of Asymmetric Volatility," Review of Financial Studies 14, 837-859. 
Table 1. Summary Statistics on Analyst Following

This table presents summary statistics on the measures of quarterly analyst following. Quarterly analyst following is proxied by two measures of number of forecasts outstanding for firm $i$ in quarter $q$. Number of forecasts is measured as the number of analyst forecasts outstanding for firm $i$ at the day the earnings for quarter $q$ are announced; the standardized number of forecasts is a standardized measure of analyst following, computed as number of forecasts for firm $i$ in quarter $q$ divided by the total number of forecasts available for all firms in quarter $q$ (the summation of number of forecasts across $i$ and keeping $q$ fixed). The standardized number of forecasts is presented in percentage terms, i.e. multiplied by 100. Details on the construction of subgroups of big, mid-size and small firms are described in the Appendix. Significance of change presents the p-values of two-tailed test of differences for mean (t-test) and median (Wilcoxon). The sample comprises observations in the periods Q4:1997-Q3:1999 (pre-FD sample) and Q4:2000-Q3:2002 (post-FD sample), except that observations with actual earnings announcements between 12/20/1999 and 10/23/2000 are excluded.

\begin{tabular}{|c|c|c|c|c|c|c|c|c|c|c|c|c|}
\hline & \multicolumn{3}{|c|}{ Pane A: All observations } & \multicolumn{9}{|c|}{ Panel B: Subgroups based on firm size } \\
\hline & \multirow[b]{2}{*}{ 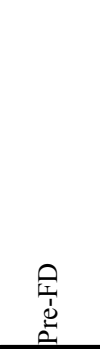 } & \multirow[b]{2}{*}{ 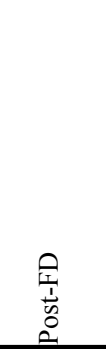 } & \multirow[b]{2}{*}{ 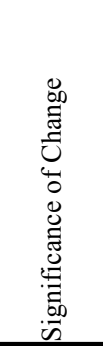 } & \multicolumn{3}{|c|}{ Big firms } & \multicolumn{3}{|c|}{ Mid-size firms } & \multicolumn{3}{|c|}{ Small firms } \\
\hline & & & & 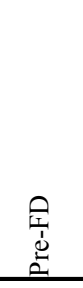 & 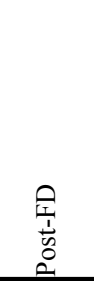 & 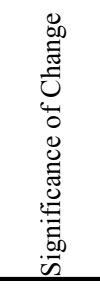 & 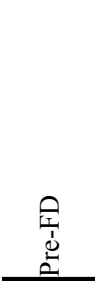 & 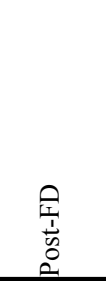 & 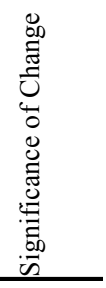 & 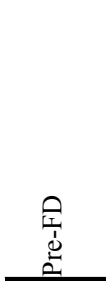 & 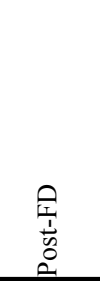 & 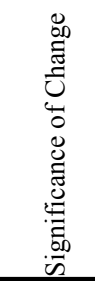 \\
\hline \multicolumn{13}{|l|}{ Number of forecasts } \\
\hline Mean & 4.4544 & 4.772 & $<.0001$ & 9.855 & 10.997 & $<.0001$ & 3.9813 & 4.1066 & 0.0071 & 1.3951 & 1.0031 & $<.0001$ \\
\hline Median & 3 & 3 & $<.0001$ & 9 & 10 & $<.0001$ & 3 & 3 & 0.0612 & 1 & 0 & $<.0001$ \\
\hline \multicolumn{13}{|l|}{ Standardized number of forecasts } \\
\hline Total number of firm-Quarters & 32450 & 30656 & & 8495 & 8257 & & 10598 & 10639 & & 13357 & 11760 & \\
\hline
\end{tabular}


Table 2. Panel Data Fixed Effects Regression to Explain Analyst Following

This table presents results of panel data fixed effects regression to explain quarterly analyst following. The dependent variables that proxy for analyst following are NOFOR $_{\mathrm{i}, \mathrm{q}}$ and NOFOR_STD $\mathrm{i}, \mathrm{q}$ : NOFOR $\mathrm{i,q}$ is the number of analyst forecasts outstanding for firm $i$ at the day the earnings for quarter $q$ are announced, while NOFOR_STD $\mathrm{S}_{\mathrm{i}, \mathrm{q}}$ is a standardized measure of analyst following, computed as $\mathrm{NOFOR}_{\mathrm{i}, \mathrm{q}}$ divided by of total number of forecasts available for all firms in quarter $q$ (the summation of NOFOR $\mathrm{R}_{\mathrm{i}, \mathrm{q}}$. across $i$ and keeping $q$ fixed). The explanatory variables are defined as follows. SIZE $_{\mathrm{i}, \mathrm{q}}$ is the log of market value of the firm at the last day of the month in which the earnings announcement is released, scaled by the market index. LOSS $_{\mathrm{i}, \mathrm{q}}$ is a dummy variable set to 1 when the actual earnings are negative. $\mathrm{ABSCAR}_{\mathrm{i}, \mathrm{q}}$ is the absolute value of the cumulative abnormal return for firm $i$ along quarter $q$. SIGNCAR $\mathrm{R}_{\mathrm{i}, \mathrm{q}}$ is a dummy set to 1 when the cumulative abnormal return for quarter $q$ is negative. The cumulative abnormal return for firm $i$ during quarter $q$ is the summation of market model's residuals from 3 days after the previous quarter's earnings announcement day up to 2 days before quarter $q$ 's earnings announcement day. $\operatorname{POSTFD}_{\mathrm{i}, \mathrm{q}}$ is a dummy set to 1 for a quarterly earnings release after the adoption of Reg FD, and 0 otherwise. POSTFD_Big $\mathrm{i}_{\mathrm{i}, \mathrm{q}}$, POSTFD_Mid $\mathrm{i}_{\mathrm{i}, \mathrm{q}}$ and POSTFD_Small $\mathrm{i}_{\mathrm{i}, \mathrm{q}}$ are the interactions of POSTFD $\mathrm{i}_{\mathrm{i}, \mathrm{q}}$ with dummies identifying whether the firm belongs, respectively, to the portfolio of big, mid-size or small firms. Details on the construction of portfolios of big, mid-size and small firms are described in Appendix. The p-values are shown below each coefficient estimate. ). The sample comprises observations in the periods Q4:1997-Q3:1999 (pre-FD sample) and Q4:2000-Q3:2002 (post-FD sample), except that observations with actual earnings announcements between 12/20/1999 and 10/23/2000 are excluded.

Panel A: Aggregating all data together

\begin{tabular}{|c|c|c|c|c|c|c|c|c|}
\hline & \multicolumn{4}{|c|}{ NOFOR } & \multicolumn{4}{|c|}{ NOFOR_STD } \\
\hline & \multicolumn{2}{|c|}{ All Data } & \multicolumn{2}{|c|}{ Balanced Panel } & \multicolumn{2}{|c|}{ All Data } & \multicolumn{2}{|c|}{ Balanced Panel } \\
\hline & I & II & III & IV & $\mathrm{V}$ & VI & VII & VIII \\
\hline \multirow[t]{2}{*}{ POSTFD } & 0.1186 & - & 0.1669 & - & 3.72E-06 & - & 4.46E-06 & - \\
\hline & $<.0001$ & $\frac{-}{08567}$ & $<.0001$ & $\frac{-}{07555}$ & $<.0001$ & $\frac{-}{400505}$ & 0.0007 & $\frac{-}{341 \mathrm{~F} 05}$ \\
\hline POSTFD_Big & - & $\begin{array}{l}0.8567 \\
<.0001 \\
\end{array}$ & $\begin{array}{l}- \\
- \\
\end{array}$ & $\begin{array}{l}0.7555 \\
<.0001 \\
\end{array}$ & - & $\begin{array}{c}\begin{array}{c}4.09 \mathrm{E}-05 \\
<.0001\end{array} \\
\end{array}$ & $\begin{array}{l}- \\
-\end{array}$ & $\begin{array}{c}3.41 \mathrm{E}-05 \\
<.0001\end{array}$ \\
\hline \multirow[t]{2}{*}{ POSTFD_Mid } & - & -0.1868 & - & -0.2720 & - & $-1.25 \mathrm{E}-05$ & - & $-1.82 \mathrm{E}-05$ \\
\hline & - & $<.0001$ & - & $<.0001$ & - & $<.0001$ & - & $<.0001$ \\
\hline \multirow[t]{2}{*}{ POSTFD_Small } & - & -0.2346 & - & -0.2414 & - & $-1.33 \mathrm{E}-05$ & - & $-1.49 \mathrm{E}-05$ \\
\hline & - & $<.0001$ & - & $<.0001$ & - & $<.0001$ & - & $<.0001$ \\
\hline \multirow[t]{2}{*}{ SIZE } & 1.3693 & 1.3330 & 1.6233 & 1.6080 & 7.72E-05 & $7.55 \mathrm{E}-05$ & $9.14 \mathrm{E}-05$ & $9.06 \mathrm{E}-05$ \\
\hline & $<.0001$ & $<.0001$ & $<.0001$ & $<.0001$ & $<.0001$ & $<.0001$ & $<.0001$ & $<.0001$ \\
\hline \multirow[t]{2}{*}{ LOSS } & 0.0512 & 0.0543 & 0.1042 & 0.1209 & 2.22E-06 & $2.39 \mathrm{E}-06$ & 4.60E-06 & $5.47 \mathrm{E}-06$ \\
\hline & 0.0370 & 0.0258 & 0.0232 & 0.0079 & 0.0975 & 0.0721 & 0.0649 & 0.0273 \\
\hline \multirow[t]{2}{*}{ ABSCAR } & 0.1954 & 0.1893 & 0.4042 & 0.4005 & 8.47E-06 & $8.17 \mathrm{E}-06$ & $1.79 \mathrm{E}-05$ & $1.77 \mathrm{E}-05$ \\
\hline & $<.0001$ & $<.0001$ & $<.0001$ & $<.0001$ & $<.0001$ & $<.0001$ & $<.0001$ & $<.0001$ \\
\hline \multirow[t]{2}{*}{ SIGNCAR } & 0.3465 & 0.3410 & 0.3746 & 0.3711 & $1.89 \mathrm{E}-05$ & $1.87 \mathrm{E}-05$ & $1.98 \mathrm{E}-05$ & $1.97 \mathrm{E}-05$ \\
\hline & $<.0001$ & $<.0001$ & $<.0001$ & $<.0001$ & $<.0001$ & $<.0001$ & $<.0001$ & $<.0001$ \\
\hline \multirow{2}{*}{$\begin{array}{c}\text { \# Observations } \\
\mathrm{R}^{2}\end{array}$} & 63106 & 63106 & 27952 & 27952 & 63106 & 63106 & 27952 & 27952 \\
\hline & 0.131 & 0.145 & 0.138 & 0.153 & 0.139 & 0.150 & 0.143 & 0.156 \\
\hline
\end{tabular}

Panel B: Running regressions in each group

\begin{tabular}{|c|c|c|c|}
\hline & \multicolumn{2}{|c|}{ NOFOR_STD } & \multirow[b]{2}{*}{$\begin{array}{l}\text { Small } \\
\text { firms }\end{array}$} \\
\hline & $\begin{array}{l}\text { Big } \\
\text { firms }\end{array}$ & $\begin{array}{l}\text { Mid-size } \\
\text { firms }\end{array}$ & \\
\hline \multirow[t]{2}{*}{ POSTFD } & $3.49 \mathrm{E}-05$ & $-1.51 \mathrm{E}-05$ & $-1.71 \mathrm{E}-05$ \\
\hline & $<.0001$ & $<.0001$ & $<.0001$ \\
\hline \multirow[t]{2}{*}{ SIZE } & $1.09 \mathrm{E}-04$ & $8.99 \mathrm{E}-05$ & $4.71 \mathrm{E}-05$ \\
\hline & $<.0001$ & $<.0001$ & $<.0001$ \\
\hline \multirow[t]{2}{*}{ LOSS } & $8.00 \mathrm{E}-06$ & $6.87 \mathrm{E}-06$ & $-3.29 \mathrm{E}-06$ \\
\hline & 0.0983 & 0.0024 & 0.0006 \\
\hline \multirow[t]{2}{*}{ ABSCAR } & $4.39 \mathrm{E}-05$ & $1.42 \mathrm{E}-05$ & $-1.94 \mathrm{E}-06$ \\
\hline & $<.0001$ & $<.0001$ & 0.1457 \\
\hline \multirow[t]{2}{*}{ SIGNCAR } & $2.87 \mathrm{E}-05$ & $1.94 \mathrm{E}-05$ & $9.80 \mathrm{E}-06$ \\
\hline & $<.0001$ & $<.0001$ & $<.0001$ \\
\hline \multirow{2}{*}{$\begin{array}{c}\text { \# Observations } \\
\mathrm{R}^{2}\end{array}$} & 16752 & 21237 & 25117 \\
\hline & 0.133 & 0.201 & 0.216 \\
\hline
\end{tabular}


Table 3. Summary Statistics on the Use of Pre-Announcements before and After Reg FD per Period of Issuance

This table presents summary statistics on the use of pre-announcements (PAs) before and after Reg FD per period of issuance. The first period comprises the interval between the second day after the previous quarter's actual earnings announcement (EA) day and date $\tau$, where $\tau$ is defined as 15 days before the end of the current quarter. The second period comprises the interval between date $\tau$ and 2 days before the current quarter's earnings announcement day. The third period is the earnings announcement period, defined as the window $[-1,+1]$ around the current quarter's earnings announcement day. Details on the construction of subgroups of big, mid-size and small firms are described in the Appendix. Significance of change presents the p-value of two-tailed test of differences in proportions. The sample comprises observations in the periods Q4:1997-Q3:1999 and Q4:2000-Q3:2002, except that observations with actual earnings announcements between 12/20/1999 and 10/23/2000 are excluded.

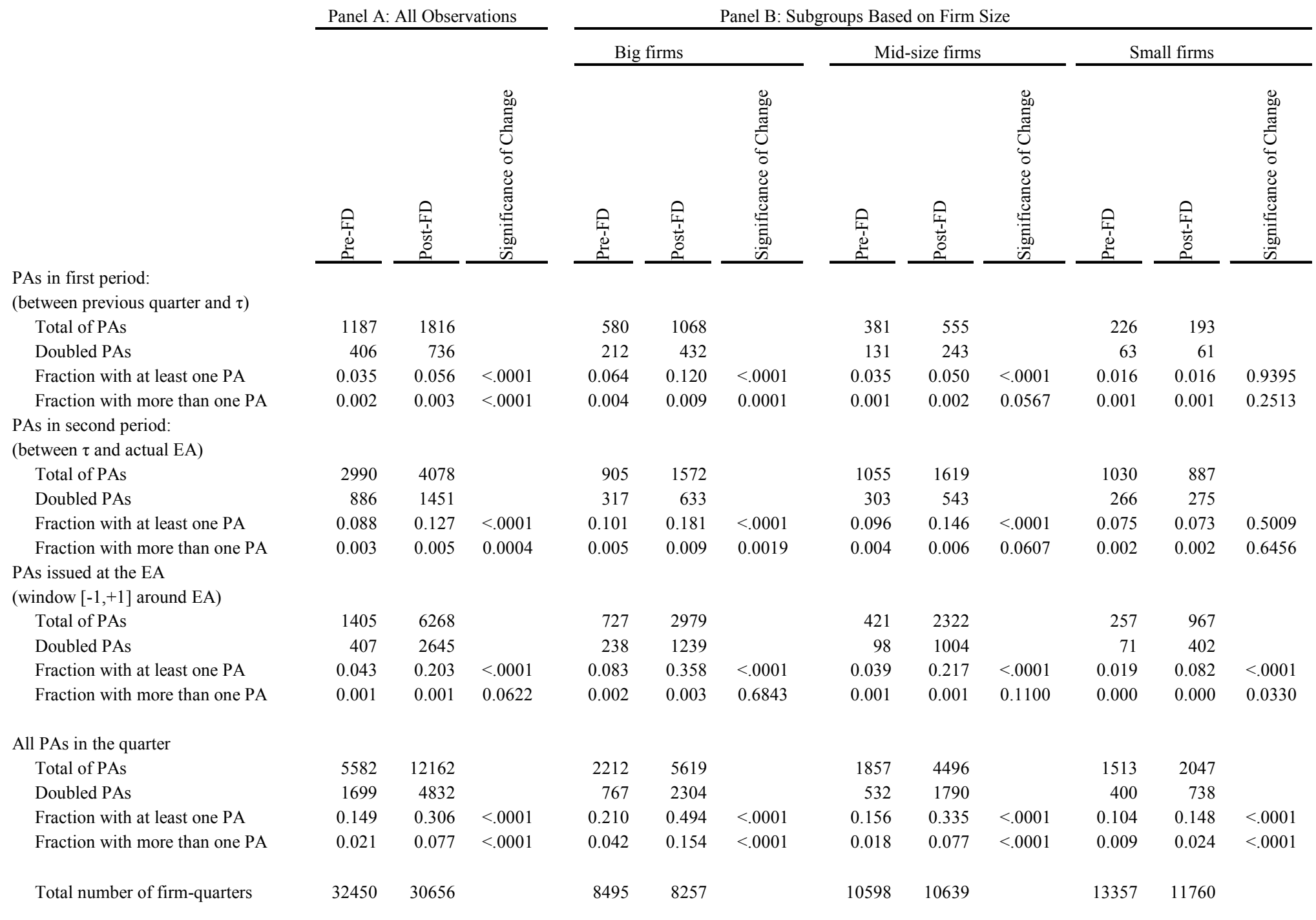


Table 4. Quarterly Cross-Sectional Regressions to Explain the Use of Pre-Announcements

This table presents results of quarterly cross-sectional logit regression on the presence of a preannouncement. For each quarter, the dependent variable PREANN $\mathrm{PR}_{\mathrm{i} q}$ is a dummy set to 1 when there is at least one pre-announcement issued by the firm from the period between 15 days before the end of the quarter $q$ (henceforth referred as date $\tau$ ) and 2 days before the actual release of that quarter's earnings announcement. SIZE $\mathrm{E}_{\mathrm{i}, \mathrm{q}}$ is the $\log$ of market value of the firm at the last day of the month in which the earnings announcement is released, scaled by the market index at the same day the market value is measured. NASDAQ, $\mathrm{q}$ is a dummy variable set to 1 when firm $i$ is traded on NASDAQ. LOSS $_{\mathrm{i}, \mathrm{q}}$ is a dummy variable set to 1 when the actual earnings are negative. SURPRISE $E_{i, q}$ is measured as the absolute value of the difference between the actual earnings and the consensus mean forecast at date $\tau$, scaled by the end of the quarter book equity per share. NEG_SURPRISE $\mathrm{i}_{\mathrm{i} q}$ is a dummy variable set to 1 when the actual earnings is below the consensus forecast available at date $\tau$. ABSCAR $\mathrm{A}_{\mathrm{i}, \mathrm{q}}$ is the absolute value of the cumulative abnormal return for firm $i$ up to date $\tau$. SIGNCAR $\operatorname{SI}_{\mathrm{iq}}$ is a dummy set to 1 when this cumulative abnormal return negative. The cumulative abnormal return for firm $i$ up to date $\tau$ is the summation of market model's residuals from 3 days after the previous quarter's earnings announcement day up to date $\tau$. PA_INDUSTRY $\mathrm{i}_{\mathrm{i} q}$ is the $\log$ of the number of the pre-announcements issued by firms in the same industry as firm $i$ in the 10 days before firm $i$ 's pre-announcement (or 10 days before date $\tau$, if firm $i$ does not issue pre-announcement on that quarter). Industry dummies are also included (results not reported). The sample comprises observations in the periods Q4:1997-Q3:1999 and Q4:2000-Q3:2002, except that observations with actual earnings announcements between 12/20/1999 and 10/23/2000 are excluded. Panel A reports results using only observations that have at least one earnings forecast not older than 90 days available for quarter $q$ at date $\tau$. Panel B reports results using all observations from the original sample.

Panel A: Using all observations

\begin{tabular}{|c|c|c|c|c|c|c|c|c|}
\hline \multicolumn{9}{|c|}{ Quarters before Reg FD } \\
\hline & 1997:IV & 1998:I & 1998:II & 1998:III & 1998:IV & 1999:I & 1999:II & 1999:III \\
\hline Intercept & $\begin{array}{l}-5.0429 \\
<.0001\end{array}$ & $\begin{array}{l}-5.9778 \\
<.0001\end{array}$ & $\begin{array}{l}-5.5561 \\
<.0001\end{array}$ & $\begin{array}{l}-5.0242 \\
<.0001\end{array}$ & $\begin{array}{l}-3.4273 \\
<.0001\end{array}$ & $\begin{array}{l}-4.3398 \\
<.0001\end{array}$ & $\begin{array}{l}-4.3055 \\
<.0001\end{array}$ & $\begin{array}{l}-4.9926 \\
<.0001\end{array}$ \\
\hline SIZE & $\begin{array}{c}0.224 \\
<.0001\end{array}$ & $\begin{array}{l}0.2021 \\
<.0001\end{array}$ & $\begin{array}{l}0.1751 \\
<.0001\end{array}$ & $\begin{array}{c}0.179 \\
<.0001\end{array}$ & $\begin{array}{l}0.0617 \\
0.0768\end{array}$ & $\begin{array}{l}0.1182 \\
0.0011\end{array}$ & $\begin{array}{l}0.0923 \\
0.0143\end{array}$ & $\begin{array}{l}0.0976 \\
0.0096\end{array}$ \\
\hline NASDAQ & $\begin{array}{l}0.1152 \\
0.5197\end{array}$ & $\begin{array}{c}-0.1453 \\
0.4167\end{array}$ & $\begin{array}{c}0.1897 \\
0.22\end{array}$ & $\begin{array}{c}-0.4504 \\
0.0016\end{array}$ & $\begin{array}{c}-0.1526 \\
0.2658\end{array}$ & $\begin{array}{l}-0.171 \\
0.2407\end{array}$ & $\begin{array}{c}-0.364 \\
0.019\end{array}$ & $\begin{array}{c}-0.2843 \\
0.0604\end{array}$ \\
\hline LOSS & $\begin{array}{l}0.1823 \\
0.3585\end{array}$ & $\begin{array}{l}0.5323 \\
0.0036\end{array}$ & $\begin{array}{l}0.2229 \\
0.1676\end{array}$ & $\begin{array}{l}0.3595 \\
0.0162\end{array}$ & $\begin{array}{l}0.0208 \\
0.8836\end{array}$ & $\begin{array}{c}0.157 \\
0.2869\end{array}$ & $\begin{array}{l}0.4037 \\
0.0104\end{array}$ & $\begin{array}{l}0.3397 \\
0.0292\end{array}$ \\
\hline ABSCAR & $\begin{array}{l}1.1203 \\
0.0188\end{array}$ & $\begin{array}{c}1.949 \\
0.0001\end{array}$ & $\begin{array}{l}1.4877 \\
0.0007\end{array}$ & $\begin{array}{c}1.863 \\
<.0001\end{array}$ & $\begin{array}{l}0.4312 \\
0.0365\end{array}$ & $\begin{array}{l}1.0833 \\
0.0002\end{array}$ & $\begin{array}{c}-0.1869 \\
0.6748\end{array}$ & $\begin{array}{l}1.0876 \\
0.0039\end{array}$ \\
\hline SIGNCAR & $\begin{array}{c}-0.0574 \\
0.7156\end{array}$ & $\begin{array}{l}0.4767 \\
0.0005\end{array}$ & $\begin{array}{l}0.5569 \\
0.0002\end{array}$ & $\begin{array}{c}0.2428 \\
0.09\end{array}$ & $\begin{array}{l}0.3044 \\
0.0053\end{array}$ & $\begin{array}{c}0.4108 \\
0.001\end{array}$ & $\begin{array}{c}0.00952 \\
0.9383\end{array}$ & $\begin{array}{l}0.5371 \\
<.0001\end{array}$ \\
\hline PA_INDUSTRY & $\begin{array}{r}-0.6197 \\
0.0039 \\
\end{array}$ & $\begin{array}{l}1.3718 \\
<.0001 \\
\end{array}$ & $\begin{array}{l}1.5057 \\
<.0001 \\
\end{array}$ & $\begin{array}{l}2.2626 \\
<.0001 \\
\end{array}$ & $\begin{array}{l}0.2468 \\
0.0792 \\
\end{array}$ & $\begin{array}{l}1.2674 \\
<.0001 \\
\end{array}$ & $\begin{array}{l}1.5539 \\
<.0001 \\
\end{array}$ & $\begin{array}{l}2.5121 \\
<.0001 \\
\end{array}$ \\
\hline \# Observations & 3629 & 3946 & 4151 & 4113 & 4108 & 4174 & 4197 & 4133 \\
\hline Pseudo $\mathrm{R}^{2}$ & 0.096 & 0.162 & 0.134 & 0.231 & 0.062 & 0.139 & 0.157 & 0.250 \\
\hline \multicolumn{9}{|c|}{ Quarters After Reg FD } \\
\hline & 2000:IV & 2001:I & 2001:II & 2001:III & 2001:IV & 2002:I & 2002:II & 2002:III \\
\hline Intercept & $\begin{array}{c}-3.4488 \\
<.0001\end{array}$ & $\begin{array}{l}-4.483 \\
<.0001\end{array}$ & $\begin{array}{c}-6.2335 \\
<.0001\end{array}$ & $\begin{array}{l}-5.585 \\
<.0001\end{array}$ & $\begin{array}{c}-3.5969 \\
<.0001\end{array}$ & $\begin{array}{c}-5.7136 \\
<.0001\end{array}$ & $\begin{array}{c}-3.9785 \\
<.0001\end{array}$ & $\begin{array}{c}-5.0062 \\
<.0001\end{array}$ \\
\hline SIZE & $\begin{array}{l}0.1234 \\
<.0001 \\
\end{array}$ & $\begin{array}{l}0.2401 \\
<.0001 \\
\end{array}$ & $\begin{array}{l}0.3066 \\
<.0001 \\
\end{array}$ & $\begin{array}{l}0.2694 \\
<.0001 \\
\end{array}$ & $\begin{array}{l}0.2008 \\
<.0001 \\
\end{array}$ & $\begin{array}{l}0.2831 \\
<.0001 \\
\end{array}$ & $\begin{array}{c}0.197 \\
<.0001 \\
\end{array}$ & $\begin{array}{l}0.2447 \\
<.0001 \\
\end{array}$ \\
\hline NASDAQ & $\begin{array}{c}-0.2945 \\
0.0164\end{array}$ & $\begin{array}{l}0.0269 \\
0.8314\end{array}$ & $\begin{array}{l}0.0861 \\
0.5331\end{array}$ & $\begin{array}{c}-0.3633 \\
0.0123\end{array}$ & $\begin{array}{c}-0.0846 \\
0.5403\end{array}$ & $\begin{array}{l}0.1032 \\
0.4921\end{array}$ & $\begin{array}{c}-0.0493 \\
0.7368\end{array}$ & $\begin{array}{c}-0.0724 \\
0.5986\end{array}$ \\
\hline LOSS & $\begin{array}{l}0.1536 \\
0.2031 \\
\end{array}$ & $\begin{array}{l}0.1367 \\
0.2596 \\
\end{array}$ & $\begin{array}{l}0.2302 \\
0.0869 \\
\end{array}$ & $\begin{array}{c}-0.0934 \\
0.5045 \\
\end{array}$ & $\begin{array}{c}-0.0429 \\
0.7411 \\
\end{array}$ & $\begin{array}{c}-0.0766 \\
0.6019 \\
\end{array}$ & $\begin{array}{c}0.241 \\
0.1096 \\
\end{array}$ & $\begin{array}{c}-0.1861 \\
0.2198 \\
\end{array}$ \\
\hline ABSCAR & $\begin{array}{l}0.1852 \\
0.5107\end{array}$ & $\begin{array}{c}0.8795 \\
0.001\end{array}$ & $\begin{array}{l}0.9833 \\
0.0042\end{array}$ & $\begin{array}{l}0.7413 \\
0.0837\end{array}$ & $\begin{array}{l}0.2606 \\
0.4429\end{array}$ & $\begin{array}{l}1.2579 \\
0.0039\end{array}$ & $\begin{array}{l}1.0689 \\
0.0075\end{array}$ & $\begin{array}{l}0.5879 \\
0.1507\end{array}$ \\
\hline SIGNCAR & $\begin{array}{c}0.247 \\
0.0168\end{array}$ & $\begin{array}{c}0.1349 \\
0.194\end{array}$ & $\begin{array}{c}0.197 \\
0.0699\end{array}$ & $\begin{array}{l}0.1834 \\
0.1071\end{array}$ & $\begin{array}{l}0.3097 \\
0.0055\end{array}$ & $\begin{array}{l}0.1729 \\
0.1514\end{array}$ & $\begin{array}{l}0.2596 \\
0.0278\end{array}$ & $\begin{array}{l}0.0903 \\
0.4199\end{array}$ \\
\hline PA_INDUSTRY & $\begin{array}{l}1.1723 \\
<.0001 \\
\end{array}$ & $\begin{array}{l}0.5282 \\
<.0001 \\
\end{array}$ & $\begin{array}{l}1.5776 \\
<.0001 \\
\end{array}$ & $\begin{array}{l}2.4992 \\
<.0001 \\
\end{array}$ & $\begin{array}{c}-0.5299 \\
<.0001 \\
\end{array}$ & $\begin{array}{l}1.0238 \\
<.0001 \\
\end{array}$ & $\begin{array}{l}0.4983 \\
0.0011 \\
\end{array}$ & $\begin{array}{l}1.2421 \\
<.0001 \\
\end{array}$ \\
\hline \# Observations & 4101 & 4054 & 4075 & 3905 & 3834 & 3704 & 3562 & 3420 \\
\hline Pseudo $\mathrm{R}^{2}$ & 0.136 & 0.153 & 0.200 & 0.420 & 0.110 & 0.198 & 0.141 & 0.190 \\
\hline
\end{tabular}


Panel B: Using only observations for which consensus forecast is available

\begin{tabular}{|c|c|c|c|c|c|c|c|c|}
\hline \multicolumn{9}{|c|}{ Quarters before Reg FD } \\
\hline \multirow{3}{*}{ Intercept } & 1997:IV & 1998:I & 1998:II & 1998:III & 1998:IV & 1999:I & 1999:II & 1999:III \\
\hline & -4.6114 & -5.1828 & -5.3378 & -4.5855 & -3.0135 & -3.9201 & -4.0907 & -5.6953 \\
\hline & $<.0001$ & $<.0001$ & $<.0001$ & $<.0001$ & $<.0001$ & $<.0001$ & $<.0001$ & $<.0001$ \\
\hline \multirow[t]{2}{*}{ SIZE } & 0.1907 & 0.1552 & 0.1481 & 0.1312 & 0.0427 & 0.0782 & 0.08 & 0.1243 \\
\hline & 0.0005 & 0.0061 & 0.0022 & 0.0034 & 0.3089 & 0.0737 & 0.0802 & 0.0071 \\
\hline \multirow[t]{2}{*}{ NASDAQ } & 0.2257 & -0.1524 & 0.2283 & -0.3973 & -0.1176 & -0.1427 & -0.3625 & -0.3819 \\
\hline & 0.248 & 0.4474 & 0.1872 & 0.012 & 0.4409 & 0.3828 & 0.0414 & 0.0299 \\
\hline \multirow[t]{2}{*}{ NEG_SURPRISE } & 0.9202 & 1.2438 & 1.3479 & 1.0639 & 0.9835 & 0.9606 & 1.402 & 1.1773 \\
\hline & $<.0001$ & $<.0001$ & $<.0001$ & $<.0001$ & $<.0001$ & $<.0001$ & $<.0001$ & $<.0001$ \\
\hline \multirow[t]{2}{*}{ SURPRISE } & 19.1174 & 25.1405 & 26.2663 & 26.8845 & 14.3069 & 20.2016 & 20.1124 & 36.8681 \\
\hline & 0.0011 & $<.0001$ & $<.0001$ & $<.0001$ & 0.007 & 0.0004 & 0.0001 & $<.0001$ \\
\hline \multirow[t]{2}{*}{ ABSCAR } & 0.5966 & 2.2315 & 0.6247 & 1.1439 & 0.1489 & 0.6426 & -0.1982 & 1.4682 \\
\hline & 0.2823 & 0.0012 & 0.2325 & 0.0041 & 0.7169 & 0.0918 & 0.7154 & 0.0031 \\
\hline \multirow[t]{2}{*}{ SIGNCAR } & -0.1544 & 0.4525 & 0.2547 & -0.0827 & 0.2498 & 0.2766 & -0.0226 & 0.5143 \\
\hline & 0.3787 & 0.0041 & 0.1368 & 0.6026 & 0.0476 & 0.0583 & 0.8735 & 0.0007 \\
\hline \multirow[t]{2}{*}{ PA_INDUSTRY } & -0.79 & 1.3398 & 0.8974 & 2.0965 & -0.0566 & 1.0455 & 1.5517 & 2.388 \\
\hline & 0.0008 & $<.0001$ & $<.0001$ & $<.0001$ & 0.7159 & $<.0001$ & $<.0001$ & $<.0001$ \\
\hline \multirow{4}{*}{$\begin{array}{l}\text { \# Observations } \\
\text { Pseudo } \mathrm{R}^{2}\end{array}$} & 2535 & 2650 & 2801 & 2811 & 2784 & 2780 & 2847 & 2793 \\
\hline & 0.138 & 0.233 & 0.206 & 0.283 & 0.110 & 0.172 & 0.250 & 0.330 \\
\hline & \multicolumn{7}{|c|}{ Quarters After Reg FD } & \\
\hline & 2000:IV & 2001:I & 2001:II & 2001:III & 2001:IV & 2002:I & 2002:II & 2002:III \\
\hline \multirow[t]{2}{*}{ Intercept } & -3.2888 & -4.7031 & -6.2854 & -5.1042 & -2.8957 & -5.4728 & -4.1258 & -5.2652 \\
\hline & $<.0001$ & $<.0001$ & $<.0001$ & $<.0001$ & $<.0001$ & $<.0001$ & $<.0001$ & $<.0001$ \\
\hline \multirow[t]{2}{*}{ SIZE } & 0.0541 & 0.2 & 0.2486 & 0.1381 & 0.1522 & 0.2457 & 0.1584 & 0.2116 \\
\hline & 0.1342 & $<.0001$ & $<.0001$ & 0.0007 & $<.0001$ & $<.0001$ & 0.0004 & $<.0001$ \\
\hline \multirow[t]{2}{*}{ NASDAQ } & -0.2674 & 0.1042 & 0.2417 & -0.2834 & -0.0997 & 0.0504 & -0.1377 & -0.0905 \\
\hline & 0.056 & 0.4614 & 0.1203 & 0.075 & 0.5031 & 0.757 & 0.3917 & 0.5487 \\
\hline \multirow[t]{2}{*}{ NEG_SURPRISE } & 0.9422 & 1.2833 & 1.4494 & 1.0336 & 0.6565 & 0.7717 & 0.971 & 0.912 \\
\hline & $<.0001$ & $<.0001$ & $<.0001$ & $<.0001$ & $<.0001$ & $<.0001$ & $<.0001$ & $<.0001$ \\
\hline \multirow[t]{2}{*}{ SURPRISE } & 14.1542 & 20.717 & 18.7542 & 18.0542 & 18.7575 & 31.2891 & 26.725 & 24.1087 \\
\hline & 0.0042 & $<.0001$ & 0.0005 & 0.0075 & 0.0012 & $<.0001$ & $<.0001$ & 0.0012 \\
\hline \multirow[t]{2}{*}{ ABSCAR } & 0.2138 & 0.4365 & 0.4643 & -0.018 & -0.0569 & 0.4871 & 0.9418 & 0.1339 \\
\hline & 0.5355 & 0.1829 & 0.2519 & 0.9721 & 0.8877 & 0.3387 & 0.0376 & 0.7664 \\
\hline \multirow[t]{2}{*}{ SIGNCAR } & 0.1345 & 0.0754 & 0.1287 & -0.0645 & 0.3569 & 0.0643 & 0.1266 & -0.0146 \\
\hline & 0.2642 & 0.5262 & 0.2953 & 0.6148 & 0.0037 & 0.6298 & 0.3387 & 0.9051 \\
\hline \multirow[t]{2}{*}{ PA_INDUSTRY } & 0.2138 & 0.4365 & 0.4643 & -0.018 & -0.0569 & 0.4871 & 0.9418 & 0.1339 \\
\hline & 0.5355 & 0.1829 & 0.2519 & 0.9721 & 0.8877 & 0.3387 & 0.0376 & 0.7664 \\
\hline \multirow{2}{*}{$\begin{array}{l}\text { \# Observations } \\
\text { Pseudo } \mathrm{R}^{2}\end{array}$} & 2637 & 2666 & 2685 & 2647 & 2663 & 2583 & 2594 & 2496 \\
\hline & 0.183 & 0.208 & 0.271 & 0.454 & 0.126 & 0.228 & 0.188 & 0.209 \\
\hline
\end{tabular}


Table 5. Panel Data Regression (Conditional Logit) to Explain the Use of Pre-announcements

This table presents results of conditional (fixed effects) logit regressions of the presence of a pre-announcement. The dependent variable PREANN $\mathrm{i}_{\mathrm{i}, \mathrm{i}}$ is a dummy set to 1 when there is at least one pre-announcement issued by the firm from the period between 15 days before the end of the quarter $q$ (henceforth referred as date $\tau$ ) and 2 days before the actual release of that quarter's earnings announcement. SIZE $\mathrm{E}_{\mathrm{i}, \mathrm{q}}$ is the log of market value of the firm at the last day of the month in which the earnings announcement is released, scaled by the market index at the same day the market value is measured. LOSS $_{\mathrm{i}, \mathrm{q}}$ is a dummy variable set to 1 when the actual earnings are negative. The variable SURPRISE $\mathrm{i}_{\mathrm{i} q}$ is measured as the absolute value of the difference between the actual earnings and the consensus mean forecast at date $\tau$, scaled by the end of the quarter book equity per share. NEG_SURPRISE $E_{i, q}$ is a dummy variable set to 1 when the actual earnings is below the consensus forecast available at date $\tau$. ABSCAR $\mathrm{i}_{\mathrm{iq}}$ is the absolute value of the cumulative abnormal return for firm $i$ up to date $\tau$. SIGNCAR $\mathrm{i}_{\mathrm{iq}}$ is a dummy set to 1 when this cumulative abnormal return negative. The cumulative abnormal return for firm $i$ up to date $\tau$ is the summation of market model's residuals from 3 days after the previous quarter's earnings announcement day up to date $\tau$. PA_INDUSTRY $Y_{\mathrm{i}, \mathrm{q}}$ is the $\log$ of the number of the pre-announcements issued by firms in the same industry as firm $i$ between date $\tau$ and the day of firm $i$ 's pre-announcement (or the actual earnings announcement, if firm $i$ does not issue pre-announcement on that quarter). POSTFD_Big $\mathrm{i}_{\mathrm{i}, \mathrm{g}}$, POSTFD_Mid ${ }_{i, q}$ and POSTFD_Small $l_{i, q}$ are the interactions of POSTFD ${ }_{i, q}$ with dummies identifying whether the firm belongs, respectively, to the portfolio of big, midsize or small firms. Details on the construction of portfolios of big, mid-size and small firms are described in the Appendix. The p-values are shown below each coefficient estimate. The sample comprises observations in the periods Q4:1997-Q3:1999 (pre-FD sample) and Q4:2000-Q3:2002 (post-FD sample), except that observations with actual earnings announcements between 12/20/1999 and 10/23/2000 are excluded. The first 2 columns of Panel A report results using all observations from the original sample, and the last 2 columns report results using only observations that have at least one earnings forecast not older than 90 days available for quarter $q$ at date $\tau$.

Panel A: Aggregating all data together

\begin{tabular}{|c|c|c|c|c|c|c|}
\hline & I & II & III & IV & V & VI \\
\hline \multirow[t]{2}{*}{ POSTFD } & 0.5226 & - & - & 0.5664 & - & - \\
\hline & $<.0001$ & - & - & $<.0001$ & - & - \\
\hline \multirow[t]{2}{*}{ POSTFD_Big } & - & 0.7582 & 0.4927 & - & 0.7548 & 0.5067 \\
\hline & - & $<.0001$ & $<.0001$ & - & $<.0001$ & $<.0001$ \\
\hline \multirow{2}{*}{ POSTFD_Mid } & - & 0.6057 & 0.3778 & - & 0.5890 & 0.3764 \\
\hline & - & $<.0001$ & $<.0001$ & - & $<.0001$ & $<.0001$ \\
\hline \multirow[t]{2}{*}{ POSTFD_Small } & - & 0.0561 & -0.1906 & - & 0.1260 & -0.0785 \\
\hline & - & 0.3780 & 0.0040 & - & 0.1500 & 0.3260 \\
\hline \multirow[t]{2}{*}{ SIZE } & 0.0989 & 0.0723 & 0.1047 & 0.1598 & 0.1412 & 0.1644 \\
\hline & 0.0010 & 0.0150 & 0.0010 & $<.0001$ & $<.0001$ & $<.0001$ \\
\hline \multirow[t]{2}{*}{ LOSS } & 0.4012 & 0.4012 & 0.4288 & - & - & - \\
\hline & $<.0001$ & $<.0001$ & $<.0001$ & - & - & - \\
\hline \multirow[t]{2}{*}{ NEG_SURPRISE } & - & - & - & 1.3556 & 1.3500 & 1.3290 \\
\hline & - & - & - & $<.0001$ & $<.0001$ & $<.0001$ \\
\hline \multirow[t]{2}{*}{ SURPRISE } & - & - & - & 6.5455 & 6.6500 & 6.1776 \\
\hline & - & - & - & $<.0001$ & $<.0001$ & $<.0001$ \\
\hline \multirow[t]{2}{*}{ ABSCAR } & 0.6745 & 0.6835 & 0.5229 & 0.5209 & 0.5246 & 0.3565 \\
\hline & $<.0001$ & $<.0001$ & $<.0001$ & $<.0001$ & $<.0001$ & $<.0001$ \\
\hline \multirow[t]{2}{*}{ SIGNCAR } & 0.2603 & 0.2618 & 0.1968 & 0.1595 & 0.1605 & 0.1007 \\
\hline & $<.0001$ & $<.0001$ & $<.0001$ & $<.0001$ & $<.0001$ & $<.0001$ \\
\hline \multirow[t]{2}{*}{ PA_INDUSTRY } & - & - & 0.8973 & - & - & 0.8371 \\
\hline & - & - & $<.0001$ & - & - & $<.0001$ \\
\hline \multirow{2}{*}{$\begin{array}{l}\text { \# Observations } \\
\text { Pseudo } \mathrm{R}^{2}\end{array}$} & 34799 & 34799 & 34799 & 31155 & 31155 & 31155 \\
\hline & 0.019 & 0.023 & 0.069 & 0.098 & 0.100 & 0.139 \\
\hline
\end{tabular}

Panel B: Running regressions in each group

\begin{tabular}{|c|c|c|c|}
\hline & $\begin{array}{l}\text { Big } \\
\text { firms }\end{array}$ & $\begin{array}{l}\text { Mid-size } \\
\text { firms }\end{array}$ & $\begin{array}{l}\text { Small } \\
\text { firms }\end{array}$ \\
\hline \multirow[t]{2}{*}{ POSTFD } & 0.7697 & 0.5874 & 0.1572 \\
\hline & $<.0001$ & $<.0001$ & 0.0800 \\
\hline \multirow[t]{2}{*}{ SIZE } & -0.0022 & 0.1449 & 0.2764 \\
\hline & 0.9710 & 0.0030 & $<.0001$ \\
\hline \multirow[t]{2}{*}{ NEG_SURPRISE } & 1.2030 & 1.4544 & 1.3010 \\
\hline & $<.0001$ & $<.0001$ & $<.0001$ \\
\hline \multirow[t]{2}{*}{ SURPRISE } & 34.0600 & 7.8479 & 4.4843 \\
\hline & $<.0001$ & $<.0001$ & 0.2760 \\
\hline \multirow[t]{2}{*}{ ABSCAR } & 0.2168 & 0.7414 & 0.3881 \\
\hline & 0.3740 & $<.0001$ & 0.0350 \\
\hline \multirow[t]{2}{*}{ SIGNCAR } & 0.1586 & 0.1499 & 0.1605 \\
\hline & 0.0040 & 0.0060 & 0.0170 \\
\hline \multirow{2}{*}{$\begin{array}{c}\text { \# Observations } \\
\text { Pseudo } \mathrm{R}^{2}\end{array}$} & 11703 & 12135 & 7327 \\
\hline & 0.100 & 0.117 & 0.857 \\
\hline
\end{tabular}


Table 6. Panel Data Fixed Effects Regression to Explain Forecast Error

This table presents results of panel data fixed effects regression to explain forecast error at quarterly earnings announcements. The dependent variable, EA_SURPRISE $\mathrm{i}_{\mathrm{i}, \mathrm{q}}$, is the absolute value of the difference between actual earnings per share for firm $i$ at quarter $q$ and the consensus (mean) forecast as of 2 days before the actual earnings announcement day for firm $i$ 's quarter $q$, divided by either firm $i$ market value of equity at the end of the quarter (specifications I and II) or firm $i$ book equity per share computed at the end of quarter $q$ (specifications III and IV). The explanatory variables are defined as follows. SIZE $\mathrm{E}_{\mathrm{i}, \mathrm{q}}$ is the log of market value of the firm at the last day of the month in which the earnings announcement is released, scaled by the market index. LOSS $_{\mathrm{i}, \mathrm{q}}$ is a dummy variable set to 1 when the actual earnings are negative. $\operatorname{ABSCAR}_{\mathrm{i}, q}$ is the absolute value of the cumulative abnormal return for firm $i$ along quarter $q$. SIGNCAR $\mathrm{SI}_{\mathrm{i}, \mathrm{q}}$ is a dummy set to 1 when the cumulative abnormal return for quarter $q$ is negative. The cumulative abnormal return for firm $i$ during quarter $q$ is the summation of market model's residuals from 3 days after the previous quarter's earnings announcement day up to 2 days before quarter $q$ 's earnings announcement day. POSTFD $\mathrm{P}_{\mathrm{i}, \mathrm{q}}$ is a dummy set to 1 for a quarterly earnings release after the adoption of Reg FD, and 0 otherwise. POSTFD_Big ${ }_{i, q}$, POSTFD_Mid ${ }_{i, q}$ and POSTFD_Small ${ }_{i, q}$ are the interactions of POSTFD ${ }_{i, q}$ with dummies identifying whether the firm belongs, respectively, to the portfolio of big, mid-size or small firms. Details on the construction of portfolios of big, mid-size and small firms are described in The Appendix. The p-values are shown below each coefficient estimate. The sample comprises observations in the periods Q4:1997Q3:1999 (pre-FD sample) and Q4:2000-Q3:2002 (post-FD sample), except that observations with actual earnings announcements between 12/20/1999 and 10/23/2000 are excluded.

Panel A: Aggregating all data together

\begin{tabular}{|c|c|c|}
\hline \multirow{2}{*}{\multicolumn{3}{|c|}{$\begin{array}{c}\text { Panel A: Aggregating all data togeth } \\
\text { Earning surprise scaled } \\
\text { by share price }\end{array}$}} \\
\hline & & \\
\hline \multirow{3}{*}{ POSTFD } & I & II \\
\hline & 0.0019 & - \\
\hline & $<.0001$ & - \\
\hline \multirow[t]{2}{*}{ POSTFD_Big } & - & 0.0006 \\
\hline & - & $<.0001$ \\
\hline \multirow[t]{2}{*}{ POSTFD_Mid } & - & 0.0019 \\
\hline & - & $<.0001$ \\
\hline \multirow[t]{2}{*}{ POSTFD_Small } & - & 0.0031 \\
\hline & - & $<.0001$ \\
\hline \multirow[t]{2}{*}{ SIZE } & -0.0038 & -0.0037 \\
\hline & $<.0001$ & $<.0001$ \\
\hline \multirow[t]{2}{*}{ LOSS } & 0.0048 & 0.0048 \\
\hline & $<.0001$ & $<.0001$ \\
\hline \multirow[t]{2}{*}{ ABSCAR } & 0.0014 & 0.0014 \\
\hline & $<.0001$ & $<.0001$ \\
\hline \multirow[t]{2}{*}{ SIGNCAR } & 0.0002 & 0.0002 \\
\hline & $<.0001$ & 0.0005 \\
\hline \multirow{2}{*}{$\begin{array}{c}\text { \# Observations } \\
\mathrm{R}^{2}\end{array}$} & 45715 & 45715 \\
\hline & 0.138 & 0.137 \\
\hline
\end{tabular}

Earning surprise scaled by book equity per share

\begin{tabular}{|c|c|}
\multicolumn{1}{c}{ III } & IV \\
\hline-0.0001 & - \\
0.4223 & - \\
\hline- & -0.0002 \\
- & 0.0387 \\
\hline- & -0.0001 \\
- & 0.5107 \\
\hline- & 0.0008 \\
- & $<.0001$ \\
\hline-0.0010 & -0.0010 \\
$<.0001$ & $<.0001$ \\
\hline 0.0046 & 0.0045 \\
$<.0001$ & $<.0001$ \\
\hline 0.0018 & 0.0018 \\
$<.0001$ & $<.0001$ \\
\hline-0.0005 & -0.0005 \\
$<.0001$ & $<.0001$ \\
\hline 45715 & 45715 \\
\hline 0.029 & 0.029 \\
\hline \multicolumn{2}{|c}{} \\
\hline
\end{tabular}

Panel B: Running regressions in each group

\begin{tabular}{|c|c|c|c|}
\hline \multicolumn{4}{|c|}{ Earning surprise scaled by book equity per share } \\
\hline \multirow{4}{*}{ POSTFD } & Big & Mid-size & Small \\
\hline & firms & & \\
\hline & -0.0004 & 0.0000 & 0.0006 \\
\hline & 0.0011 & 0.8936 & 0.0258 \\
\hline \multirow[t]{2}{*}{ SIZE } & -0.0008 & -0.0012 & -0.0007 \\
\hline & $<.0001$ & $<.0001$ & 0.0013 \\
\hline \multirow[t]{2}{*}{ LOSS } & 0.0020 & 0.0041 & 0.0069 \\
\hline & $<.0001$ & $<.0001$ & $<.0001$ \\
\hline \multirow[t]{2}{*}{ ABSCAR } & 0.0012 & 0.0022 & 0.0016 \\
\hline & 0.0007 & $<.0001$ & 0.0007 \\
\hline \multirow[t]{2}{*}{ SIGNCAR } & -0.0004 & -0.0005 & -0.0006 \\
\hline & $<.0001$ & $<.0001$ & 0.0029 \\
\hline \multirow{2}{*}{$\begin{array}{c}\text { \# Observations } \\
\mathrm{R}^{2}\end{array}$} & 15786 & 17942 & 11987 \\
\hline & 0.011 & 0.031 & 0.044 \\
\hline
\end{tabular}




\section{Table 7. Panel Data Fixed Effects Regression to Explain Volatility (Market Response) at Earnings Announcements}

This table presents results of panel data fixed effects regression to explain volatility (market response) at earnings announcements. The dependent variable, volatility, is defined as the cumulative absolute abnormal return during the 3 days (window $[-1,+1]$ ) around the earnings announcement day, where the abnormal return is obtained as the residual from the market model. The explanatory variables are defined as follows. SIZE $\mathrm{E}_{\mathrm{i}, \mathrm{q}}$ is the log of market value of the firm at the last day of the month in which the earnings announcement is released, scaled by the market index. LOSS $_{\mathrm{i}, \mathrm{q}}$ is a dummy variable set to 1 when the actual earnings are negative. SURPRISE $\mathrm{i}_{\mathrm{i}, \mathrm{i}}$ is measured as the absolute value of the difference between the actual earnings and the consensus mean forecast two days before the earnings announcement, scaled by the end of the quarter book equity per share. NEG_SURPRISE ${ }_{\mathrm{i}, \mathrm{q}}$ is a dummy variable set to 1 when the actual earnings is below the consensus forecast. ABSCAR $\mathrm{R}_{\mathrm{i}, \mathrm{i}}$ is the absolute value of the cumulative abnormal return for firm $i$ along quarter $q$. SIGNCAR $\mathrm{i}_{\mathrm{i}, \mathrm{q}}$ is a dummy set to 1 when the cumulative abnormal return for quarter $q$ is negative. The cumulative abnormal return for firm $i$ during quarter $q$ is the summation of market model's residuals from 3 days after the previous quarter's earnings announcement day up to 2 days before quarter $q$ 's earnings announcement day. VIX is the value of the volatility index for the Chicago Board Options Exchange at the earnings announcement day. POSTFD ${ }_{\mathrm{i}, \mathrm{q}}$ is a dummy set to 1 for a quarterly earnings release after the adoption of Reg FD, and 0 otherwise. POSTFD_Big ${ }_{\mathrm{i}, \mathrm{q}}$, POSTFD_Mid ${ }_{i, q}$ and POSTFD_Small $i_{i, q}$ are the interactions of POSTFD $\mathrm{i}_{\mathrm{i}, \mathrm{q}}$ with dummies identifying whether the firm belongs, respectively, to the portfolio of big, midsize or small firms. Details on the construction of portfolios of big, mid-size and small firms are described in the Appendix. The p-values are shown below each coefficient estimate. The sample comprises observations in the periods Q4:1997-Q3:1999 (pre-FD sample) and Q4:2000-Q3:2002 (post-FD sample), except that observations with actual earnings announcements between 12/20/1999 and 10/23/2000 are excluded.

Panel A: Aggregating all data together

\begin{tabular}{|c|c|c|c|c|}
\hline & I & II & III & IV \\
\hline \multirow[t]{2}{*}{ POSTFD } & 0.0091 & - & 0.0021 & - \\
\hline & $<.0001$ & - & 0.0023 & - \\
\hline \multirow[t]{2}{*}{ POSTFD_Big } & - & 0.0081 & - & 0.0009 \\
\hline & - & $<.0001$ & - & 0.4052 \\
\hline \multirow[t]{2}{*}{ POSTFD_Mid } & - & 0.0093 & - & 0.0024 \\
\hline & - & $<.0001$ & - & 0.0251 \\
\hline \multirow[t]{2}{*}{ POSTFD_Small } & - & 0.0109 & - & 0.0042 \\
\hline & - & $<.0001$ & - & 0.0045 \\
\hline \multirow[t]{2}{*}{ SIZE } & -0.0114 & -0.0113 & -0.0113 & -0.0113 \\
\hline & $<.0001$ & $<.0001$ & $<.0001$ & $<.0001$ \\
\hline \multirow[t]{2}{*}{ LOSS } & -0.0043 & -0.0043 & -0.0039 & -0.0039 \\
\hline & 0.0002 & 0.0002 & 0.0005 & 0.0005 \\
\hline \multirow[t]{2}{*}{ NEG_SURPRISE } & 0.0047 & 0.0047 & 0.0048 & 0.0048 \\
\hline & $<.0001$ & $<.0001$ & $<.0001$ & $<.0001$ \\
\hline \multirow[t]{2}{*}{ SURPRISE } & 0.5589 & 0.5577 & 0.5641 & 0.5626 \\
\hline & $<.0001$ & $<.0001$ & $<.0001$ & $<.0001$ \\
\hline \multirow[t]{2}{*}{ ABSCAR } & 0.0424 & 0.0425 & 0.0393 & 0.0393 \\
\hline & $<.0001$ & $<.0001$ & $<.0001$ & $<.0001$ \\
\hline \multirow[t]{2}{*}{ SIGNCAR } & 0.0094 & 0.0094 & 0.0060 & 0.0060 \\
\hline & $<.0001$ & $<.0001$ & $<.0001$ & $<.0001$ \\
\hline \multirow[t]{2}{*}{ VIX } & - & - & 0.0015 & 0.0015 \\
\hline & - & - & $<.0001$ & $<.0001$ \\
\hline \multirow{2}{*}{$\begin{array}{c}\text { \# Observations } \\
\mathrm{R}^{2}\end{array}$} & 48630 & 48630 & 48630 & 48630 \\
\hline & 0.035 & 0.035 & 0.055 & 0.055 \\
\hline
\end{tabular}

Panel B: Running regressions in each group

\begin{tabular}{|c|c|c|c|}
\hline & $\begin{array}{l}\text { Big } \\
\text { firms }\end{array}$ & $\begin{array}{l}\text { Mid } \\
\text { firms }\end{array}$ & $\begin{array}{l}\text { Small } \\
\text { firms }\end{array}$ \\
\hline \multirow[t]{2}{*}{ POSTFD } & 0.0005 & 0.0014 & 0.0046 \\
\hline & 0.6230 & 0.2165 & 0.0077 \\
\hline SIZE & $\begin{array}{l}-0.0078 \\
<.0001\end{array}$ & $\begin{array}{l}-0.0091 \\
<.0001\end{array}$ & $\begin{array}{l}-0.0176 \\
<.0001\end{array}$ \\
\hline \multirow[t]{2}{*}{ LOSS } & 0.0012 & -0.0048 & -0.0063 \\
\hline & 0.5236 & 0.0080 & 0.0027 \\
\hline \multirow[t]{2}{*}{ NEG_SURPRISE } & 0.0050 & 0.0067 & 0.0021 \\
\hline & $<.0001$ & $<.0001$ & 0.1715 \\
\hline \multirow[t]{2}{*}{ SURPRISE } & 0.6917 & 0.6118 & 0.5159 \\
\hline & $<.0001$ & $<.0001$ & $<.0001$ \\
\hline \multirow[t]{2}{*}{ ABSCAR } & 0.0554 & 0.0371 & 0.0325 \\
\hline & $<.0001$ & $<.0001$ & $<.0001$ \\
\hline \multirow[t]{2}{*}{ SIGNCAR } & 0.0084 & 0.0053 & 0.0033 \\
\hline & $<.0001$ & $<.0001$ & 0.0165 \\
\hline \multirow[t]{2}{*}{ VIX } & 0.0015 & 0.0016 & 0.0015 \\
\hline & $<.0001$ & $<.0001$ & $<.0001$ \\
\hline \multirow{2}{*}{$\begin{array}{c}\text { \# Observations } \\
\mathrm{R}^{2}\end{array}$} & 16366 & 18960 & 13304 \\
\hline & 0.076 & 0.054 & 0.045 \\
\hline
\end{tabular}




\section{Table 8. Fama-French Regression on Size-Based Portfolios}

This table presents results of regressions motivated by the Fama and French (1993) 3-factor model for the portfolios of firms created based on the division by size. The dependent variable is the value-weighted monthly return of each size-based portfolio in excess of the T-bill. The explanatory variables RMRF, SMB and HML are defined in Fama and French (1993). POSTFD is a dummy set to 1 for the months after Oct 2000, and 0 otherwise; POSTFD_SMB is the interaction of POSTFD and SMB. The sample period is Jan 1997 to December 2002.

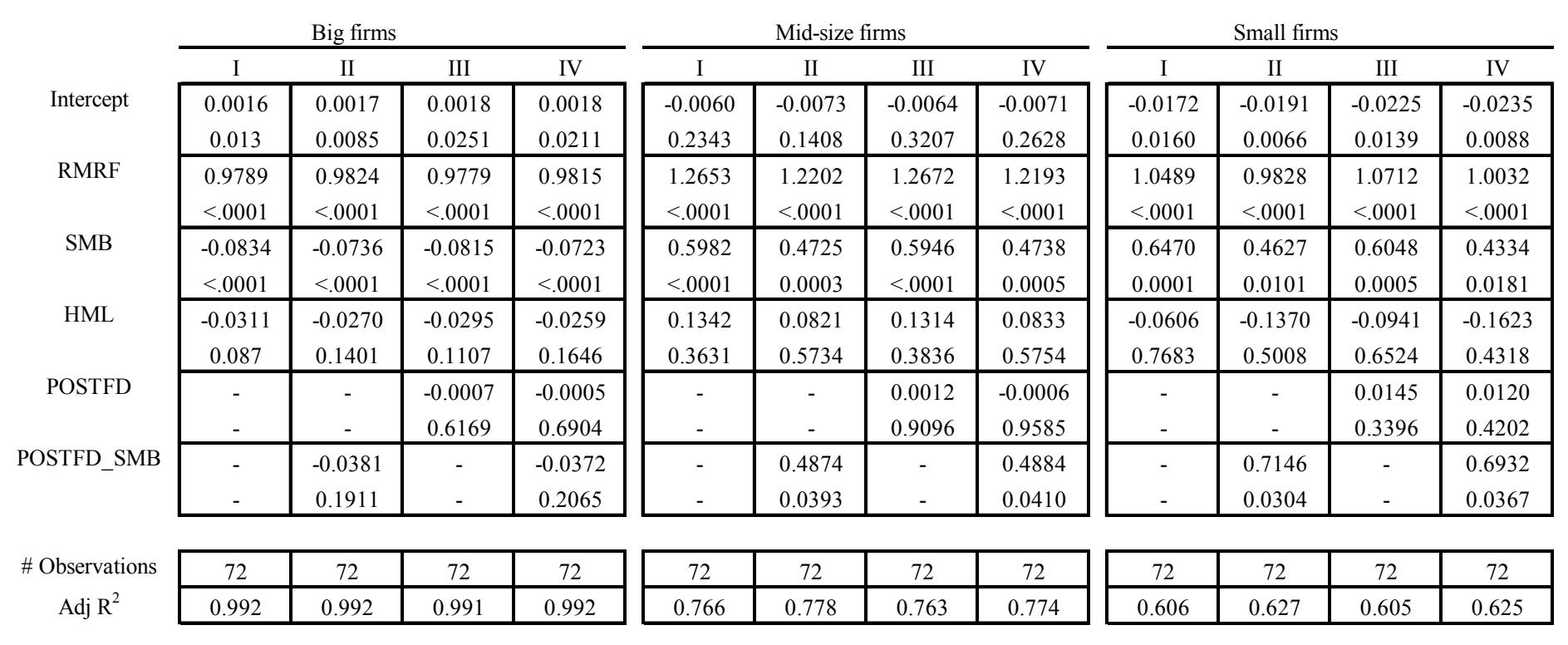


Table 9. Fama-French Portfolios and the Period Post-Reg FD

This table analyzes results based on the 25 portfolios formed on size and book-to-market from Fama and French (1993). Panels A and B presents results of regression based on the Fama and French (1993) 3-factor model for Fama-French 25 portfolios. The dependent variable is the value-weighted monthly return of each portfolio in excess of the T-bill. The explanatory variables RMRF, SMB and HML are defined in Fama and French (1993). POSTFD is a dummy set to 1 for the months after Oct 2000, and 0 otherwise; POSTFD_SMB is the interaction of POSTFD and SMB. The sample period is Jan 1997 to December 2002. Panel $\mathrm{C}$ presents the correlation of returns between our portfolios of big, mid-size and small firms and the 25 Fama-French portfolios for the period between Jan 1997 and Dec 2002.

Panel A: Fama-French results for the period between Jan 1997 and Dec 2002

\begin{tabular}{|c|c|c|c|c|c|c|c|c|c|c|}
\hline \multirow[b]{2}{*}{ Size } & \multicolumn{9}{|c|}{ Book-to-market equity (BE/ME) quintiles } & \multirow[b]{2}{*}{ High } \\
\hline & Low & 2 & 3 & 4 & High & Low & 2 & 3 & 4 & \\
\hline & \multicolumn{5}{|c|}{ RMRF } & \multicolumn{5}{|c|}{$\mathrm{t}(\mathrm{RMRF})$} \\
\hline Small & 1.33 & 1.21 & 1.01 & 0.97 & 0.99 & 5.95 & 6.31 & 7.50 & 9.40 & 11.44 \\
\hline 2 & 1.35 & 1.14 & 1.02 & 1.09 & 1.15 & 8.56 & 11.90 & 17.63 & 19.95 & 21.08 \\
\hline 3 & 1.16 & 1.20 & 1.13 & 1.10 & 1.13 & 8.63 & 16.05 & 20.84 & 18.70 & 16.83 \\
\hline 4 & 1.26 & 1.17 & 1.17 & 1.12 & 1.11 & 11.12 & 20.03 & 17.16 & 21.07 & 12.36 \\
\hline \multirow[t]{2}{*}{ Big } & 0.91 & 1.02 & 0.98 & 0.94 & 0.95 & 25.59 & 14.60 & 11.88 & 9.56 & 8.29 \\
\hline & \multicolumn{5}{|c|}{ SMB } & \multicolumn{5}{|c|}{$\mathrm{t}(\mathrm{SMB})$} \\
\hline Small & 0.44 & 0.60 & 0.55 & 0.61 & 0.63 & 1.77 & 2.79 & 3.68 & 5.26 & 6.48 \\
\hline 2 & 0.32 & 0.51 & 0.58 & 0.59 & 0.61 & 1.84 & 4.73 & 8.87 & 9.61 & 9.92 \\
\hline 3 & 0.19 & 0.36 & 0.40 & 0.52 & 0.45 & 1.30 & 4.28 & 6.52 & 7.92 & 6.02 \\
\hline 4 & -0.01 & 0.33 & 0.26 & 0.25 & 0.31 & -0.11 & 5.04 & 3.45 & 4.28 & 3.08 \\
\hline \multirow[t]{2}{*}{ Big } & -0.25 & 0.03 & 0.10 & 0.13 & 0.21 & -6.34 & 0.36 & 1.11 & 1.19 & 1.62 \\
\hline & \multicolumn{5}{|c|}{ HML } & \multicolumn{5}{|c|}{$\mathrm{t}(\mathrm{HML})$} \\
\hline Small & -0.20 & 0.30 & 0.47 & 0.62 & 0.67 & -0.70 & 1.20 & 2.73 & 4.66 & 6.02 \\
\hline 2 & -0.04 & 0.51 & 0.69 & 0.91 & 0.97 & -0.19 & 4.10 & 9.17 & 12.80 & 13.67 \\
\hline 3 & -0.30 & 0.57 & 0.83 & 1.00 & 0.94 & -1.73 & 5.92 & 11.76 & 13.25 & 10.84 \\
\hline 4 & -0.14 & 0.66 & 0.84 & 0.85 & 0.87 & -0.98 & 8.80 & 9.49 & 12.32 & 7.48 \\
\hline \multirow[t]{2}{*}{ Big } & -0.34 & 0.37 & 0.42 & 0.76 & 0.74 & -7.43 & 4.09 & 4.00 & 5.93 & 4.99 \\
\hline & \multicolumn{5}{|c|}{ POSTFD_SMB } & & \multicolumn{4}{|c|}{ t(POSTFD_SMB) } \\
\hline Small & 0.72 & 0.56 & 0.30 & 0.27 & 0.41 & 1.56 & 1.42 & 1.07 & 1.24 & 2.27 \\
\hline 2 & 0.76 & 0.57 & 0.37 & 0.37 & 0.65 & 2.35 & 2.89 & 3.07 & 3.25 & 5.79 \\
\hline 3 & 0.66 & 0.19 & 0.13 & 0.03 & 0.31 & 2.39 & 1.26 & 1.15 & 0.24 & 2.22 \\
\hline 4 & 0.57 & 0.00 & -0.03 & 0.02 & 0.03 & 2.43 & -0.02 & -0.25 & 0.15 & 0.16 \\
\hline Big & -0.04 & -0.06 & 0.16 & -0.04 & -0.69 & -0.59 & -0.44 & 0.93 & -0.18 & -2.91 \\
\hline \multicolumn{11}{|c|}{$\mathrm{R}^{2}$} \\
\hline Small & 0.59 & 0.54 & 0.57 & 0.67 & 0.76 & & & & & \\
\hline 2 & 0.71 & 0.78 & 0.87 & 0.89 & 0.91 & & & & & \\
\hline 3 & 0.75 & 0.83 & 0.88 & 0.85 & 0.83 & & & & & \\
\hline 4 & 0.79 & 0.87 & 0.82 & 0.87 & 0.70 & & & & & \\
\hline Big & 0.96 & 0.79 & 0.72 & 0.59 & 0.53 & & & & & \\
\hline
\end{tabular}


Panel B: Fama-French results for the period between Jul 1963 and Dec 2002

\begin{tabular}{|c|c|c|c|c|c|c|c|c|c|c|}
\hline \multirow[b]{2}{*}{ Size } & \multicolumn{10}{|c|}{ Book-to-market equity (BE/ME) quintiles } \\
\hline & Low & 2 & 3 & 4 & High & Low & 2 & 3 & 4 & High \\
\hline & \multicolumn{5}{|c|}{ RMRF } & \multicolumn{5}{|c|}{$\mathrm{t}$ (RMRF) } \\
\hline Small & 1.19 & 1.09 & 1.01 & 0.96 & 1.02 & 27.50 & 30.58 & 37.38 & 42.55 & 49.06 \\
\hline 2 & 1.21 & 1.08 & 1.01 & 1.01 & 1.12 & 37.31 & 47.46 & 57.70 & 61.09 & 67.14 \\
\hline 3 & 1.16 & 1.08 & 1.02 & 0.99 & 1.10 & 42.88 & 52.16 & 55.53 & 57.38 & 57.73 \\
\hline 4 & 1.13 & 1.09 & 1.07 & 1.04 & 1.15 & 47.24 & 53.61 & 53.87 & 58.10 & 47.78 \\
\hline \multirow[t]{2}{*}{ Big } & 0.95 & 1.01 & 0.95 & 0.96 & 1.00 & 66.97 & 54.99 & 44.61 & 44.94 & 35.67 \\
\hline & \multicolumn{5}{|c|}{ SMB } & \multicolumn{5}{|c|}{$\mathrm{t}(\mathrm{SMB})$} \\
\hline Small & 1.06 & 1.02 & 0.91 & 0.90 & 0.99 & 18.25 & 21.35 & 25.18 & 29.76 & 35.59 \\
\hline 2 & 0.75 & 0.75 & 0.70 & 0.63 & 0.74 & 17.16 & 24.42 & 30.04 & 28.69 & 33.29 \\
\hline 3 & 0.53 & 0.47 & 0.45 & 0.42 & 0.54 & 14.53 & 17.10 & 18.23 & 18.28 & 21.08 \\
\hline 4 & 0.16 & 0.23 & 0.20 & 0.18 & 0.33 & 5.12 & 8.27 & 7.44 & 7.39 & 10.35 \\
\hline \multirow[t]{2}{*}{ Big } & -0.23 & -0.17 & -0.17 & -0.10 & 0.05 & -11.93 & -6.80 & -5.96 & -3.55 & 1.41 \\
\hline & \multicolumn{5}{|c|}{ HML } & \multicolumn{5}{|c|}{$\mathrm{t}(\mathrm{HML})$} \\
\hline Small & -0.13 & 0.25 & 0.42 & 0.54 & 0.73 & -2.05 & 4.73 & 10.29 & 16.03 & 23.53 \\
\hline 2 & -0.26 & 0.25 & 0.45 & 0.63 & 0.82 & -5.22 & 7.40 & 17.07 & 25.40 & 32.77 \\
\hline 3 & -0.33 & 0.25 & 0.50 & 0.65 & 0.81 & -8.21 & 7.95 & 18.17 & 24.98 & 28.35 \\
\hline 4 & -0.33 & 0.25 & 0.49 & 0.63 & 0.79 & -9.10 & 8.21 & 16.53 & 23.19 & 21.97 \\
\hline \multirow[t]{2}{*}{ Big } & -0.39 & 0.10 & 0.24 & 0.58 & 0.74 & -18.47 & 3.66 & 7.43 & 17.91 & 17.50 \\
\hline & \multicolumn{5}{|c|}{ POSTFD SMB } & \multicolumn{5}{|c|}{$\mathrm{t}($ POSTFD SMB) } \\
\hline Small & 0.19 & 0.18 & -0.05 & -0.02 & 0.07 & 0.97 & 1.14 & -0.40 & -0.20 & 0.73 \\
\hline 2 & 0.29 & 0.26 & 0.15 & 0.24 & 0.46 & 2.00 & 2.51 & 1.95 & 3.26 & 6.18 \\
\hline 3 & 0.31 & 0.00 & -0.01 & 0.02 & 0.18 & 2.51 & -0.02 & -0.11 & 0.29 & 2.12 \\
\hline 4 & 0.37 & -0.01 & -0.06 & 0.04 & -0.04 & 3.40 & -0.09 & -0.67 & 0.45 & -0.40 \\
\hline Big & -0.09 & 0.04 & 0.37 & 0.12 & -0.57 & -1.47 & 0.50 & 3.82 & 1.27 & -4.47 \\
\hline \multicolumn{11}{|c|}{$\mathrm{R}^{2}$} \\
\hline Small & 0.79 & 0.81 & 0.85 & 0.88 & 0.91 & & & & & \\
\hline 2 & 0.86 & 0.89 & 0.92 & 0.92 & 0.94 & & & & & \\
\hline 3 & 0.88 & 0.89 & 0.90 & 0.90 & 0.90 & & & & & \\
\hline 4 & 0.89 & 0.88 & 0.88 & 0.89 & 0.85 & & & & & \\
\hline Big & 0.94 & 0.88 & 0.82 & 0.81 & 0.74 & & & & & \\
\hline
\end{tabular}


Panel C: Correlation of monthly returns of portfolio based on firm size and Fama-French portfolios, 1997:2002

Portfolio of big firms

\begin{tabular}{|c|c|c|c|c|c|}
\hline \multicolumn{6}{|c|}{ Portfolio of big firms } \\
\hline \multirow[b]{2}{*}{ Size } & \multicolumn{5}{|c|}{ Book-to-market equity (BE/ME) quintiles } \\
\hline & Low & 2 & 3 & 4 & High \\
\hline Small & 0.63 & 0.57 & 0.58 & 0.58 & 0.61 \\
\hline 2 & 0.73 & 0.71 & 0.69 & 0.65 & 0.63 \\
\hline 3 & 0.75 & 0.81 & 0.76 & 0.65 & 0.69 \\
\hline 4 & 0.83 & 0.84 & 0.76 & 0.76 & 0.68 \\
\hline Big & 0.97 & 0.87 & 0.81 & 0.62 & 0.57 \\
\hline \multicolumn{6}{|c|}{ Portfolio of mid-size firms } \\
\hline & \multicolumn{5}{|c|}{ Book-to-market equity (BE/ME) quintiles } \\
\hline Size & Low & 2 & 3 & 4 & High \\
\hline Small & 0.91 & 0.91 & 0.88 & 0.86 & 0.83 \\
\hline 2 & 0.94 & 0.90 & 0.85 & 0.78 & 0.79 \\
\hline 3 & 0.95 & 0.80 & 0.64 & 0.54 & 0.56 \\
\hline 4 & 0.94 & 0.66 & 0.49 & 0.57 & 0.43 \\
\hline Big & 0.67 & 0.50 & 0.48 & 0.19 & 0.13 \\
\hline \multicolumn{6}{|c|}{ Portfolio of small firms } \\
\hline & \multicolumn{5}{|c|}{ Book-to-market equity (BE/ME) quintiles } \\
\hline Size & Low & 2 & 3 & 4 & High \\
\hline Small & 0.93 & 0.91 & 0.89 & 0.87 & 0.86 \\
\hline 2 & 0.89 & 0.80 & 0.72 & 0.66 & 0.67 \\
\hline 3 & 0.88 & 0.65 & 0.49 & 0.35 & 0.41 \\
\hline 4 & 0.83 & 0.51 & 0.33 & 0.38 & 0.26 \\
\hline Big & 0.56 & 0.37 & 0.37 & 0.05 & -0.01 \\
\hline
\end{tabular}




\section{Table 10. Summary Results of Breaking Small Firms According to Analyst Following}

This table presents results involving the break-up of small firms according to analyst following characteristics. The first subgroup includes firms present in both pre-FD and post-FD periods and that have no analyst following in any of the firm-quarters of the sample. The second subgroup includes firms that had some analyst following in at least one of the pre-FD quarters but no analyst following in any of the post-FD quarters. The third subgroup includes all the remaining small firms. Panel A present univariate statistics based on these subgroups. Panel B presents results of running Fama-French regressions (as in Table 8) for all the small firms taken together as a group as well as for each subgroup of small firms defined above.

Panel A: Univariate statistics

\begin{tabular}{|c|c|c|c|c|c|c|c|c|}
\hline \multirow{3}{*}{ \# firms } & \multicolumn{2}{|c|}{ All small firms } & \multicolumn{2}{|c|}{$\begin{array}{l}\text { Small firms with no } \\
\text { analyst following } \\
\text { pre-FD }\end{array}$} & \multicolumn{2}{|c|}{$\begin{array}{l}\text { Small firms with some } \\
\text { analyst following pre- } \\
\text { FD but none post-FD }\end{array}$} & \multicolumn{2}{|c|}{$\begin{array}{l}\text { All other } \\
\text { small firms }\end{array}$} \\
\hline & \multicolumn{2}{|c|}{3166} & \multicolumn{2}{|c|}{364} & \multicolumn{2}{|c|}{339} & \multicolumn{2}{|c|}{2463} \\
\hline & $\underline{\text { Pre-FD }}$ & $\underline{\text { Post-FD }}$ & $\underline{\text { Pre-FD }}$ & $\underline{\text { Post-FD }}$ & $\underline{\text { Pre-FD }}$ & $\underline{\text { Post-FD }}$ & $\underline{\text { Pre-FD }}$ & $\underline{\text { Post-FD }}$ \\
\hline Size (\$MM) & 72 & 68 & 46 & 54 & 76 & 46 & 77 & 76 \\
\hline Number of forecasts & 1.40 & 1.00 & 0.00 & 0.35 & 1.27 & 0.00 & 1.72 & 1.34 \\
\hline Pre-announcement & 0.08 & 0.07 & 0.01 & 0.02 & 0.09 & 0.05 & 0.08 & 0.08 \\
\hline
\end{tabular}

Panel B: Fama-French regressions

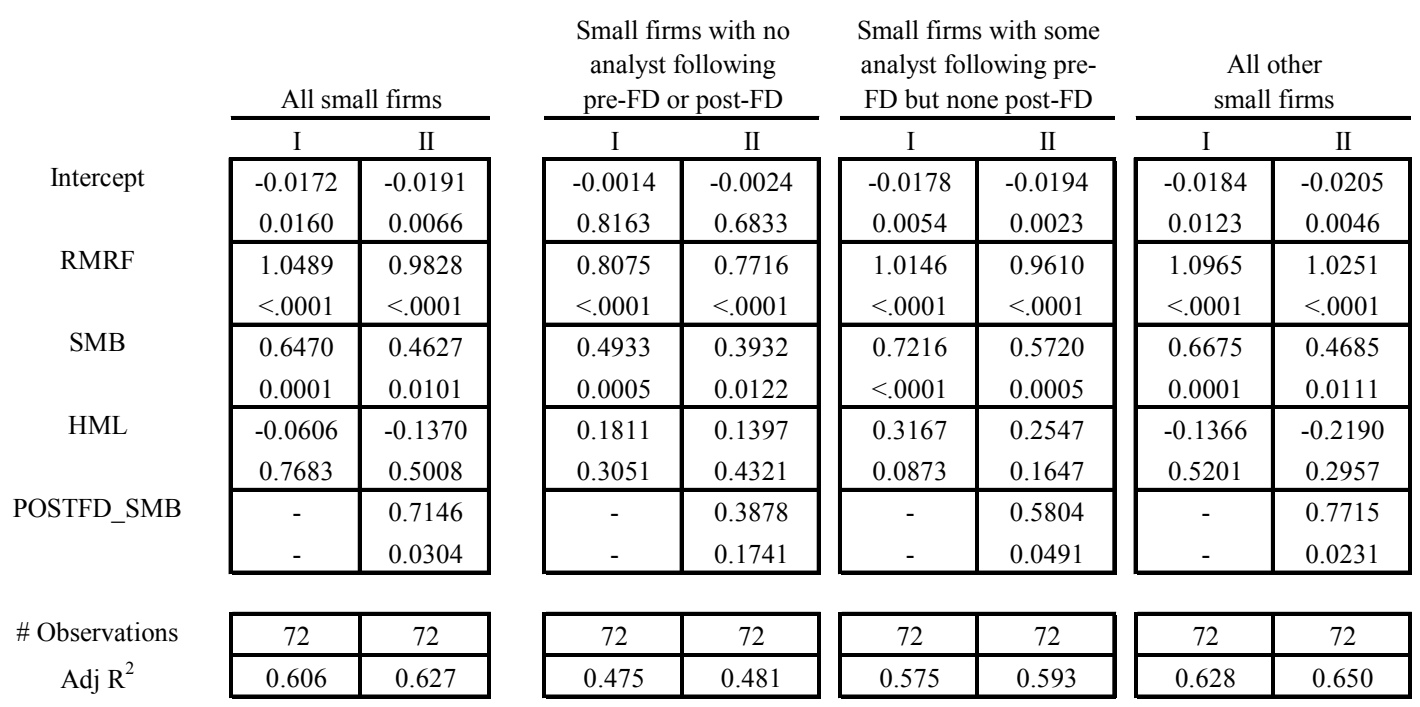




\section{Table 11. Summary Results of Breaking Firms in Groups based on Size and on Intangibles}

This table presents results involving the break-up of sample in groups based on size (big, mid-size and small firms) and intangibles (low and high). Panel A presents results on panel data regressions. The first column under each variable presents the estimates of post-FD dummies corresponding to each group definition in multivariate panel data regressions (other coefficients' estimates are omitted) as done before for the break-up on size alone, with the exception that now we also include book-tomarket and intangibles as control variables; for the analyst following regression we start from specification VI in Table 2, for the pre-announcement regression we start from specification V in Table 5, for the forecast error regression we start from specification IV in Table 6 and for volatility regression we start from specification IV in Table 7; and then we add book-to-market and intangibles as regressors. The second column under each variable is computed by dividing the post-FD dummy by the preFD average of that variable (except for pre-announcement, when we show simply the pre-FD average). The intra-group differential impact shows p-values of tests of differences in intra-group coefficients on high and low intangibles. Panel B presents results of running Fama-French regressions for each group of firms; each row presents the coefficients estimates of SMB and POSTFD_SMB regressors from running specification type II in Table 8 (other coefficients' estimates are omitted).

Panel A: Panel data regressions

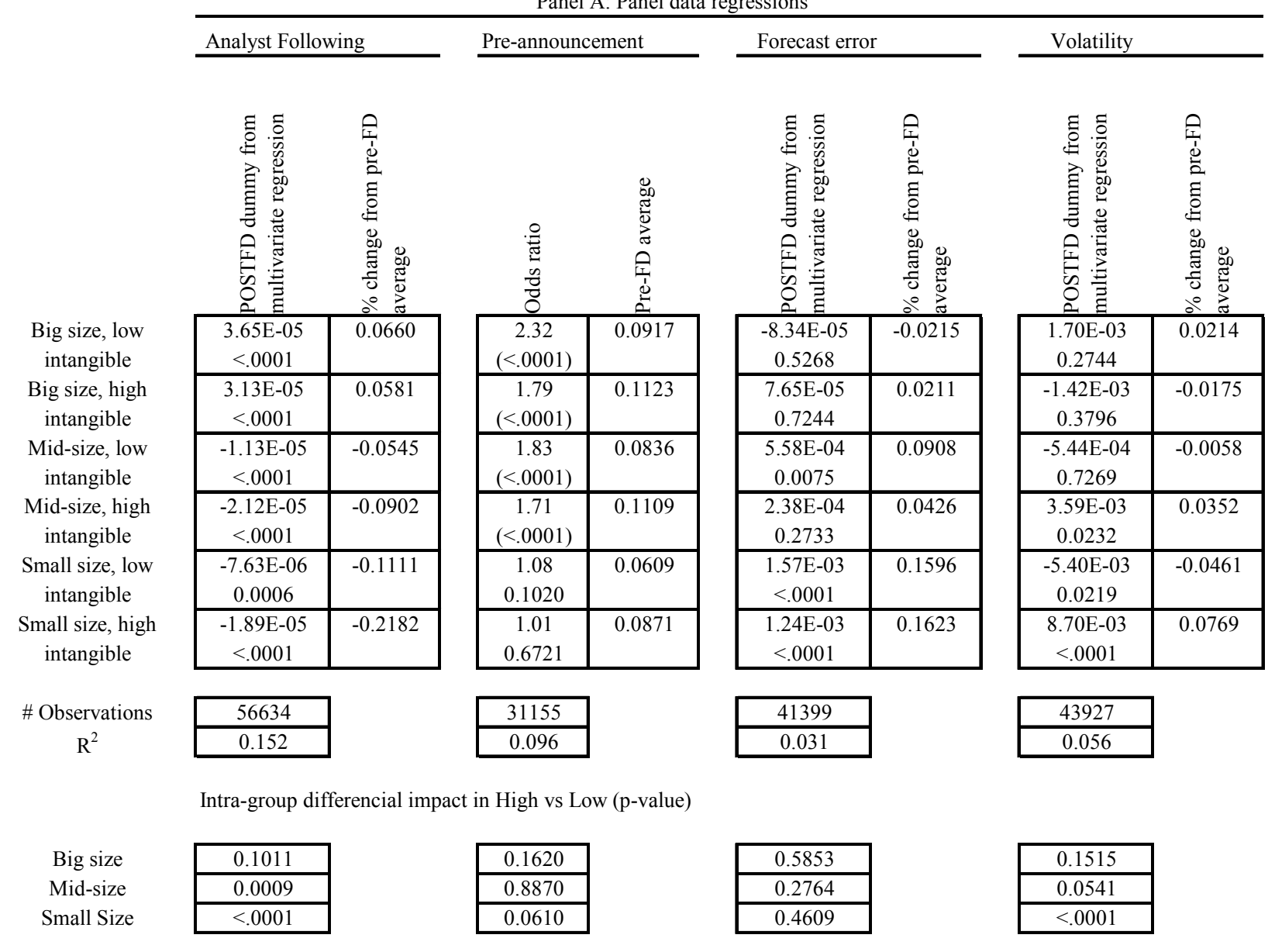

Panel B: Fama-French Regressions

\begin{tabular}{|c|c|}
\hline$\sum_{i=1}^{n}$ & $\begin{array}{l}\vec{E} \\
\text { On } \\
0\end{array}$ \\
\hline-0.1201 & 0.0387 \\
\hline 0.0001 & 0.4927 \\
\hline-0.0203 & -0.1121 \\
\hline 0.6134 & 0.1339 \\
\hline 0.4514 & 0.5467 \\
\hline 0.0028 & 0.0435 \\
\hline 0.5366 & 0.5065 \\
\hline$<.0001$ & 0.0367 \\
\hline 0.4175 & 0.6534 \\
\hline 0.0228 & 0.0528 \\
\hline 0.5248 & 0.7520 \\
\hline 0.0029 & 0.0195 \\
\hline
\end{tabular}




\section{Table 12. Summary Results of Breaking Big Firms between Democracies and Dictatorships}

This table presents results involving the break-up of big firms between democracies and dictatorships. Big are defined as described in the Appendix; democracies (dictatorships) are firms with average $\mathrm{G}$ in the lowest (highest) quintile of the distribution of $\mathrm{G}$ among all firms in the sample. Panel A presents results on panel data regressions. The first column under each variable presents the estimates of post-FD dummies corresponding to each group definition in multivariate panel data regressions (other coefficients' estimates are omitted) as done before for the break-up on size alone; for the analyst following regression we use specification VI in Table 2, for the pre-announcement regression we use specification V in Table 5, for the forecast error regression we use specification IV in Table 6 and for volatility regression we use specification IV in Table 7. The second column under each variable is computed by dividing the post-FD dummy by the pre-FD average of that variable (except for pre-announcement, when we show simply the pre-FD average). The intra-group differential impact shows p-values of tests of differences in intragroup coefficients on high and low G. Panel B presents results of running Fama-French regressions for each group of firms; each row presents the coefficients estimates of SMB and POSTFD_SMB regressors from running specification type II in Table 8 (other coefficients' estimates are omitted).

Panel A: Panel data regressions

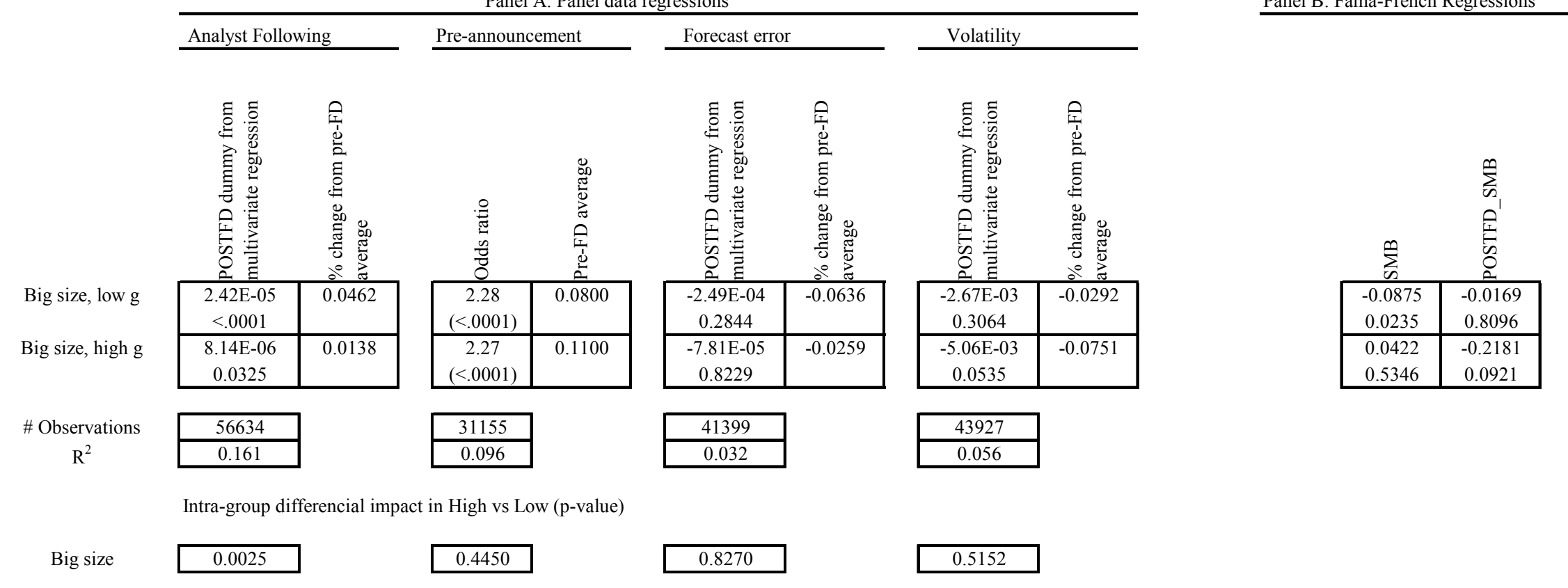




\section{Table 13. Summary Results of Breaking Firms in Groups based on Size and on Litigation Risk Industries}

This table presents results involving the break-up of sample in groups based on size (big, mid-size and small firms) and industries subject to litigation risk (low and high risk). Big, mid-size and small firms are defined as described in the Appendix; inside each group of firms based on size, we define a firm as having high litigation risk if belongs to a high litigation risk industry, i.e. with SICCD in the ranges 2833-2836, 3570-3577, 3600-3674, 5200-5961, 7370-7379 or 8731-8734. Panel A presents results on panel data regressions. The first column under each variable presents the estimates of post-FD dummies corresponding to each group definition in multivariate panel data regressions (other coefficients' estimates are omitted) as done before for the break-up on size alone; for the analyst following regression we use specification VI in Table 2, for the pre-announcement regression we use specification V in Table 5, for the forecast error regression we use specification IV in Table 6 and for volatility regression we use specification IV in Table 7. The second column under each variable is computed by dividing the post-FD dummy by the pre-FD average of that variable (except for pre-announcement, when we show simply the pre-FD average). The intra-group differential impact shows p-values of tests of differences in intra-group coefficients on high and low litigation risk. Panel B presents results of running Fama-French regressions for each group of firms; each row presents the coefficients estimates of SMB and POSTFD_SMB regressors from running specification type II in Table 8 (other coefficients' estimates are omitted).

Panel A: Panel data regressions

Panel B: Fama-French Regressions

\begin{tabular}{|c|c|}
\hline \multicolumn{2}{|c|}{ Analyst Following } \\
\hline 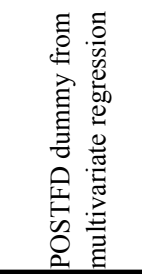 & 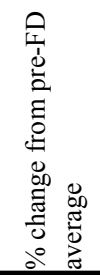 \\
\hline $\begin{array}{c}2.34 \mathrm{E}-05 \\
<.0001 \\
\end{array}$ & 0.0458 \\
\hline $\begin{array}{c}6.60 \mathrm{E}-05 \\
<.0001\end{array}$ & 0.1033 \\
\hline $\begin{array}{c}-2.23 \mathrm{E}-05 \\
<.0001 \\
\end{array}$ & -0.1035 \\
\hline $\begin{array}{c}4.59 \mathrm{E}-07 \\
0.8704 \\
\end{array}$ & 0.0020 \\
\hline $\begin{array}{c}-1.35 \mathrm{E}-05 \\
<.0001 \\
\end{array}$ & -0.1756 \\
\hline $\begin{array}{c}-1.28 \mathrm{E}-05 \\
<.0001\end{array}$ & -0.1639 \\
\hline
\end{tabular}

$\underline{\text { Pre-announcement }}$

Big size, low

litigation risk

Big size, high

litigation risk

Mid-size, low

litigation risk

Mid-size, high

litigation risk

Small size, low

litigation risk

Small size, high

litigation risk

\# Observations

$\mathrm{R}^{2}$

\begin{tabular}{|l|}
\hline 56634 \\
\hline 0.154 \\
\hline
\end{tabular}

Intra-group differencial impact in High vs Low (p-value)

Big size

Mid-size

\begin{tabular}{|c|}
\hline$<.0001$ \\
\hline$<.0001$ \\
\hline 0.8388 \\
\hline
\end{tabular}

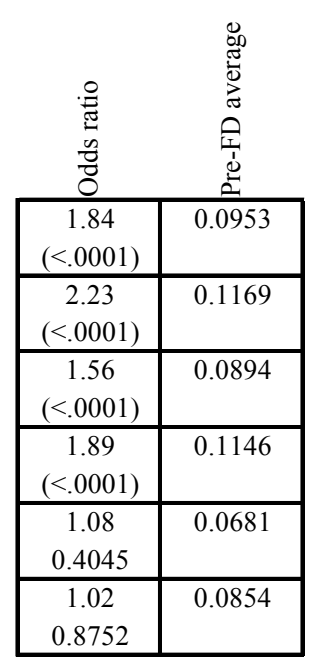

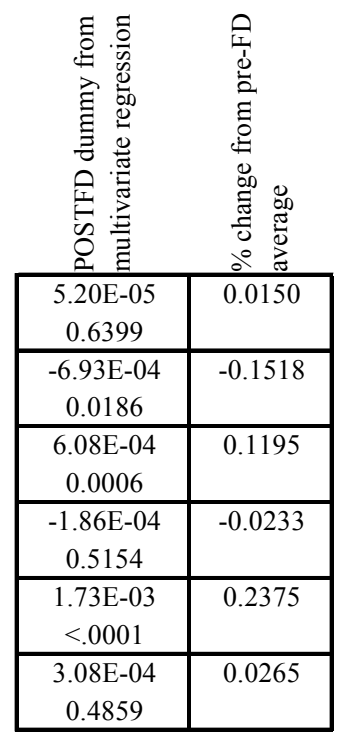

Volatility
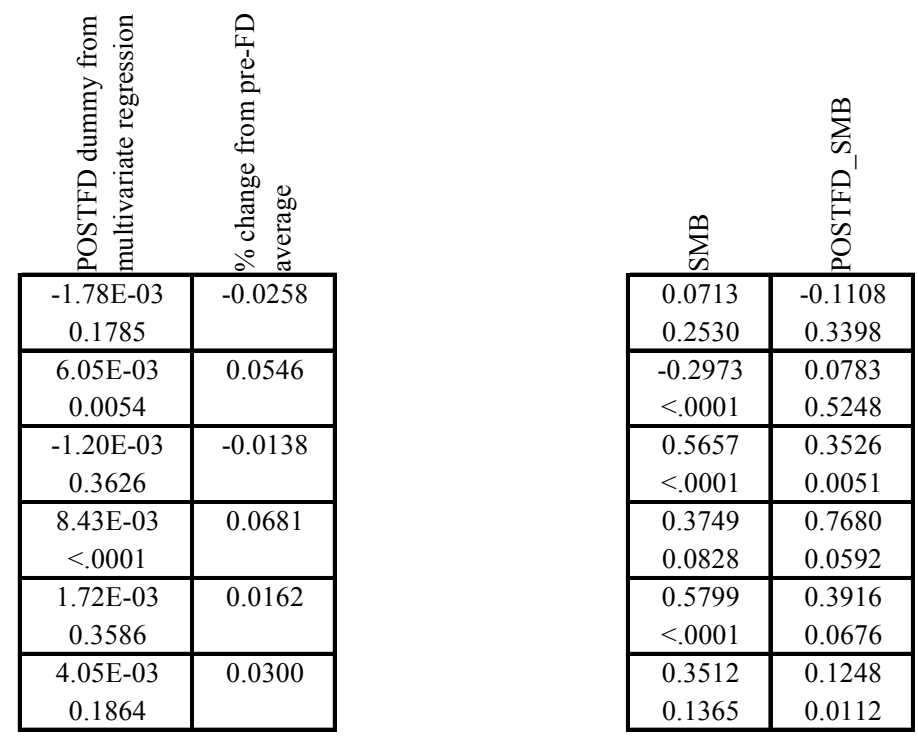

\section{9}

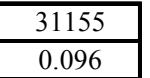

\begin{tabular}{|l|}
\hline 0.0450 \\
\hline 0.0350 \\
\hline 0.8390 \\
\hline
\end{tabular}

\begin{tabular}{|l|}
\hline 0.0172 \\
\hline 0.0158 \\
\hline 0.0049 \\
\hline
\end{tabular}

\section{7}

\begin{tabular}{|l|}
\hline 0.0016 \\
\hline$<.0001$ \\
\hline 0.5088 \\
\hline
\end{tabular}




\section{Table 14. Size Summary Statistics for Groups of Firms}

This table presents summary statistics on the partition of the sample in groups of big, mid and small firms, based on firm-quarter observations. Age is defined as the difference between year of current observation and the first year firm data is available on CRSP database. Size is the market value of the firm at the last day of the month in which the quarterly earnings announcement is made. Log scaled size is the log of the market value of firm scaled by the market index. Panel B presents for each group the fraction (in percentage terms) of firm-quarters that belongs to each Fama and French (1997) industry. Details on the construction of portfolios of big, mid-size and small firms are described in the Appendix. The sample comprises observations in the periods Q4:1997-Q3:1999 (pre-FD sample) and Q4:2000-Q3:2002 (post-FD sample), except that observations with actual earnings announcements between 12/20/1999 and 10/23/2000 are excluded.

Panel A: Summary statistics on number of firms, age and size

\begin{tabular}{|c|c|c|c|c|c|c|c|c|c|}
\hline & \multicolumn{3}{|c|}{ Group of big firms } & \multicolumn{3}{|c|}{ Group of mid-size firms } & \multicolumn{3}{|c|}{ Group of small firms } \\
\hline & All & Pre-FD & Post-FD & All & Pre-FD & Post-FD & All & Pre-FD & Post-FD \\
\hline \# Firms & 1371 & & & 2035 & & & 3166 & & \\
\hline NYSE & 925 & & & 643 & & & 257 & & \\
\hline NASDAQ & 446 & & & 1392 & & & 2909 & & \\
\hline \multicolumn{10}{|l|}{ Age } \\
\hline Mean & 24.7 & 24.4 & 24.9 & 13.0 & 12.8 & 13.2 & 10.3 & 9.4 & 11.4 \\
\hline Median & 18.0 & 18.0 & 18.0 & 9.0 & 8.0 & 9.0 & 7.0 & 6.0 & 8.0 \\
\hline \# Firm-quarters & 16,752 & 8,495 & 8,257 & 21,237 & 10,598 & 10,639 & 25,117 & 13,357 & 11,760 \\
\hline \multicolumn{10}{|l|}{ Size (MM) } \\
\hline Mean & 9,619 & 8,854 & 10,405 & 432 & 417 & 448 & 71 & 73 & 68 \\
\hline Median & 2,609 & 2,478 & 2,731 & 349 & 338 & 359 & 53 & 55 & 49 \\
\hline Std Dev & 26,734 & 24,217 & 29,078 & 328 & 322 & 333 & 67 & 66 & 69 \\
\hline \multicolumn{10}{|l|}{ Log scaled size } \\
\hline Mean & 8.0 & 7.9 & 8.1 & 5.7 & 5.6 & 5.8 & 3.8 & 3.8 & 3.7 \\
\hline Median & 7.7 & 7.7 & 7.8 & 5.7 & 5.7 & 5.8 & 3.8 & 3.9 & 3.8 \\
\hline Std Dev & 1.2 & 1.2 & 1.2 & 0.7 & 0.7 & 0.7 & 0.9 & 0.9 & 1.0 \\
\hline
\end{tabular}

Panel B: Industry Membership (fraction of the group's observations belonging to the industry)

\begin{tabular}{|c|c|c|c|c|c|c|c|c|c|c|c|}
\hline & .00 & 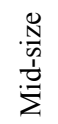 & $\begin{array}{l}\overline{\bar{\Xi}} \\
\text { छ }\end{array}$ & & 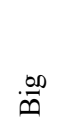 & 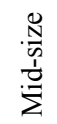 & $\begin{array}{l}\overline{\text { च्च }} \\
\text { फ }\end{array}$ & & $\stackrel{00}{m}$ & 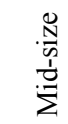 & 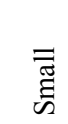 \\
\hline Agriculture & 0.4 & 0.1 & 0.3 & Construction & 0.7 & 1.4 & 1.0 & Business services & 10.0 & 13.4 & 13.5 \\
\hline Food products & 2.3 & 1.0 & 1.1 & Steel works etc & 1.5 & 2.0 & 1.3 & Computers & 3.5 & 3.3 & 5.6 \\
\hline Candy and soda & 0.2 & 0.1 & 0.1 & Fabricated prods & 0.0 & 0.5 & 0.5 & Electronic eq. & 5.7 & 5.9 & 5.7 \\
\hline Alcoholic Bev & 0.5 & 0.1 & 0.4 & Machinery & 2.8 & 3.4 & 2.9 & Meas. \& control eq. & 1.5 & 1.6 & 2.8 \\
\hline Tobacco prods & 0.1 & 0.1 & 0.0 & Electrical eq. & 0.7 & 1.1 & 1.0 & Business supplies & 1.9 & 1.1 & 0.7 \\
\hline Recreational prods & 0.3 & 0.7 & 1.2 & Miscelaneous & 0.5 & 0.2 & 0.5 & Shipping Cont. & 0.3 & 0.5 & 0.1 \\
\hline Entertainment & 1.2 & 1.5 & 1.2 & Auto and trucks & 1.4 & 1.7 & 1.0 & Transportation & 2.7 & 2.6 & 2.0 \\
\hline Print \& publishing & 1.9 & 0.5 & 0.5 & Aircraft & 0.5 & 0.2 & 0.2 & Wholesale & 2.1 & 3.9 & 3.9 \\
\hline Consumer Goods & 1.5 & 1.7 & 1.5 & Shipb., railroad eq. & 0.2 & 0.2 & 0.2 & Retail & 6.7 & 5.0 & 5.0 \\
\hline Apparel & 0.6 & 1.5 & 1.6 & Defense & 0.2 & 0.1 & 0.1 & Restaurantes etc & 1.1 & 1.8 & 2.2 \\
\hline Healthcare & 1.3 & 1.1 & 1.5 & Precious metals & 0.2 & 0.1 & 0.1 & Banking & 10.0 & 11.1 & 16.3 \\
\hline Medical eq & 1.5 & 2.6 & 5.5 & Nonmetalic mining & 0.3 & 0.3 & 0.1 & Insurance & 6.2 & 3.4 & 2.1 \\
\hline Pharmac. prods & 4.1 & 6.7 & 4.7 & Coal & 0.0 & 0.1 & 0.0 & Real estate & 0.2 & 0.4 & 0.5 \\
\hline Chemicals & 2.8 & 1.5 & 0.8 & Petro and nat gas & 3.7 & 2.8 & 2.1 & Trading & 2.4 & 1.2 & 1.2 \\
\hline Rubber and plastic & 0.5 & 0.8 & 1.1 & Utilities & 7.5 & 2.7 & 1.2 & Unindentified & 0.3 & 0.8 & 0.8 \\
\hline Textiles & 0.1 & 0.6 & 0.8 & Telecom & 4.1 & 3.0 & 0.8 & & & & \\
\hline Construction mat. & 1.4 & 2.4 & 1.4 & Personal services & 0.5 & 1.1 & 1.2 & & & & \\
\hline
\end{tabular}


Figure 1. Quarterly Fraction of Companies Using Pre-Announcements

This figure presents the quarterly fraction of companies that issues at least one pre-announcement between 15 days before the end of the quarter and 2 days before the actual release of that quarter's earnings announcement. The vertical lines indicate the period when Reg FD was being proposed and discussed; the pre-FD period thus finishes before the first vertical line and the post-FD period starts after the second vertical line. The break-up of companies on the groups based on size (big, mid and small companies) is described in the Appendix.

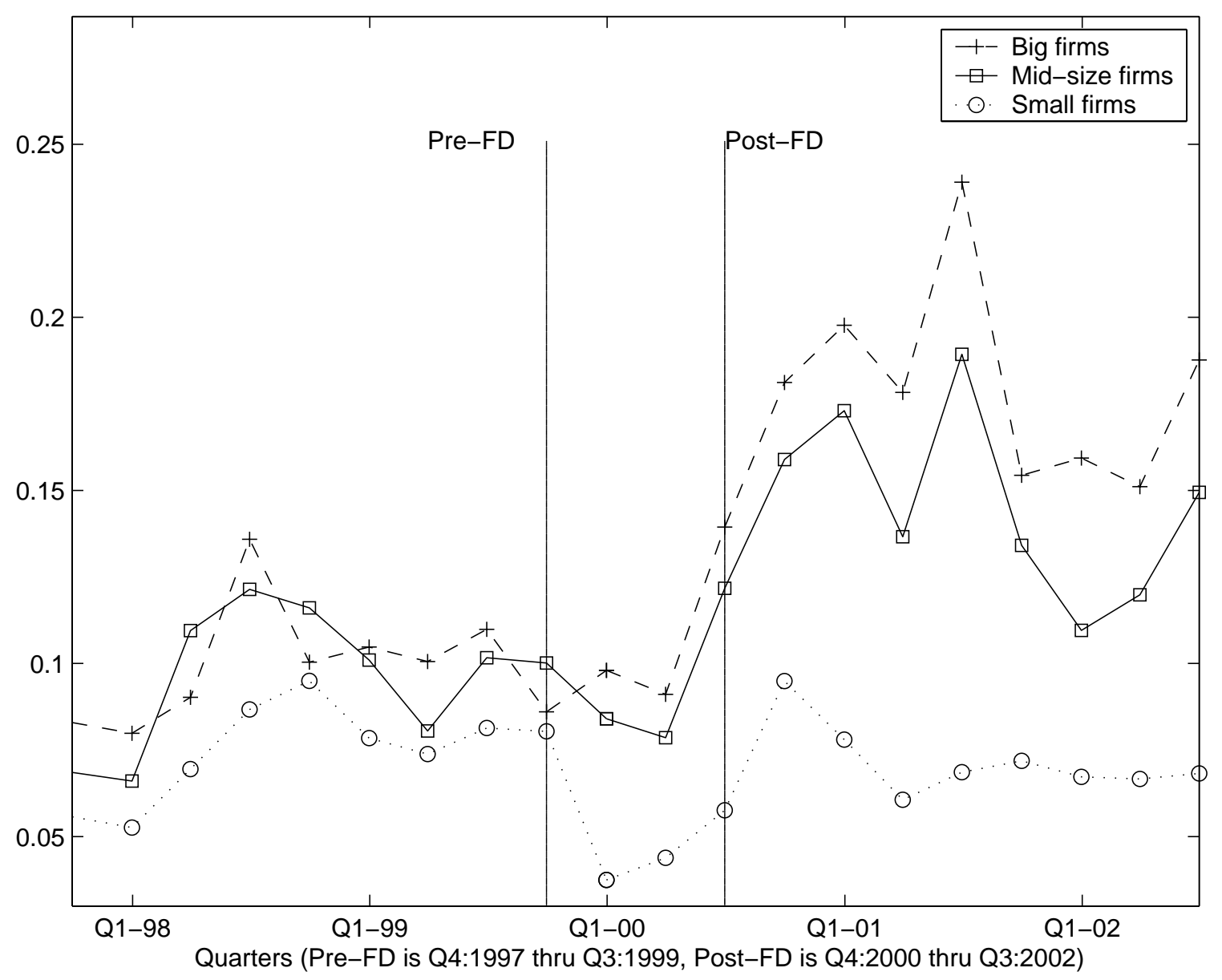


Figure 2. Quarterly Fraction of Firms without Forecasts Available

This figure presents the quarterly fraction of firm-quarters in each group that have at least one forecast available for the upcoming earnings announcement. The vertical lines indicate the period when Reg FD was being proposed and discussed; the pre-FD period thus finishes before the first vertical line and the post-FD period starts after the second vertical line. The break-up of companies on the groups based on size (big, mid and small companies) is described in the Appendix.

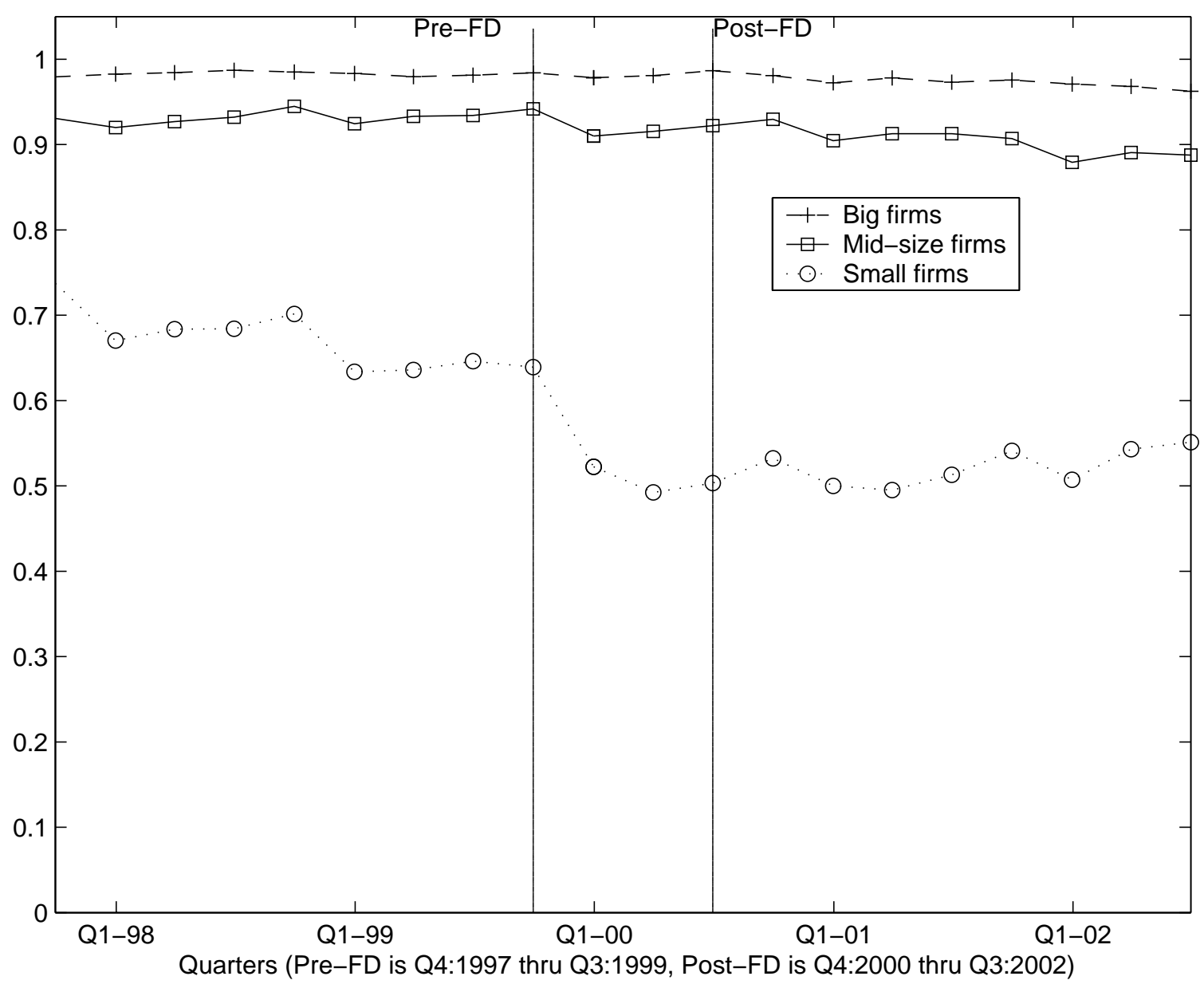


Figure 3. Quarterly Average Volatility (Market Response) at Earnings Announcements

This figure presents the quarterly average volatility for each group of firms. Volatility is the cumulative absolute abnormal return over the window $[-1,+1]$ around the earnings announcement day. The vertical lines indicate the period when Reg FD was being proposed and discussed; the pre-FD period thus finishes before the first vertical line and the post-FD period starts after the second vertical line. The break-up of companies on the groups based on size (big, mid and small companies) is described in the Appendix.

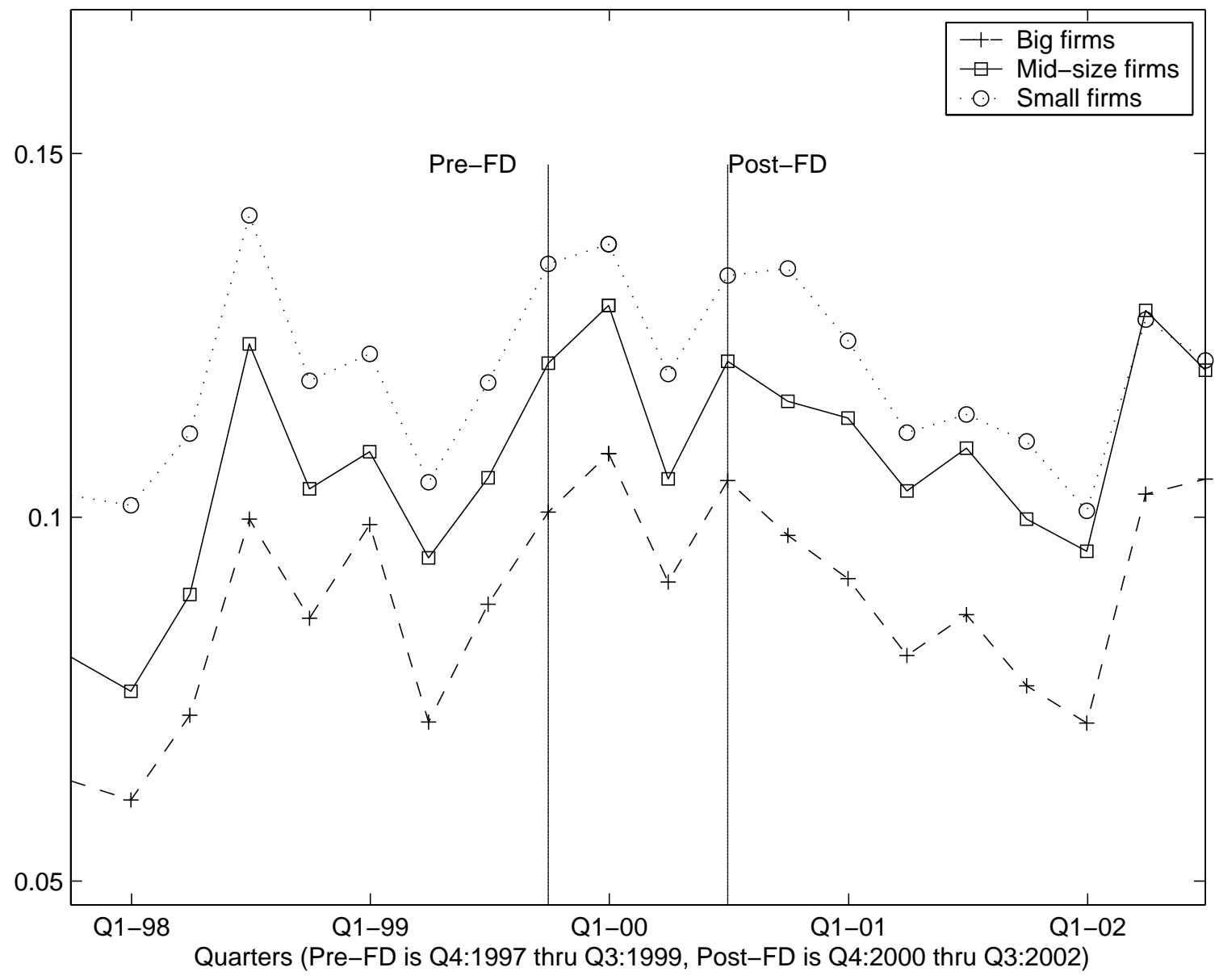


Figure 4. Quarterly Fraction of Firms Using Conference Calls around Earnings Announcements

This figure presents the fraction of firms in each group that uses conference calls (from FirstCall) at the window $[-1,+1]$ around the current quarter's earnings announcement day. The vertical lines indicate the period when Reg FD was being proposed and discussed; the pre-FD period thus finishes before the first vertical line and the post-FD period starts after the second vertical line. The break-up of companies on the groups based on size (big, mid and small companies) is described in the Appendix.

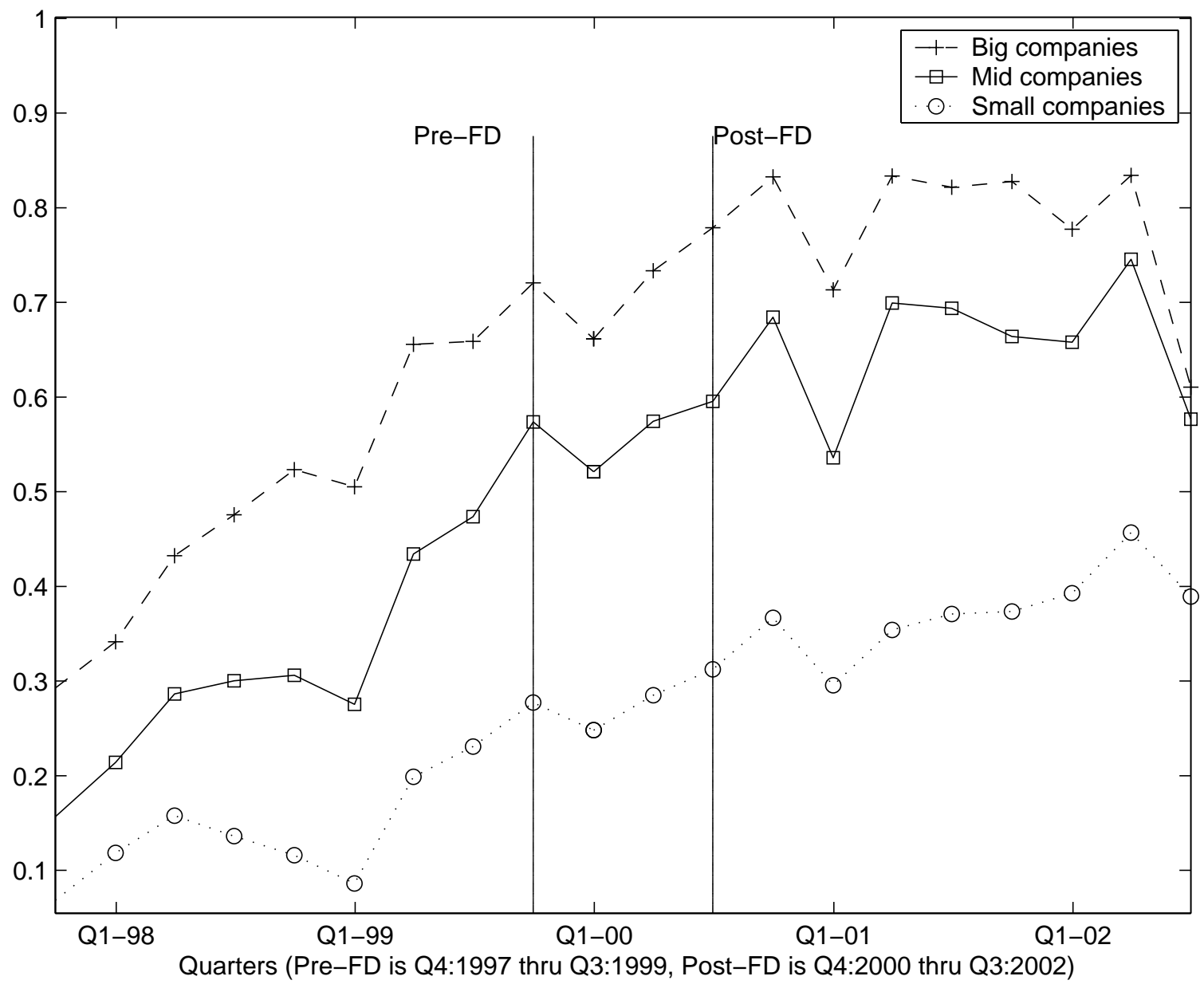

